(RE)DISCOVERING TORONTO'S WATEFRONT: INFRASTRUCTURE AND CONNECTIVITY IN A POST-INDUSTRIAL LANDSCAPE

by

Geordie Gordon,

Bachelor of Arts in Geography, University of Victoria, 2009

An MRP

presented to Ryerson University

in partial fulfillment of the

requirements for the degree of

Master of Planning

in the Program of

Urban Development

Toronto, Ontario, Canada, 2014

(C) Geordie Gordon, 2014 


\section{Author's Declaration}

I hereby declare that I am the sole author of this major research paper. This is a true copy of the major research paper, including any required final revisions, as accepted by my examiners.

I authorize Ryerson University to lend this major research paper to other institutions or individuals for the purpose of scholarly research

I further authorize Ryerson University to reproduce this major research paper by photocopying or by other means, in total or in part, at the request of other institutions or individuals for the purpose of scholarly research.

I understand that my major research paper may be made electronically available to the public. 


\title{
(RE)DISCOVERING TORONTO'S WATEFRONT: INFRASTRUCTURE AND CONNECTIVITY IN A POST-INDUSTRIAL LANDSCAPE
}

(C) Geordie Gordon, 2014

\author{
Master of Planning \\ in \\ Urban Development \\ Ryerson University
}

\begin{abstract}
The transition of waterfront land use from industrial to post-industrial is a global phenomenon. There are several forces that are driving this change, including the advancement of shipping technology and the relocation of industrial processes to areas with greater availability of land. In place of industrial uses, many cities have undertaken, or are in the process of undertaking the redevelopment of their waterfront. As a result of past industrial use, there often exists, a significant amount of transportation infrastructure that isolates the city from the waterfront. This paper establishes the context for waterfront redevelopment, before examining the impact of infrastructure urban forms by using the work of Kevin Lynch as a tool for analysis. Several case precedents are used to examine the course of action that other North American cities have pursued to mitigate the impact of infrastructure forms on the waterfront and how they may influence the way Toronto deals with its waterfront infrastructure.
\end{abstract}

Key words: post-industrial waterfront, urban morphology, urban expressway 


\section{Acknowledgements}

I would like to gratefully acknowledge the guidance of my supervisor, Professor Nina-Marie Lister. Her advice and input throughout the process of writing this paper was invaluable.

I would also like to thank my second reader, Allison Reid, for her thoughtful feedback and guidance. 


\section{Introduction 1}

Justification 1

Intent 2

\section{Section 1: Watefront History 4}

Cities and Waterfront Development: A Brief History 4

The Process of City-Waterfront Disconnection and Reconnection 12

The Evolution of Waterfront Redevelopment Approaches $\quad 15$

Waterfront Redevelopment in Practice 19 Jurisdictional Struggle 20

The Growth of Barriers to the Waterfront 23

Economic Revitalization 23

Governance 24

Urban Design 25

Public Participation 26

Locational advantages. $\quad 28$

Modernist Planning 29

Expressway Teardown 34

\section{Section 2: Method 36}

Kevin Lynch: The Image of the City $\quad 37$

Paths 38

Edges 39

Nodes 40

Districts 40

Landmarks 41

Applying Lynch to Case Precedents 41

\section{Section 3: Case Precedents 42}

Case Precendent: Seattle 42

Background 49

Waterfront Infrastructure 44

An Analysis of Infrastructure and Urban Forms 46

The Politics of Mobility 48

Case Precedent: Boston 49

Background 49

Waterfront Infrastructure 50

An Analysis of Infrastructure and Urban Forms 55

Lynch: Then and Now 55

Case Precedent: San Francisco 56

Background 56

Waterfront Infrastructure 57

An Analysis of Infrastructure and Urban Forms 58

The Impact of Neoliberalism on the Waterfront 61 


\section{Table of Contents Continued}

\section{Section 3: Case Precedents Continued}

Case Precedent: Toronto 63

Background 63

Toronto Waterfront Redevelopment History 63

Waterfront Infrastructure 67

An Analysis of Infrastructure and Urban Forms 70

Anatomy of a debate $\quad 74$

Aging Infrastructure 74

Public Consultation 76

Evaluation of Options 78

Section 4: Conclusions and Recommendations 79

Appendix A - Preliminary Evaluation Results Matrix

Bibliography 84 


\section{List of Figures}

Figure 1 Settlement pattern of Fort York, $1818 \quad 5$

Figure 2 Fort York barracks, $1804 \quad 5$

Figure 3 Soil types of Toronto Harbour and area, $1913 \quad 6$

Figure 4 Toronto waterfront in 1884 looking east from John St $\quad 7$

Figure 5a-d Progression of harbour infilling 1858-1930 8

Figure 6 Toronto waterfront in 19189

Figure 7 Waterfront redevelopment patterns 10

Figure 8 Harbourfront Toronto, 200827

Figure 9 HafenCity, Hamburg 27

Figure 10 Teardown of the Alaskan way Viaduct $\mathbf{3 3}$

Figure 11 Location of Alaskan Way Viaduct 43

Figure 12 Alaskan Way Viaduct, 200848

Figure 13 Tunnel to replace Alaskan Way Viaduct 45

Figure 14 Barriers created by Alaskan Way Viaduct 47

Figure 15 Removal of barriers after demolition of Alaskan Way Viduct 48

Figure 16 Boston Central Artery Before the Big Dig $\mathbf{5 1}$

Figure 17 Location of Boston Central Artery pre-Big Dig 52

Figure 18 Location of Boston Central Artery Tunnel 53

Figure 19 Construction of Boston Central Artery circa 195654

Figure 20 The Big Dig before and after 54

Figure 21 Location of the Embarcadero Freeway 59

Figure 22 San Francisco waterfront after the removal of Embarcadero Freeway $\mathbf{5 9}$

Figure 23 Embarcadero Freeway and Ferry Building 60

Figure 24 Current state of the Ferry Building after removal of the Embarcadero 60

Figure 25 Regional context of Toronto and connection to St. Lawrence RIver 64

Figure 26 Toronto Waterfront 64

Figure 27 Accumulation of waterfront infrastructure circa $1982 \quad 69$

Figure 28 Location of Gardiner Expressway 71

Figure 29 Potential city-waterfront connection with removal of the Gardiner Expressway $\mathbf{7 2}$

Figure 30 Eastern section of the Gardiner Expressway 72

Figure 31 Condition for pedestrians underneath the Gardiner Expressway 73

Figure 32 Lack of accomodation for pedestrians results in unsafe crossing 73

Figure 33 Section of the Gardiner Expressway subject to Environmental Assessment $\mathbf{7 7}$ 


\section{Introduction}

\section{Justification}

A waterfront can be a tremendous asset to a city: a place of recreation, a vibrant tourist attraction, a desirable place of residence, a local treasure that greatly enhances the quality of life for all urban inhabitants. However, these are only some of the possible conditions for a waterfront, and is by no means inevitable. This outcome requires a tremendous amount of social, environmental, political and economic coordination. Many post-industrial cities have been left with waterfronts that are contaminated from industrial processes, disconnected from the natural processes that shaped them, thoroughly isolated from the urban fabric that surrounds them, and subject to seemingly endless debate about what their future state should be.

Cities with post-industrial waterfronts are therefore confronted with important planning decisions. Due to a number of forces, urban waterfront areas around the globe have become available for redevelopment. Given the desirability of waterfronts as places of recreation, leisure, and commerce, the redevelopment of waterfronts is an attractive undertaking for cities. However, it is critical to get this redevelopment right, to redevelop the waterfront in such a way that users regard it as an attractive and popular destination that is easily accessible for urban inhabitants. This involves addressing the issue of the infrastructure pattern surrounding waterfronts that has been shaped by decades of transportation and industrial uses, and will be the focus of this paper. 


\section{Intent}

This paper looks specifically at the accessibility issues that are presented by infrastructure barriers to the waterfront, in particular urban expressways, and the way in which those barriers can be mitigated in the context of the redevelopment of Toronto's waterfront. The investigation and evaluation of accessible waterfronts has become a critical aspect of contemporary urban planning practice. The field of urban planning is replete with examples of cities that are seeking to address waterfront issues with innovative planning interventions. Plans for waterfront revitalization in some countries are pushing the planning status quo by attempting to acknowledge the complexity that waterfront regeneration often entails. Accessibility is just one of the issues, yet it is arguably the most critical, as a pre-condition to waterfront redevelopment being successful. A spectacular waterfront is only successful if people are able to freely and easily access it. This is not to say that waterfronts need be centers of spectacle. Many contemporary waterfront revitalization projects seek to reestablish a more natural relationship between the city and water to become places to live, work and play.

This discussion is especially pertinent in the context of the current debate concerning the future of the eastern portion of Toronto's Gardiner Expressway, a piece of infrastructure that acts as a physical and psychological barrier to waterfront access. The debate is being played out in public consultations, the political arena, and the news media. It is a contentious issue in part due to what it represents for Toronto - removing it represents a break with the planning mentality that has shaped the post-WWII growth in 
Toronto; repairing or replacing it represents reinvesting in that same mentality.

The current debate has its genesis in the freeway revolts of the 1960's - which prevented more widespread adoption of expressway building in many North American cities. As an outcome of that era, the Gardiner is still a part of the legacy of that planning era. The debate centers on the function of the expressway - what purpose it currently serves, and what it could become. This purpose is determined in part by its urban form, the way in which it impacts the urban landscape of Toronto.

An understanding of the functions of urban form will be necessary to evaluate the way that infrastructure functions in relation to the accessibility of the waterfront. As a means for facilitating this understanding, the work of Kevin Lynch, specifically his method of analysis articulated in The Image of the City, will be utilized as set of tools to interpret and understand the perception and function of different urban forms, paying special attention to the urban expressway.

An understanding of waterfront history and development patterns is an important foregrounding to this discussion, and this is where the paper begins. The second section looks at the methodological tactics for assessing waterfronts as informed by Lynch's work. The third section looks at important case precedents from other cities before looking specifically at the situation of the Toronto waterfront. The fourth section provides some recommendations for the future of the Gardiner Expressway based on the discussion presented in this paper. 


\section{Section 1}

\section{Cities and Waterfront Development: A Brief History}

It is by no coincidence that many of the major urban areas around the world are situated closely to waterfront areas. Urban settlement began with the land immediately adjacent to the waterfront, especially in the case of colonization in North America. Modern cities have grown from these early settlements that were selected in large part for their adaptability to port construction, which was necessary in order to facilitate the transportation of goods and people (Moir, 2011, Hayuth, 1982).

Since waterfronts were the initial point of access to land, and as shipping was the primary mode of transportation, access to waterways was vital to new settlements. Harbours that offered good defensive positions, as well as access to inland waterways were especially valuable. As an example, the initial settlement of what later became the city of Toronto in 1793 was as a military outpost - Fort York (Figure 1). The site was chosen for its protected harbour and presence of two rivers - the Don River to the east and Humber River to the west (Desfor \& Laidley, 2011).

The pattern of settlement in colonies evolved according to the grid pattern that was imposed on the landscape by early land surveyors, often irrespective of the natural topography. The imposition of the grid on newly settled land occurred for a number of reasons - military control being chief among them (Stanislawski, 1946). There was also the attraction that the grid could be extended easily from the initial settlement area, and servicing was most easily managed in the grid pattern. 


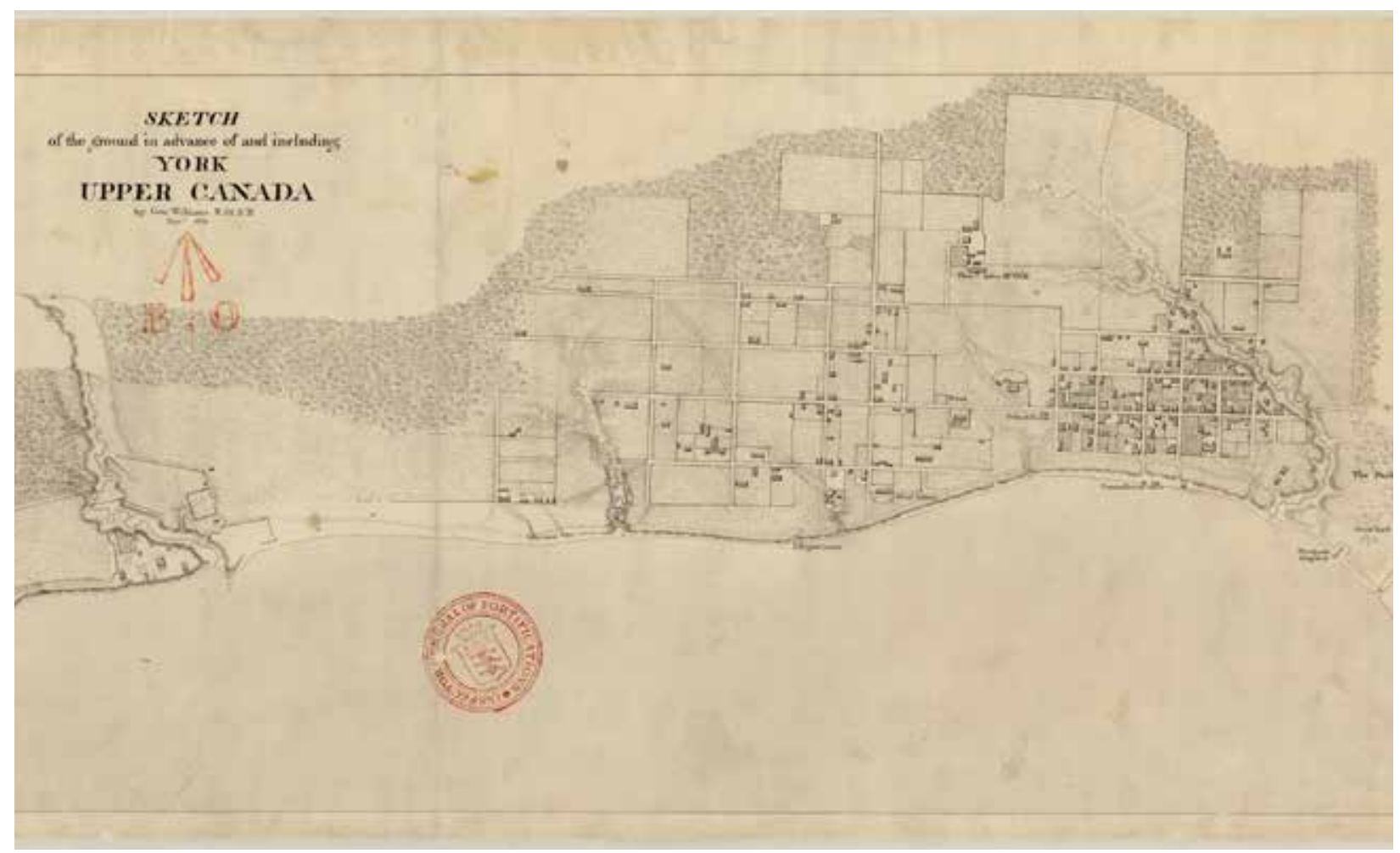

Figure 1 Map showing the settlement pattern of Fort York in 1818 (Library and Archives Canada, 2008).

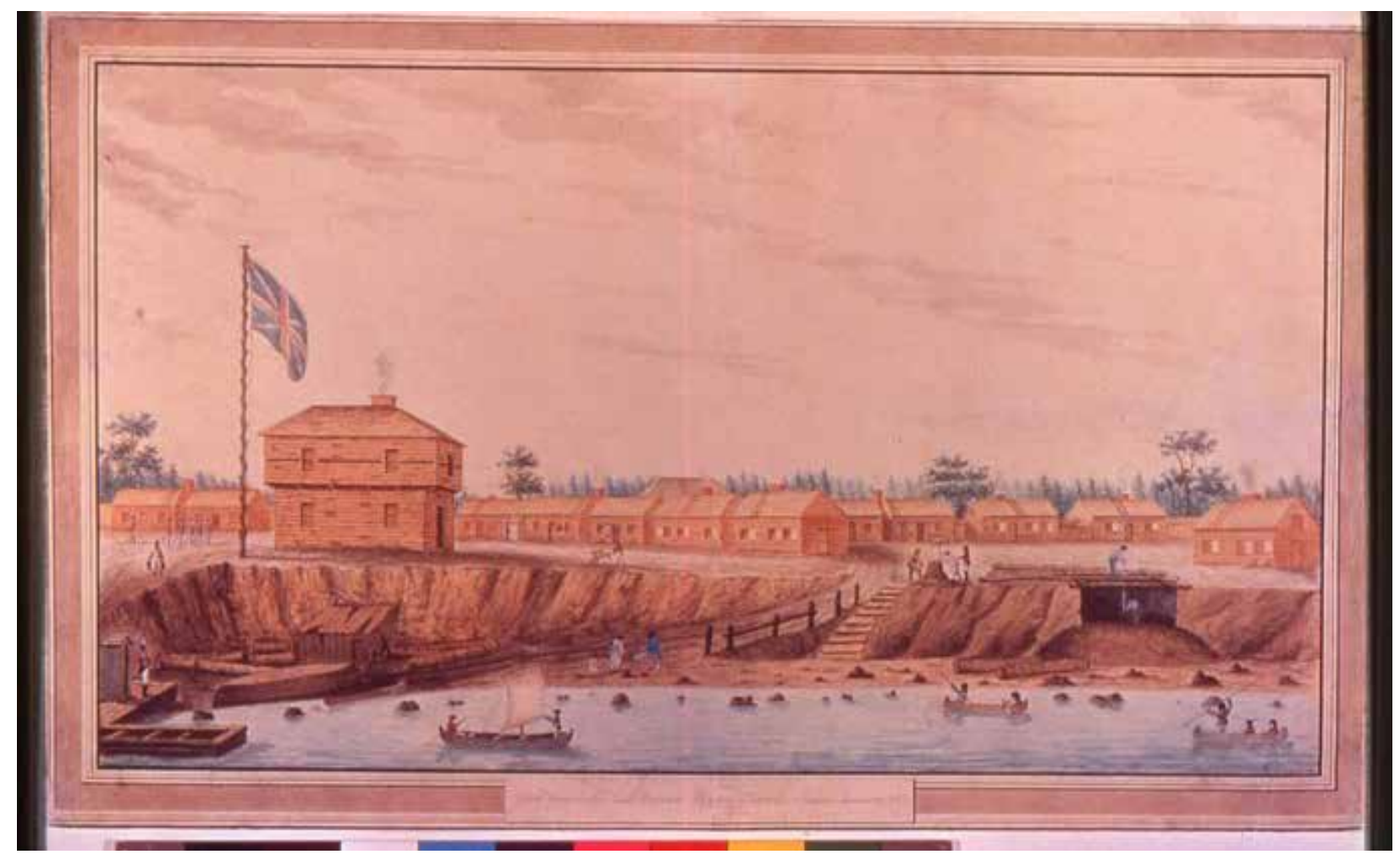

Figure 2 Painting showing the Fort York barracks in relation to the waterfront in 1804 (Waterfront Toronto, 2014). 


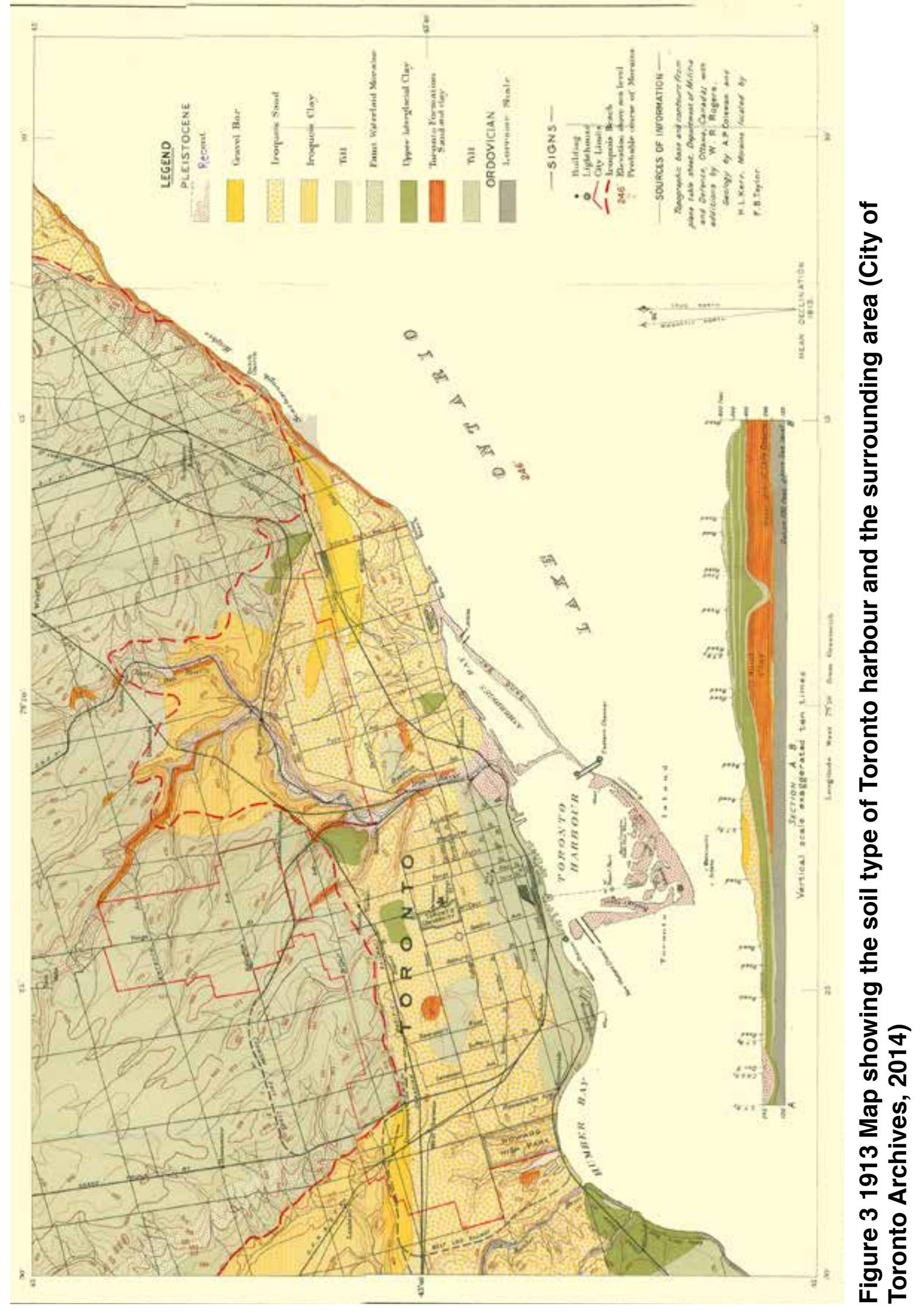




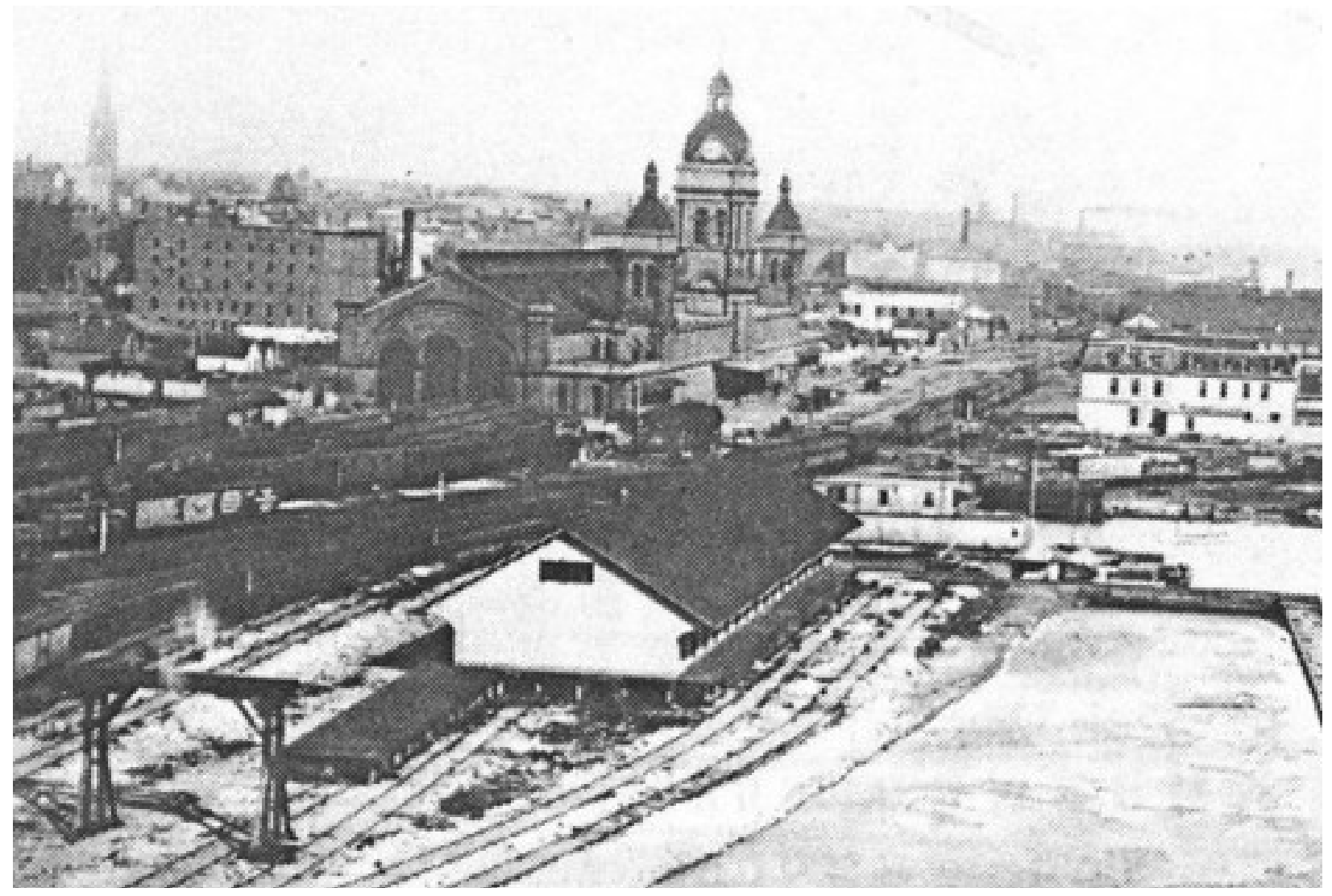

Figure 4 Toronto waterfront in 1884 looking east from John St (Waterfront Toronto, 2014)

As settlements expanded and populations grew, so to did the infrastructure necessary to accommodate increasing shipping activity. This infrastructure typically took two forms - water and inland infrastructure. The water based infrastructure that was built included finger piers, wharves, and docks (see Figure 7). As ports continued to grow, techniques for land reclamation allowed for expansion of port facilities by filling in harbours and creating more land. Flood control measures such as the channelization of rivers made natural processes subservient to the needs of the port to function. All potential disruption from natural processes was minimized, often to the detriment of natural waterfront areas, such as marshes and rivers. 

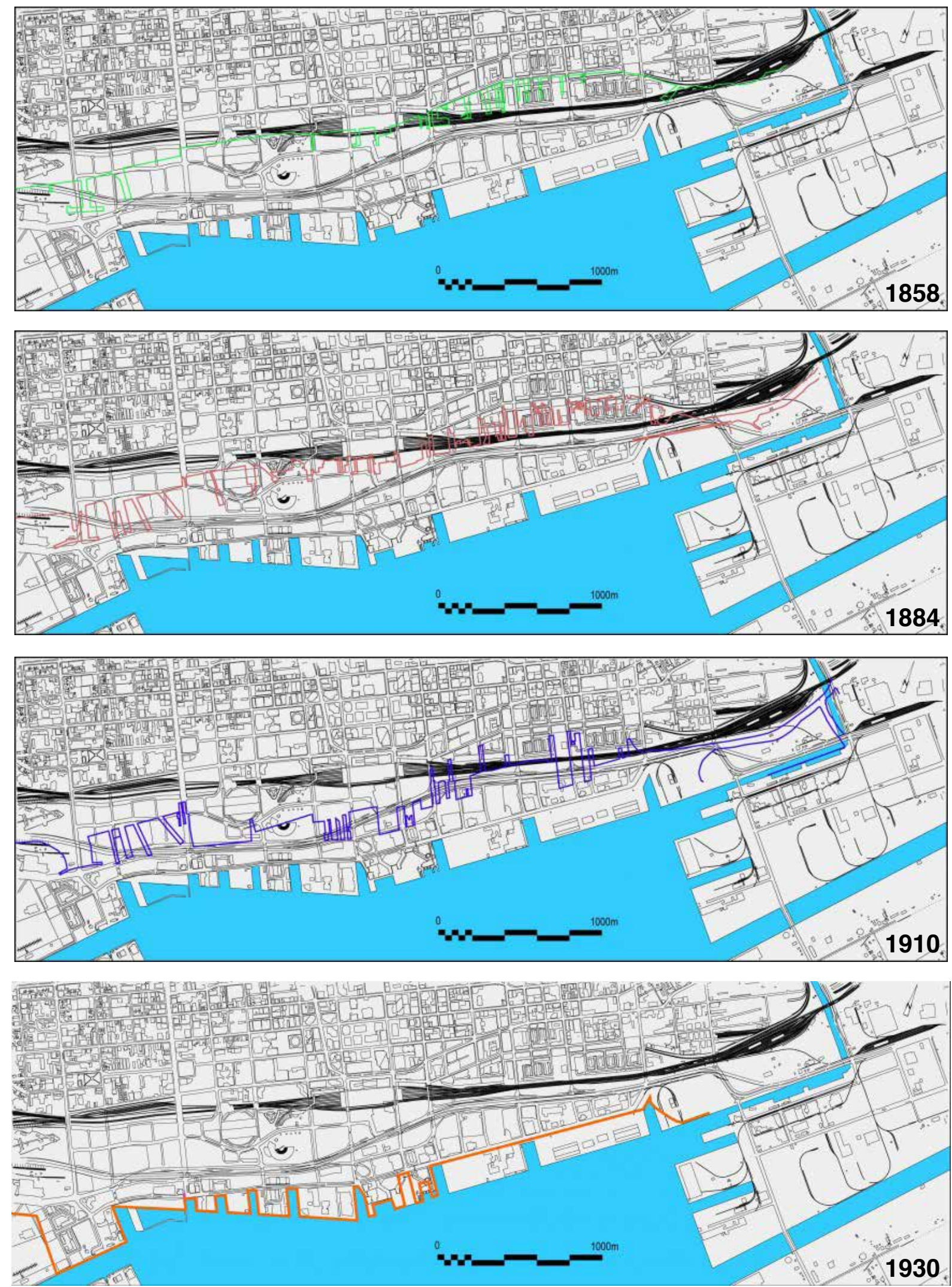

Figures 5 a-d Series of maps showing the progression of harbour infilling. (Waterfront Toronto, 2014). 


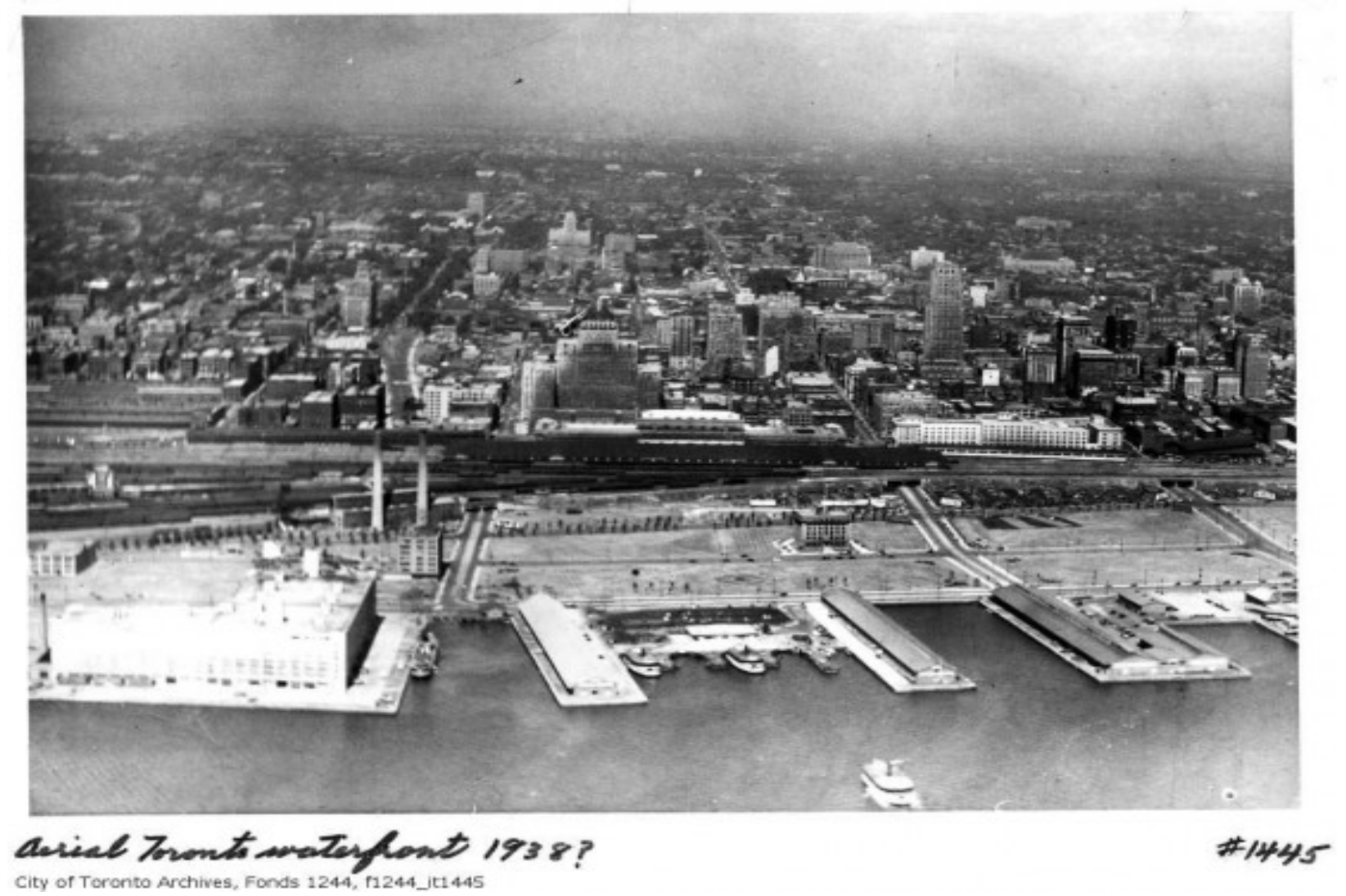

Figure 6 Toronto waterfront in 1918. There is a clear division between the industrial waterfront and the city (Waterfront Toronto, 2014).

Inland infrastructure included specialized facilities for handling cargo, as well as transportation infrastructure that was necessary to move goods in and out. This infrastructure initially included railways and rail marshaling yards, and later involved increasing waterfront road capacity in the form of highways (Fisher, 2004). This infrastructure that was necessary for the financial prosperity of the port city had other consequences. This increasing need for infrastructure, related to the expansion of shipping and cargo-handling activities, meant that the rest of the city was becoming increasingly separated from the waterfront. As David L. A. Gordon explains, port facilities were intended to be inaccessible, for two reasons. One was to discourage 


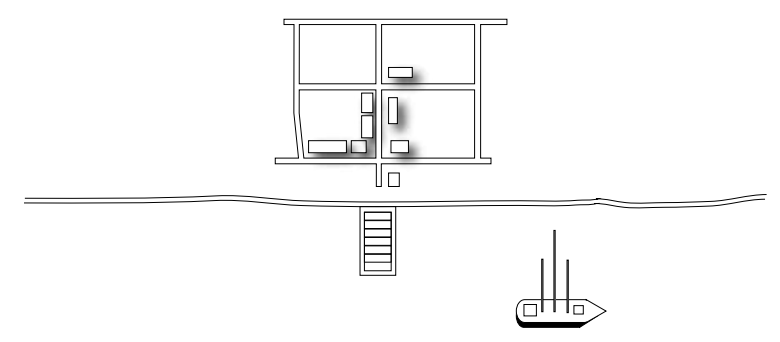

1. Initial settlement pattern

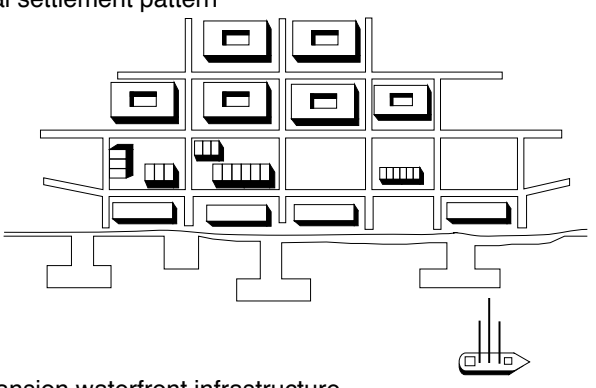

3. Expansion waterfront infrastructure

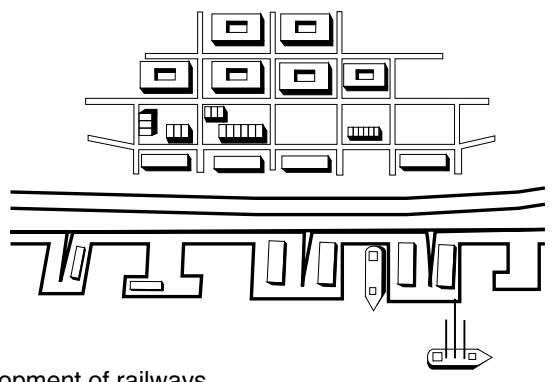

5. Development of railways

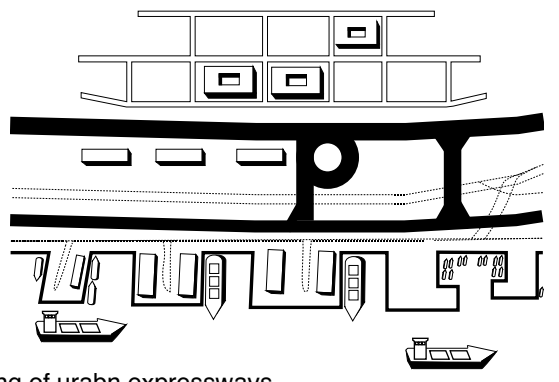

7. Building of urabn expressways

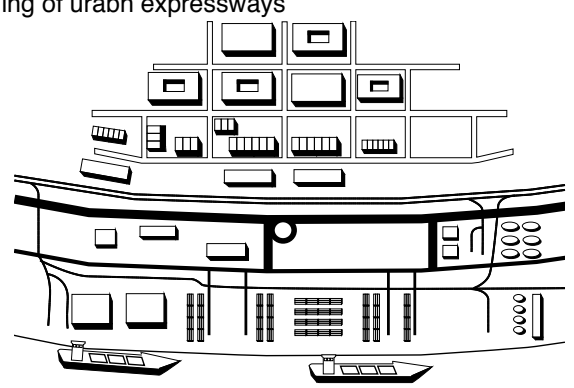

8b. Continued industrial use, increased infrastructure

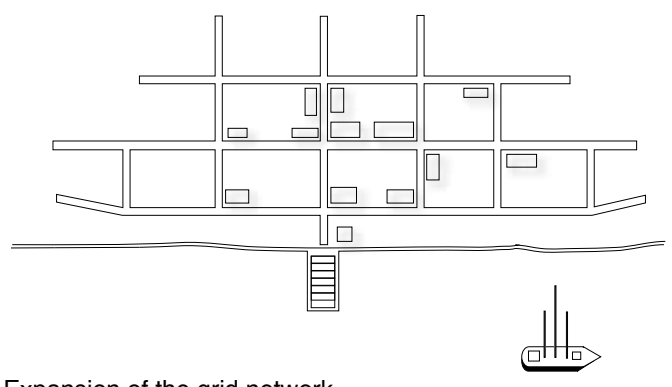

2. Expansion of the grid network

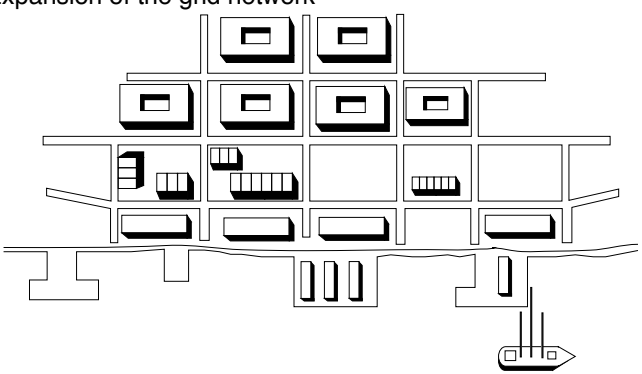

4. Increase in water-related infrastructure

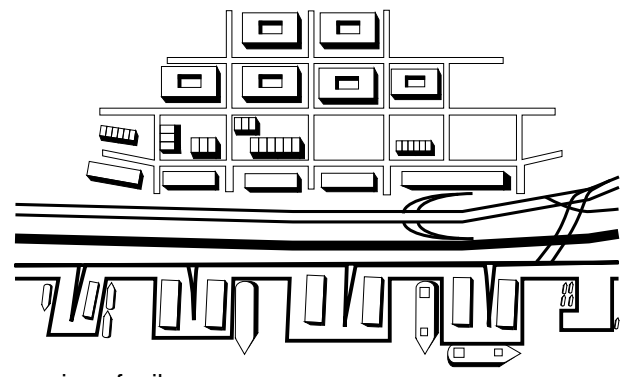

6. Expansion of railways

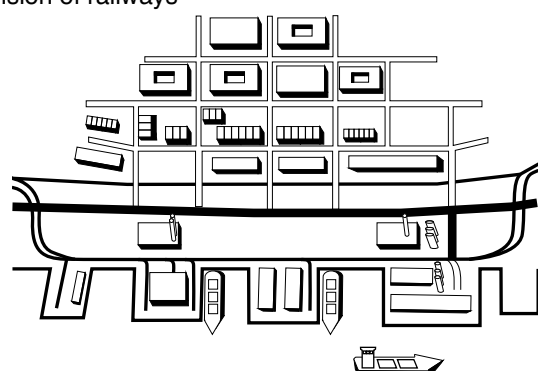

8a. Continued industrial use, decline of infrastructure

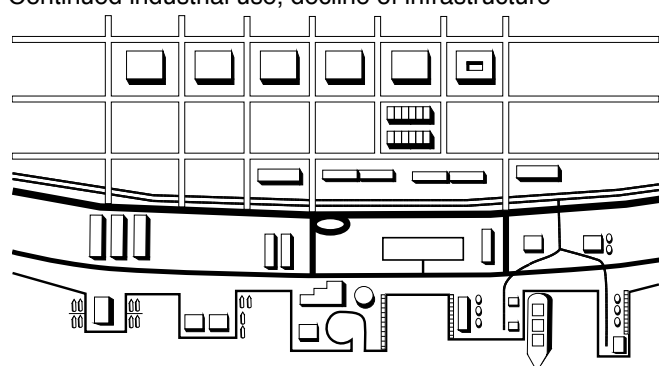

8c. Development of residential and recreational uses

Figure 7 Waterfront redevelopment pattern. After stage 7, there are different development patterns that can occur. (Adapted by Gordon, 2014, from Fisher, 2004) 
theft of cargo, and the other was to control vehicular movement (Gordon,1996). Ports, while often located in relatively close proximity to the downtown, were not a part of the downtown city fabric, and the two had little relation to each other (see Figure 6).

Subsequent changes to shipping technology, specifically containerization and the increasing size of cargo ships meant that not all ports remained suitable for shippingrelated uses. The land required to handle these changes in technology have meant that an inability to expand port functions left some ports obsolete. Expansion of existing port facilities often proved to be impossible due to the lack of suitable land available or prohibitive costs of doing so. Port activities have been relocated to areas that have large amounts of land available for cargo handling, and deep waters to accommodate increasingly large ships (Smith \& Ferrari, 2012). The port and city became even more spatially and functionally segregated as port functions moved to the outskirts of urban areas (Hayuth, 1982). These changes in port capacity requirements left many ports in urban areas as unused, post-industrial sites. With their function as ports effectively concluded, waterfront areas became sites in need of revitalization. Due to the nature of their former industrial land use, and their disconnected relationship to the surrounding urban areas, this revitalization is often a long and complex process. The process of waterfront redevelopment is typically debated within the political arena, which, while a necessary part of the redevelopment process, can often add to the complexity and length of the process. Redevelopment is also by nature very costly, as it frequently involves major infrastructure decisions and investment. A closer examination of the portcity relationship shows why it is often so complex. 


\section{The Process of City-Waterfront Disconnection and Reconnection}

Initially, waterfronts and cities were closely related, by function and geographical proximity. However, this relationship has changed over time, and has resulted in a separated city and waterfront. There is a significant literature that deals with this relationship. The degree to which industrial uses have migrated away from the waterfront varies by waterfront. Those waterfronts that are not able to accommodate the changing needs of shipping are sites that have experienced the most waterfront decline, and have had the most land become available for redeveloping. This is the initiation of the cycle of waterfront industrial development, which results in disconnection, and redevelopment that can result in reconnection.

Hoyle (1989) examines what has been termed the "port-city interface" (Hayuth, 1982). The port-city interface can be conceptualized in different forms, depending on the city it can be: the area of transition between the lands used for port activities and the urban areas that surround it; an interactive economic system; an area of transport integration; or an area of conflict in policy formulation and implementation (Hoyle, 1989). Depending on the city and its particular dynamics, different port-city relationships can be cooperative, depending on the objectives and priorities of the port and city (Hoyle, 1989). When waterfront redevelopment is considered, the relationship between the port and city takes on an increased level of significance, either in support of, or in opposition to, waterfront redevelopment.

While historically significant, the relationship between the city and the waterfront has become increasingly separated. There are important implications for this, 
especially in the context of waterfront redevelopment. As the traditional port functions move away from built up urban areas, it changes the nature of the port-city relationship. Waterfronts fall into disuse, but due to their value in redevelopment, waterfronts are often important for economic growth and job creation (Hoyle, 1989). Waterfront redevelopment typically requires political approval, and the type of redevelopment undertaken can depend in part on the administration in power. The outcomes of waterfront redevelopment have the potential to change with a change in political leadership, although this is not always the case. Economic considerations are often a main theme in waterfront redevelopment. It is often necessary to be able to attract capital to enable redevelopment to occur. The social interests of waterfront redevelopment can be at odds with economic interests, such as the balance between providing open space for recreation versus more office space. Citizens groups have become effective at advocating for social interests, although their effectiveness is often a condition of the economic climate in which development is occurring. In more prosperous times, it is easier to achieve social-minded whereas in more difficult economic conditions, the outcomes that generate the most economic growth are more likely to occur (Hoyle, 2000).

Hoyle describes a process common to the waterfront-city relationship in most cities around the globe, and that is a 'retreat from the waterfront'. This is the process that describes the separation of port and city, and has been caused by four main factors: the evolution of maritime technology; the increasing scale of ports and their space requirements; a decline in port-related employment; and the environmental perspectives on port-industrial and urban activities. 
The first three factors can be seen as being somewhat interrelated, with the driving cause being changes in technology. The changes in shipping technology has meant that some ships in use are able to accommodate over twenty times more cargo than they could in the 1950's (Kremer, 2013). Ports that are unable to accommodate these changes (due to increased space requirements) see a decline in port related employment as port activities are relocated. Separate from these technological, spatial and economic forces is a greater awareness of the environmental impacts of industrial port activities, which have had considerable negative impacts. As a result of these forces, there is a large amount of vacant space that has become available at the heart of the urban core. While the area may become vacant, and available for redevelopment, the prior uses often mean that sites are contaminated brownfield areas that require remediation before redevelopment can proceed. This remediation can add significantly to the cost of redevelopment and in some cases make redevelopment financially unfeasible.

Hoyle also identifies five stages of the port-city interface: the primitive port/city; expanding port/city; modern industrial port/city; retreat from the waterfront; and the redevelopment of the waterfront. The first three stages of this interface development see an increasing degree of separation between the port and city, reaching its peak during the modern industrial stage wherein industrial uses drive growth and separation of the city and port. The last two stages see a decline in port functions as uses migrate elsewhere, giving way to a need for redevelopment. The final stage presents significant planning issues, such as brownfield remediation, establishing land use plans, and providing for different modes of transit. These issues need to be addressed before the 
port and city can be reintegrated.

In a continuation of his analysis of the port-city interface, Hoyle examines the process of urban renewal in the context of waterfront redevelopment. Hoyle notes a distinction between the North American and European understanding of waterfront decline. In the European context, it is seen as a maritime issue - the result of changing marine technology. North American cities are inclined to view waterfront redevelopment as a part of the overall process of urban evolution, and that the cessation of port activities is part of this natural progression of development.

Hoyle describes waterfront renewal as a decidedly global phenomenon, that nearly every advanced city with a waterfront is in the process of undertaking, or has undertaken a program of renewal. This process of renewal is often a contentious one, involving the concerns of authorities (at different levels of government), developers, and communities. Waterfront redevelopment is described as almost and inevitability, provided that the economic rationale and political will are present. (Hoyle, 2000).

\section{The Evolution of Waterfront Redevelopment Approaches}

Waterfront redevelopment initiatives have become an international phenomenon, with virtually every waterfront city in the developing world undertaking some sort of waterfront revitalization program. Waterfront revitalization is a decades-old trend, originally occurring primarily in North American cities, and spreading globally (Schubert, 2011). The need for waterfront revitalization has been recognized as an important aspect of re-invention of post-industrial cities (Galland \& Hansen, 2012). The nature of 
waterfront revitalization means that they are often large undertakings, both temporally and spatially. Projects can range from the 37-hectare redevelopment of Battery Park in New York City to the 520-hectare redevelopment of the Dublin Docks in Ireland. (Waterfront Toronto, 2013).

Rafferty and Holst (2004) identify six factors that have contributed to the increasing amount of waterfront redevelopment that is occurring in post-industrial cities. These factors are: available land; cleaner water and land; the historic preservation movement; citizen activism and leadership; urban revitalization; and the return recreational water uses.

Shaw (2001) identified four different waves of post-industrial waterfront development that have influenced different stages of waterfront development. Shaw postulates that there is roughly a 30-year cycle for architecture and planning ideas to be introduced; experimented with; and standardized and consolidated. These stages correspond with the first three waves of waterfront redevelopment, with a fourth wave emerging today that will be more radical in the reviewing of established redevelopment methods, and putting forth new ideas (Smith \& Ferrari , 2012).

Within North America, the regeneration of Baltimore's waterfront, begun in the 1970 's, is regarded as a pioneer of post-industrial waterfront redevelopment. Inner-city decay had necessitated the large-scale redevelopment of Baltimore's waterfront. It was recognized that the scope of the project was beyond the private sector to effectively overcome the industrial legacy of the harbor on its own. Public money was required to make the redevelopment financially feasible. The redevelopment was guided by Baltimore's Inner Harbor Renewal Plan, which provided for the establishment of "flagship" projects, such as an aquarium and festival-marketplaces. 
The second wave of development in the 1980's, while evident in North American redevelopments, such as those in Boston and Toronto, was ultimately pioneered in European projects. Redevelopment in this period often involved the convening of special-purpose corporations that put waterfront redevelopment initiatives into practice, including those ideas and attractions that were pioneered in Baltimore. A proto-typical corporation for this wave of development was the London Docklands Development Corporation (LDDC), which was given power to coordinate private investment in the redevelopment of the waterfront, and had little local accountability. The redevelopment of the London Docklands was somewhat of a departure from previous planning practices, as there was no master plan for the development, but rather local area plans, due to the disconnected nature of the redevelopment and the large scale of the project. A characteristic of this project, like the Baltimore redevelopment, was the involvement of the private sector. There was the assumption that the private sector had more expertise to accomplish such a redevelopment. There was also considerable attention paid to the idea of conservation of built form. However, this may be a somewhat sitespecific characteristic, as not all waterfront cities have the historically significant building stock that is seen in London. Nevertheless, heritage conservation continues to be a characteristic of waterfront redevelopments.

The first and second waves of waterfront redevelopment were occurring at time when cities were becoming increasingly interconnected, as an outcome of the forces of economic globalization and technological advancements. The effect was one of increasing homogenization of cities, particularly in the case of waterfront redevelopments. Especially in the late 1970's and 1980's (the time of developments 
such as Baltimore, Toronto and London) the outcomes of waterfront redevelopments were corresponding in their features - festival marketplaces, marine museums, and aquariums (Desfor \& Laidley, Introduction, 2011)

The third generation of waterfront redevelopment that emerged in the 1990's has been characterized by the consolidation and standardization of the approach that characterized the first two waves. The approaches that were posited and refined throughout the first two waves were developed into scalable initiatives, in order to allow them to be implemented at sites that differed in size, and added to the homogenization of redevelopment projects. Projects that could be described as third wave approaches are global in scope, with examples in Boston, New York, Sydney, Perth, and Vancouver.

The forth wave, as suggested by Shaw at the time of his writing, is has been emerging since the late 1990's global recession, and is typified by large scale European projects, including several located on the North Sea. There is an emerging trend that sees waterfront regeneration as an avenue for city building. In addition, there has been a greater emphasis that has been placed on conservation of resources, and a reconnection with the natural environment. All waterfronts are made unique by the natural forces that have shaped the area, despite all efforts to control nature. There has been an emerging emphasis on the re-discovery of these natural processes (Fisher, 2004), and attempts to re-establish these underlying processes on the waterfront are evident in many of the fourth wave redevelopment projects . Sustainability - social, economic, and environmental - has become a key aspect of current waterfront redevelopment projects (Daamen \& Vries, 2013). A more recent series of fourth-wave waterfront redevelopment proposals seeks to move beyond the idea of what is 
traditionally thought of as green redevelopment and implement plans for the remediation of waterfront areas by using 'naturalized' infrastructure (Lister, 2009). As discussed earlier, industrial waterfront development often involved the conquering of natural processes to facilitate movement of goods or prevent natural events, such as flooding. Some of the more recent innovative proposals, for sites in cities such as Toronto, Mumbai, and New York would allow for the re-establishment of these processes (Lister, 2009). Some of the projects remain speculative, but challenge conventional ideas about what a sustainable redevelopment might look like. Instead of transforming nature, these projects account for and accommodate natural processes, such as the meandering nature of rivers, as well as seasonal flooding by reintroducing naturalized hydrologies (Lister, 2009).

\section{Waterfront Redevelopment in Practice}

There is an inherent complexity with waterfront redevelopment projects. As the methods and outcomes of the successive waves of waterfront redevelopment are assessed and debated, there is an opportunity to establish new redevelopment approaches. This opportunity is not without its own challenges. Complexity can stem from a number of different variables related to the redevelopment of waterfronts. Galland and Hansen (2012) identify some of the factors that can affect current and future waterfront redevelopment, which include local institutional arrangements; project leadership; planning rationalities; types of urban areas; and existing market conditions. These conditions create different planning processes and outcomes that can vary by 
location, as no two waterfront redevelopment projects are identical. Each site has its own history of industrial development, as well as unique arrangement of infrastructure and differing amounts of brownfields in need of remediation before redevelopment can occur. Institutional arrangements can have an impact on the way that development proceeds. Top-down, master planned initiatives that implement a singular vision for redevelopment have become less popular in the face of project-based plans that are often used in areas that are open to market forces, where market conditions are typically the drivers of redevelopment. Generally, the stronger the market conditions, the more private investment is likely. Weak market forces can mean that redevelopment is driven by the public interest, as opposed to private interest.

\section{Jurisdictional Struggle}

A common method for many large-scale waterfront redevelopment projects is the establishment of urban development corporations (UDCs), which differs from both the conventional development approach, and the establishment of a coordinating agency (Eidelman, 2011). In the context of Canadian cities, such as Toronto, conventional development approaches involve each level of government (federal, provincial, and municipal) pursuing their own projects in accordance with their own interests and jurisdiction. Coordinating agencies, as the name implies, attempt to coordinate the redevelopment projects initiated by the different levels of government, but the agency does not actually assume any ownership of the land being redeveloped. What sets UDC's apart from these two other approaches is that the government agencies either 
transfer the land, or cede temporary control to the UDC, which then undertakes redevelopment. The UDC method is utilized to alleviate many of the jurisdictional issues that can stall waterfront development. The Toronto Waterfront Redevelopment Corporation (TWRC, later renamed Waterfront Toronto) is a UDC that was established in 2001 to oversee the redevelopment of Toronto's waterfront. Three levels of government -federal, provincial, and municipal - funded the initial costs associated with redevelopment equally with each level of government providing $\$ 500$ million. While Waterfront Toronto (WT) is responsible for the redevelopment of 800 hectares of waterfront, there is no top-down implementation of a singular waterfront vision. The use of international design competitions is an approach that characterizes the current approach to waterfront redevelopment, and has been utilized in the case of Toronto. Other examples of these UDCs include the London Docklands Development Corporation (LDDC), which was established in 1981 to guide the development of the eastern docklands in London. The Battery Park City Authority (BPCA) in New York was established in 1968 to oversee the development of a site at the southwest tip of Manhattan.

It wasn't until the establishment of Waterfront Toronto that the redevelopment of the Toronto waterfront could effectively move beyond jurisdictional issues that had hampered any large-scale redevelopment initiative. Up until 1999, waterfront landdevelopment in Toronto had been under the purview of the federally incorporated Toronto Harbour Commission (THC), which had been established in 1911, due to the fact that jurisdiction over ports and navigable waterways is a responsibility of the federal government. (Sanderson \& Fillion, 2011). This federal involvement in the land 
development process on the Toronto waterfront was problematic and generated federalmunicipal conflict. There is no formal, constitutional connection between the federal and municipal level of government; the authority to create and dissolve municipalities resides with the provincial level of government (Sanderson \& Fillion, 2011). The THC was primarily concerned with port functions, as this was consistent with the interests and jurisdiction of the federal government. The lack of concern at the federal level with the land-use development aspect of the THC's mandate led to conflict between the federal government and the City of Toronto. There were several issues that highlight the causes of conflict, which included: insensitivity to emerging land uses, alleged impropriety in connection with land sales, overly aggressive land development proposals, incompatible land uses that would have reoriented waterfront functions, and its overall land development tactics that involved selling land to cover operating expenses (Sanderson \& Fillion, 2011). Ultimately the federal government convened a royal commission to study the options for the future of the Toronto waterfront, led by former Toronto mayor David Crombie. The findings of the report highlight the level of jurisdictional struggle regarding the Toronto waterfront: Crombie found that there were at least forty seven institutional 'actors' that could have a claim to jurisdiction over the waterfront in some capacity (Eidelman, 2011).

The prospect of Toronto hosting the 2008 summer Olympics provided the catalyst for a thoughtful examination of Waterfront redevelopment potential, and led to the establishment of the Waterfront Revitalization Task Force to undertake redevelopment. Although the bid was unsuccessful, the waterfront revitalization enterprise remained, and the UDC that is now Waterfront Toronto was established as a way to move past 
the jurisdictional hurdles towards a meaningful redevelopment initiative. Much of the groundwork for the establishment of Waterfront Toronto had been laid over the preceding decade, as the jurisdictional issues that prevented cohesive redevelopment were examined and ultimately resolved.

\section{The Growth of Barriers to the Waterfront}

Economic Revitalization

In many cases of waterfront redevelopment, the objective is to use the waterfront as a way to reverse the fortunes of a declining urban area. This was the case with the redevelopment of the waterfront in Copenhagen, Denmark. The question of redevelopment began to be considered by the end of the 1970's as Copenhagen was experiencing a period of economic decline (Ferrari \& Fraser, 2012). There was a new overall economic strategy put forward for Denmark in the 1980s, which saw Copenhagen as the main driver of growth, as it was argued that Copenhagen was the Danish city best equipped to compete on the international level (Desfor \& Jorgensen, 2004). For a variety of reasons, namely the suitability of the harbour, Copenhagen's waterfront was a desirable location for activities related to the new economic growth strategies (Desfor \& Jorgensen, 2004). This growth-focused approach has become somewhat typical of waterfront redevelopment schemes, as post-industrial cities seek to attact more discerning and footloose investment dollars. This is partially due to the forces of globalization and the shifting of redevelopment focused on social objectives to primarily economic objectives (Smith \& Ferrari, 2012). This shift is particualrilty notable in a city such as Copenhagen, where the focus on economic objectives with little 
regard for their social impact was a distinct change from earlier policies that would have required greater assessment of the social outcomes of any redevelopment initiative (Desfor \& Jorgensen, 2004).

The desire to become or remain globally competitive for capital investment is often a driver for waterfront redevelopment. Waterfronts that are suitable for postindustrial, twenty-first century economic uses are seen as being able to create a cycle of private investment that can fuel growth, create jobs, and generate tax revenues (Laidley, 2011). Toronto's waterfront redevelopment strategy is no exception, with the TWRC's initial plan for the waterfront situating waterfront redevelopment as a 'competitive necessity', given the twenty first century economic structure (Laidley, 2011). Much in the way that the redeveopment of Copenhagen's waterfront was presented as a national interest, the redevelopment of Toronto's watefront was regarded as being economically imporatnt not only to Toronto, but the province of Ontario, and Canada as a whole (Laidley, 2011).

Governance

The experience in Copenhagen also highlights another important aspect of the redevelopment process, which is the changing nature of interactions between the actors that participate in urban governance. Desfor and Jorgensen describe the urban govenrence of the redevelopment of Copenhagen as 'flexible urban governance', which invlolves new organizational and institutional realtionships (Desfor \& Jorgensen, 2004, p. 480). This chage in governance structure has had an impact on the way 
that redevelopment has proceeded on the waterfront, and invloves "an ensemble of individuals and organizations that are highly intertwined with a broader regime of economic accumulation" (Desfor \& Jorgensen, 2004, p.480).

The redevelopment of Toronto's waterfront also provides an example of governance flexibility. The institutional actors involved in the watefront redevelopment process recognized that the existing structures and relationships were not producing redevelopment outcomes that were considered a success either locally, or at the global level. Waterfront Toronto was established as a response to the governance and jurisdictional issues that hampered earlier attempts at redevelopment, and exhibitied the governance flexibility that is often necessary for redevelopment.

\section{Urban Design}

Opposition to some of the outcomes in completed redevelopment projects highlights the increasing level of public awareness as to what constitutes good urban design. With intial redevelopment outcomes in Copenhagen meeting with public outcry over the precieved lack of quality architecture and urban design, a steering committee was formed to ensure that the future waterfront redevelopment maxmized the economic potential of the waterfront, and did not repeat the precieved design mistakes of initial waterfront redevelopment (Desfor \& Jorgensen, 2004). The steering committee, known as the "Vision Group", is analogous to Waterfront Toronto.

Waterfront Toronto has been sensitive to the question of urban design, and to that end has constitued a design review panel that consists of leading practitioners 
from the fields of architecture, landscape architecture, engineering and planning. The purpose of the panel is to "set new design standards across the waterfront and help Toronto achieve worldwide recognition as a centre of creativity and good design" (Waterfront Toronto, 2014). The goal of urban design is not only to create a desirable landscape for the residents of Toronto, but also to ensure that Toronto's waterfront is recognized worldwide.

\section{Public Participation}

More recent waterfront redevelopment approaches have sought to encourage citizen participation in redevelopment plans, a tendency that has become more consistent across urban development decisions of all types. This process of participation in the case of waterfront redevelopment can present some challenges due to a number of different stakeholder scenarios; there may not be any residents that can participate in the redevelopment, because the waterfront area is not home to any. This was the case in some areas of the redevelopment that is occurring in the HafenCity redevelopment in Hamburg, Germany (Smith \& Ferrari, 2012). In this instance, the major landowner, the city, gave authority for the redevelopment to the arms-length public development company, HafenCity Hamburg GmhB. The responsibilities of the public company include managing the 'special city and port fund', which is funded by the sale of land within the development area. This money is then used to fund public investment in the waterfront redevelopment project, such as infrastructure, as well as preparing sites, building public spaces, coordinating real estate development and handling communication and public 


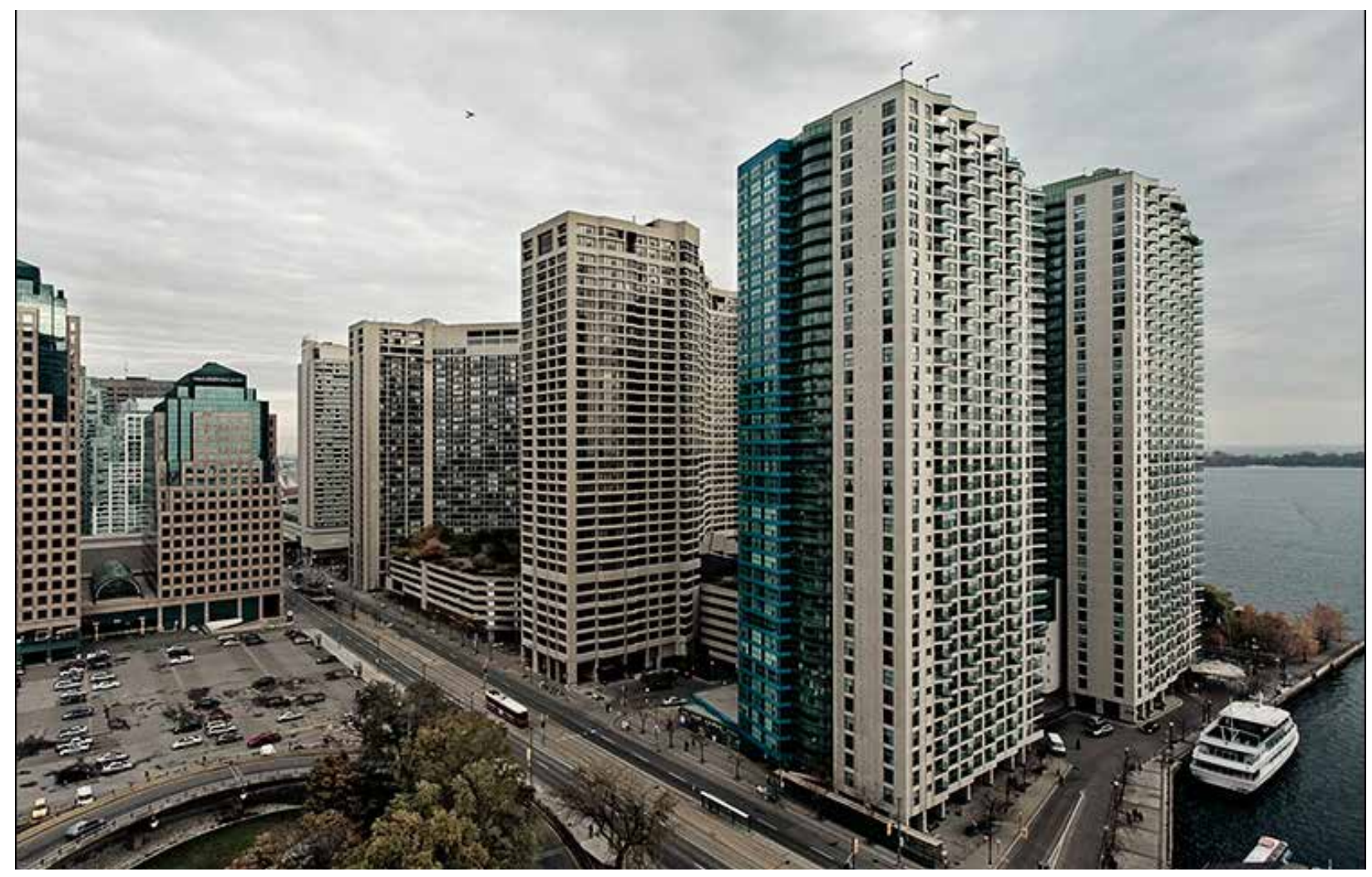

Figure 8 Harbourfront, Toronto (Sam Javanrouh, 2008)

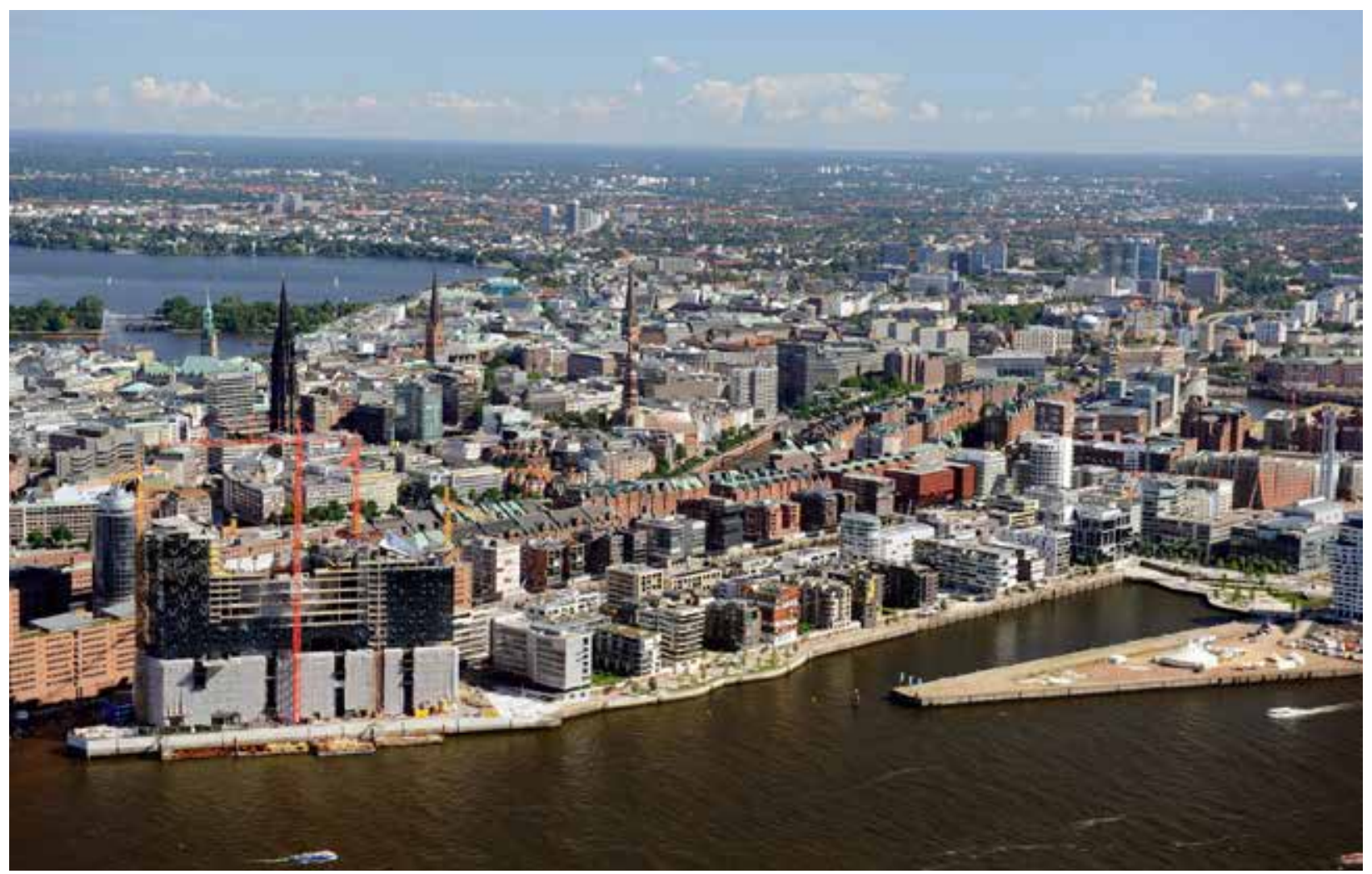

Figure 9 HafenCity, Hamburg (KCAP, 2014) 
relations for the redevelopment (HafenCity Hamburg, 2014). The initial redevelopment decisions for HafenCity were made in a somewhat secretive way, for a number of different reasons. Fearing opposition from port stakeholders or the wider population, as well as preparing sites, building public spaces, coordinating real estate development and handling communication and public relations for the redevelopment (HafenCity Hamburg, 2014). The initial redevelopment decisions for HafenCity were made in a somewhat secretive way, for a number of different reasons. Fearing opposition from port stakeholders or the wider population, as well as potential increases in land value that would have increased the cost of redevelopment, the city made initial decisions with little participation (Smith \& Ferrari, Exprerinces in participation in the port city of Hamburg, 2012). Once the decision-making process reached a smaller scale, more consultation was incorporated into the redevelopment process. This lack of initial consultation was only possible due to the virtual absence of any immediate resident stakeholders.

Waterfront redevelopment is therefore both complex and value-laden. Waterfront redevelopment is often seen as a way to either add to the value of a city or as an engine to revive lagging growth. With so much at stake with redevelopment, the fundamental question of how this redevelopment relates to the rest of the city cannot be overlooked.

\section{Locational advantages}

The pattern of waterfront redevelopment has had a profound impact on the way that the waterfront is able to relate to the rest of the city. As the industrial waterfront 
developed, it was not required to be accessible to urban inhabitants; there was little incentive to take into account accessibility as transportation infrastructure was built. As a result, many North American cities had their waterfronts effectively removed from the city fabric through the establishment of infrastructure related to industrial functions, as well as the exclusionary nature of industrial land use itself. In the transitional zone between the waterfront and the city, engineers recognized an opportunity to bring infrastructure into the inner city by building expressways along this seam. The alignment of the expressways parallel to the waterfront means that this infrastructure still functions to cut off the waterfront physically and psychologically long after waterfront industrial uses have ceased (Gordon,1996). This continued isolation speaks to the utility, but not the continued necessity of some waterfront infrastructure, especially in the case of expressways. This type of infrastructure may in fact be an impediment to maximizing the potential of waterfront redevelopment. Understanding the purpose with which they were built can provide insight into why they may no longer be the type of infrastructure that waterfront cities require.

\section{Modernist Planning}

While the locational decisions for expressways can be understood by taking advantage of unused or unusable open space, there were also other forces that were shaping the planning decision making process at the time. These planning decisions had a direct impact on the relationship between the city and waterfront, which are still felt today. 
In the context of post-WWII planning, Modernist city planning ideals began to have a significant impact on the urban landscape. These planning ideals had been formulated in response to the perceived problem with traditional city forms; especially those associated with the late 19th and early 20th century industrial towns. However, It was not until the end of WWII that these forms began to shape the planning of cities. The city-waterfront relationship was not immune from these planning decisions and was often affected by Modernist planning outcomes. An understanding of these planning objectives and why they were implemented can provide further explanation of the establishment of waterfront barriers.

Modernist planning goals envisioned a break with traditional urban forms; in their place would be plans based on the rational-comprehensive planning model and informed by 'expert' input. The visions included "the low density and functionally and socially segregated suburb; the high accessibility city crisscrossed by expressways; the renovated downtown made of high-rise buildings and open plazas; the redeveloped inner city composed of apartment towers surrounded by green space; and a planned metropolitan region structured by new towns and green belts." (Filion, 1999, p. 423). As planning practice is a product of its time, large-scale infrastructure projects characterized the Modernist era of planning. The booming post-war population was also a driver for suburban expansion. In relation to the issue of suburban population growth, expressways were seen as ways to encourage exurban growth yet maintain accessibility to the city. Suburban expansion was accompanied by dramatic increases in car ownership, and so the focus on expressway building was a logical way to accommodate this growth. 
Urban renewal programs that were undertaken in North America in the 1960's and 1970's proved to be detrimental to waterfront access. Highways were seen as a path of revitalization - to allow for greater access to the city from the suburbs. In reality, many of theses highways effectively cut off the city from the waterfront - such as those constructed in Philadelphia and Boston (West, 1989). Expressway construction at the time was viewed as a way to facilitate car use and ensure economic growth (Filion, 1999).

The use of urban expressways has its roots in the pre-WWII 'Parkways' that were built in New York in the 1920's. What is considered the first modern parkway, the Bronx River Parkway, designed by the landscape architects Herman Merkel and Gilmore Clarke, opened in 1923 (Gutfreund, 2007). The initial building of urban parkways and expressways is closely associated with one man, Robert Moses, who constructed dozens of parkways, bridges and expressways in New York between the 1920's and 1960's (Gutfreund, 2007). While the initial Parkways were at-grade, scenic roadways, over time the morphology of the road changed. As automobile use grew, focus shifted to accommodating the speed and volume of traffic, especially post-WWII.

The infrastructure associated with expressways began to occupy more and more of the landscape as lane widths were expanded, on and off ramps were extended, and expressways began to be constructed above grade, elevated to allow for minimal disruptions (Gutfreund, 2007). Another important factor was planning and design of the expressway was no longer in the hands of landscape architects, but rather engineers. This shift in the profession meant that expressways met technical criteria for road construction, but any aesthetic and scenic factors were given minimal consideration, or 
no longer considered altogether. Ultimately, the type of expressway construction that Moses presided over began to fall out of favour with the public in early 1960's. Two proposed expressway projects in New York City City - one that would bisect Midtown, the other Manhattan, proved to be too disruptive in such a dense, built environment and elicited strong public opposition.

Toronto was not immune to the forces of modernist city planning; the construction of the Gardiner Expressway is evidence of this. Other North American cities had urban areas significantly altered by modernist planning programs as well. Boston's experience with urban expressways - the Central Artery - effectively cut off the North End of the city and ultimately led to the need for one of the largest infrastructure projects in United States history - nicknamed "The Big Dig" to deal with the congestion and isolation that the expressway caused. New York, San Francisco, and Seattle - to name just a few more - are all cities that have dealt with modernist city planning visions that have seen the construction of urban expressways along a path that bifurcated the urban area from the waterfront.

There has been significant criticism of modernist planning visions, perhaps one of the most visible and widely read is the work of Jane Jacobs, specifically her The Death and Life of Great American Cities, which is essentially a rejection of Modernist planning goals. Her work captured the zeitgeist of the early 1960's that was beginning to oppose the outcomes of modernist planning. Jacobs did not see the construction of urban expressways as improving the accessibility of cities, but rather eviscerating them (Jacobs, 1993). A rejection of Modernism can be seen in the decline in popularity of Modernist planning projects, as is the case of the canceled Spadina Expressway in 
Toronto that would have run an expressway through the centre of downtown (Robinson, 2011). This conclusion was exemplary of the sort of defeat that Modernist planning goals would begin to suffer as citizen groups became more vocal in opposition to them. However, the early outcomes of modernist planning still had a significant impact on the urban landscape, and these impacts can still be seen today.

Expressways that cut off the waterfront from the rest of the city are a significant outcome of the post-war planning period, and an issue that presents considerable debate regarding the future of this infrastructure. While expressways may be unpopular for some urban inhabitants, they are nonetheless widely used - often in excess of their intended capacity. The question of what can be done is often subject to considerable debate given the continued use of expressways and questions of viable alternatives. This debate can involve not just aesthetic questions, but can be framed as a question dealing with the politics of mobility by asking who benefits from what planning outcomes. Removing expressways can be beneficial to some urban inhabitants, while have negative impacts on those that require expressways for commuting. This debate is especially pertinent in the context of the current debate over the future of the eastern section of Toronto's Gardiner Expressway. The current debate over the Gardiner is another instance the kind of debate that has been occurring for decades - the one that has been occurring ever since Jane Jacobs first confronted Robert Moses and his vision of New York. 


\section{Expressway Teardown}

By the 1970's, opposition to urban expressway construction was in full swing. Jane Jacobs's arguments against the building of expressways were supported by public protest against further expressway construction - the so-called "freeway revolts" that occurred in many American cities in the 1960's and 1970's (Mohl, 2004). The displacement of thousands of residents and the barriers created by expressways proved to be too unpopular and created a groundswell of opposition to expressways. In addition to the activist opposition to expressway construction, there was the question of financing expressways that began to impact cities ability to build expressways (Brown, Morris, \& Taylor, 2009). This was due to a number of different factors, including the rising cost of construction materials and labour, right-of-way acquisition cost, as well as political inertia to either maintain existing sources of expressway funding, or to implement new taxes to pay for continued construction (Brown, Morris, \& Taylor, 2009).

The opposition to and unpopularity of expressways was such that, beginning in the 1970's, there began a expressway teardown movement that saw dozens of North American cities discuss tearing down inner city expressways (Mohl, 2012). Several cities have completed total or partial teardowns; while others continue with planning for teardown. The impetus for teardown comes from a number of different reasons - such as those urban expressways that are "aging, unappealing, environmentally damaging and dangerous" (Mohl, 2012, p. 90). There is also a greater understanding that by their physical structure, expressways often serve to divide neighbourhoods, and that tearing them down can allow for the rejoining of neighbourhoods that were disconnected 
(Skelley, 2011). The way that urban areas can be divided by expressways is a function of their form. By understanding the way that urban inhabitants perceive these urban forms, it is possible to determine how segregating waterfront expressways can be for the fabric of the city.

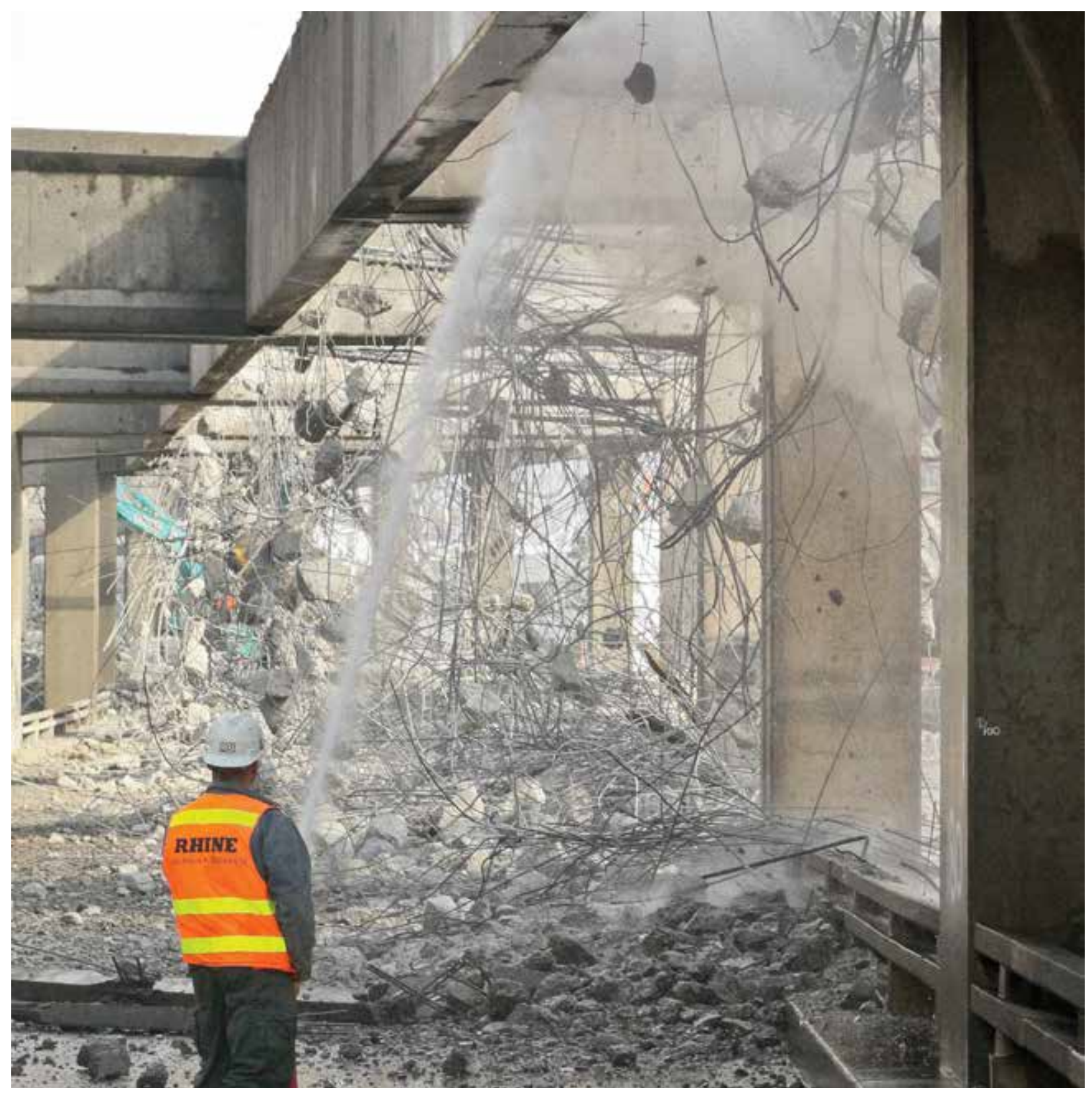

Figure 10 Teardown of the Alaskan Way Viaduct, Seattle (Washington DOT, 2014) 


\section{Section 2}

Waterfront Study - Ways of Looking at the City-Waterfront Connection Understanding the city-waterfront relationship can be achieved through a number of different methods. The historical, economic, and theory-based explanations for the evolution of the city-waterfront relationship have been established in detail in the preceding section. Understanding these forces that shaped the development of the industrial waterfront does not result in a complete understanding of the situation on many post-industrial waterfronts. The reason why these forms - such as expressways exist has been established, but how they function has yet to be examined. The focus of this paper can now turn to the on-the-ground experiences and outcomes of the forces that have shaped the city-waterfront relationship. By studying the urban forms that have resulted from industrial development, as well as the Modernist planning era, it is possible to understand the way in which these urban forms continue to have an impact on access to the waterfront. The purpose of the subsequent sections of this paper is to understand the effect that urban forms have on accessibility to the waterfront. A framework for interpreting urban forms is a necessary starting point for establishing this understanding, so that experiences in waterfront redevelopment may be compared using a standardized conception of forms. This framework will also allow for the comparison of the arrangement of forms in different cites, and how the rearrangement of those forms can result in greater connectivity between city and waterfront.

The work of Kevin Lynch is used here as the methodological tool to investigate the cities selected as case precedents and understand how changing urban form can 
change the perception of a city (or in this case, the waterfront) to its inhabitants. Lynch's framework is valuable for a number of different reasons: its language is universal to all urban areas; it is scalable, one can use it to look at an entire city or a particular block; and it provides an understanding of the relationship between the existing urban forms. The case precedents are examined to provide a broader context for the decisions that area currently facing Toronto as it pursues waterfront redevelopment.

Kevin Lynch: The Image of the City

Kevin Lynch's seminal work The Image of the City (1960) provides an important understanding of how city inhabitants make sense of their surroundings. While Lynch's work is influenced by theories on urban aesthetics, Lynch attempts to move beyond the issues of aesthetic subjectivity by grounding his work in the empirically based disciplines of psychology, sociology, and anthropology (Raynsford, 2011). By moving beyond the considerations of aesthetics, Lynch is able to establish a method of understanding urban areas based on form. A central concept of Lynch's work is imageability, by which he means the qualities present in urban forms and the image that they can provoke in an observer. These qualities that contribute to the formation of a strong central image may relate to shape, colour, and arrangement. Lynch writes that it could be called legibility or visibility as well (Lynch, 1960, p. 9). In essence, it is how inhabitants make sense of their surroundings, and how they are able to move through the city in relation to a number of different forms, which will be outlined below. 
First, it is important to note that a highly legible city does not necessarily equate to an urban area that is interesting or enjoyable, nor is an interesting or enjoyable urban area necessarily legible, or easily made sense of (Taylor, 2009). The true value of Lynch's work in the context of this paper is to be able to understand and compare urban forms and the way that they function, both individually and in relation to one another. Lynch describes five distinct urban forms, which are briefly summarized below: paths, edges, nodes, districts, and landmarks.

\section{Paths}

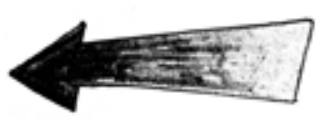

Paths are the basic element through which inhabitants customarily, occasionally, or potentially move. The most common example of a path is a sidewalk. Paths are typically the most recognized urban form, although their meaning and usage varies depending on the users familiarity with the city. Those that are least familiar with the path structure of a city tend to use other elements to organize the city. Users with greater familiarity of the path structure are able to think about specific paths and their interrelationships. Lynch also notes that users with the greatest understanding of the path structure tended to rely on small landmarks (see following description) for navigation. Lynch describes a number of qualities that can make a path more prominent to a user: major access lines; concentration of special use or activity; characteristic spatial qualities; special façade characteristics; proximity to special features; visual exposure of the path, or exposure of parts of the city from the path; and structural qualities. Paths that lack a clear identity are problematic; they can be confused for other 
paths and cause users to become disoriented. Beyond being easily identified, paths should have a sense of continuity, as well as a directional quality - one direction can easily be distinguished from the reverse.

Paths also have the potential to confuse the user, depending on the form that the path takes. For example, elevated expressways can be clear and legible while the user is travelling along them in a car, but due to their nature of being removed from the city fabric, can result in confusion and disorientation once the user exits them.

\section{Edges}

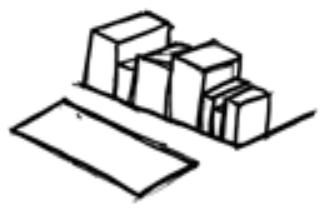

Edges are linear elements that often (but not always) separate two distinct areas. Some edges are naturally occurring (for example waterfronts and harbours). Other instances of edges can limit access to a particular group of urban inhabitants (e.g. the way that urban expressways are inaccessible to pedestrians). Edges can function to physically or psychologically cut off access to an area. While it may be physically possible to walk underneath an expressway, the imposing nature and primary use as an automobile path creates an environment that is not welcoming to pedestrian movement.

The degree of permeability can also vary by the edge being considered. The important quality is that the edge has some characteristic that provokes a response in the observer that can be recognized as an edge. In the case of urban expressways, that characteristic is the aforementioned scale and heavy automobile use. 
Nodes

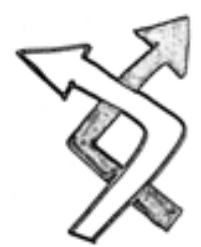

Nodes are the focused areas within an urban from - typically the junction of several paths, or the concentration of some other characteristic. What defines a node can vary depending on the scale that is being considered - if looked at a large enough scale (national or regional), the entire city can be seen as a node. Nodes are often important junctures for transportation modes - a place where directional decisions need to be made. Due to the closer attention that needs to be paid at nodes, they often can be distinct areas of the city in people's minds. Nodes can depend on one's method of travel - subway stations, railway stations for transit users; street intersections, freeway exits/ entrances for drivers; and public squares and spaces for pedestrians.

\section{Districts}

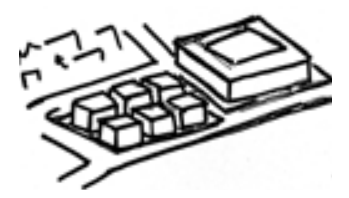

Districts are relatively large spaces with in an urban area that have some sort of consistent characteristic. They are recognizable to the observer from within the district. Districts can be used for navigation, if they are distinct enough. Some cities have distinct enough districts that these area the main forms that the city is perceived in (for example, New York and Boston). There is no limit to the qualities that can define a district, but some of them that Lynch provides are: texture, space, form, detail, symbol, building type, use, activity, inhabitants, degree of maintenance, topography. The boundaries of districts can vary - they can be definite and precise, while others can be uncertain. Districts can also be overlapping, especially depending on the characteristic 
that is being used to define what constitutes a district.

\section{Landmarks}

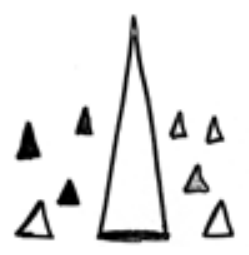

Landmarks are elements of the urban form that stand out for observers and users. Landmarks can be used as guides and for orientation. Urban inhabitants often develop a system of significant landmarks as guides, and these landmarks would differ from those of someone experiencing a city for the first time. The important characteristic of a landmark is singularity - something that makes it stand out, have a clear form, and are prominently located.

\section{Applying Lynch to Case Precedents}

Using the descriptions that Lynch establishes, it is possible to investigate the functions of different urban elements in several different waterfront cities. It is important to note two exceptions to Lynch's methodology as proposed in The Image of the City. First, while the initial Lynchian methodology would see the observer undertake field studies, this approach has not been explicitly followed in all case precedents. Lynch's work was produced at a time when changes in mapping technology would not have been anticipated. The advancement of some of this technology (in particular, Google maps) allows for an unprecedented ability to examine urban form remotely. Second, Lynch undertook a limited quantity of interviews with urban inhabitants, an approach that has not been replicated here. For the purposes of this analysis, the functions of infrastructure of exclusion, urban expressways have already been well established. 


\section{Section 3: Case Precedents}

This section examines a number of cities that have undertaken or are in the process of undertaking post-industrial waterfront redevelopment. The focus of these cases is primarily concerned with the impact of infrastructure on waterfront accessibility and what has been done to mitigate its impact. Toronto serves as the principal case study for this investigation, while other cities experiences are examined for the information that they can provide in overcoming infrastructure barriers to the waterfront. The secondary case studies have dealt with waterfront access issues that are similar to those that Toronto is facing, particularly with respect to the future of their waterfront expressways. Some differences exist between the case precedents in terms of the impetus for undertaking changes to their waterfront infrastructure; these will be examined in the case precedent analyses.

Case Precedent: Seattle

\section{Background}

Seattle is located in Washington State on Peugeot Sound, an inlet of the Pacific Ocean. With a population of just over 634,000 it is one of the largest cities in the United States Pacific Northwest (US Census Bureau , 2014). Like many waterfront cities in North America, the urban area of Seattle grew around an industrial port, one that 


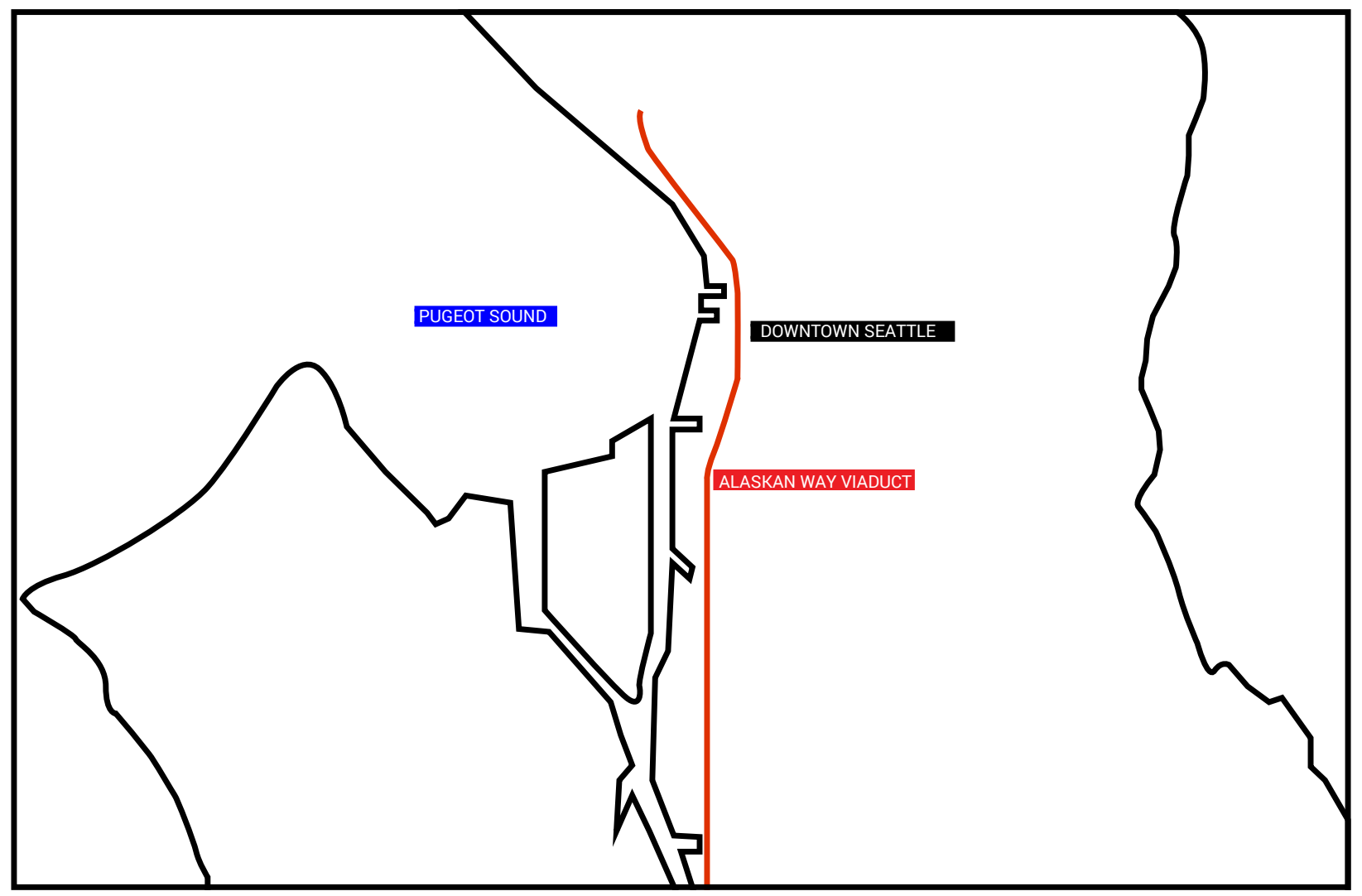

Figure 11 Location of Alaskan Way Viaduct (Base map: Google, 2014)

continues to function to the south of the downtown core. The Port of Seattle is the 14th largest port in North America by TEUs (Twenty Foot Equivalent Units, which is the unit used to measure the capacity of containers ships) (Port of Seattle , 2014).

The waterfront of Seattle is comprised of several vibrant, historically significant districts which attracting residents and tourists. The waterfront is home to the one of the oldest public markets in the United States, Pike Place Market. 


\section{Waterfront Infrastructure}

Like many North American cities, Seattle constructed an expressway through its downtown. The Alaskan Way Viaduct is a six-lane, two-level, elevated expressway that runs along the waterfront section in downtown Seattle over what was primarily an industrial area at the time of construction. Constructed in 1951, the expressway was used by 25 percent of Seattle's north-south vehicle traffic - about 110,000 cars per day (Ramsey, 2011). Concerns about the structural integrity of the expressway began to be raised in 1995, and a 2001 earthquake brought the question of what should be done about the expressway into sharp relief. Engineers concluded that while the expressway remained safe to drive on, another seismic event could result in the expressway becoming structurally compromised and potentially collapsing. This began a decadelong debate about what should be done with the Viaduct. A number of replacement options were deemed viable and subject to considerable debate: replacing the elevated expressway with a tunnel, replacing the structure with a larger elevated expressway, or replacing the expressway with an at-grade boulevard and transit route. Each of these different options would have a corresponding different impact on the accessibility of Seattle's waterfront.

After considerable debate which included ballot referendums, it was decided that the Alaskan Way Viaduct would be replaced with a tunnel. This decision was arrived at in no small part due to the availability of $\$ 2.8$ billion in federal funding for the project. This outcome highlights the government's role in waterfront redevelopment - Seattle residents were at an impasse regarding a decision on the tunnel - until federal 


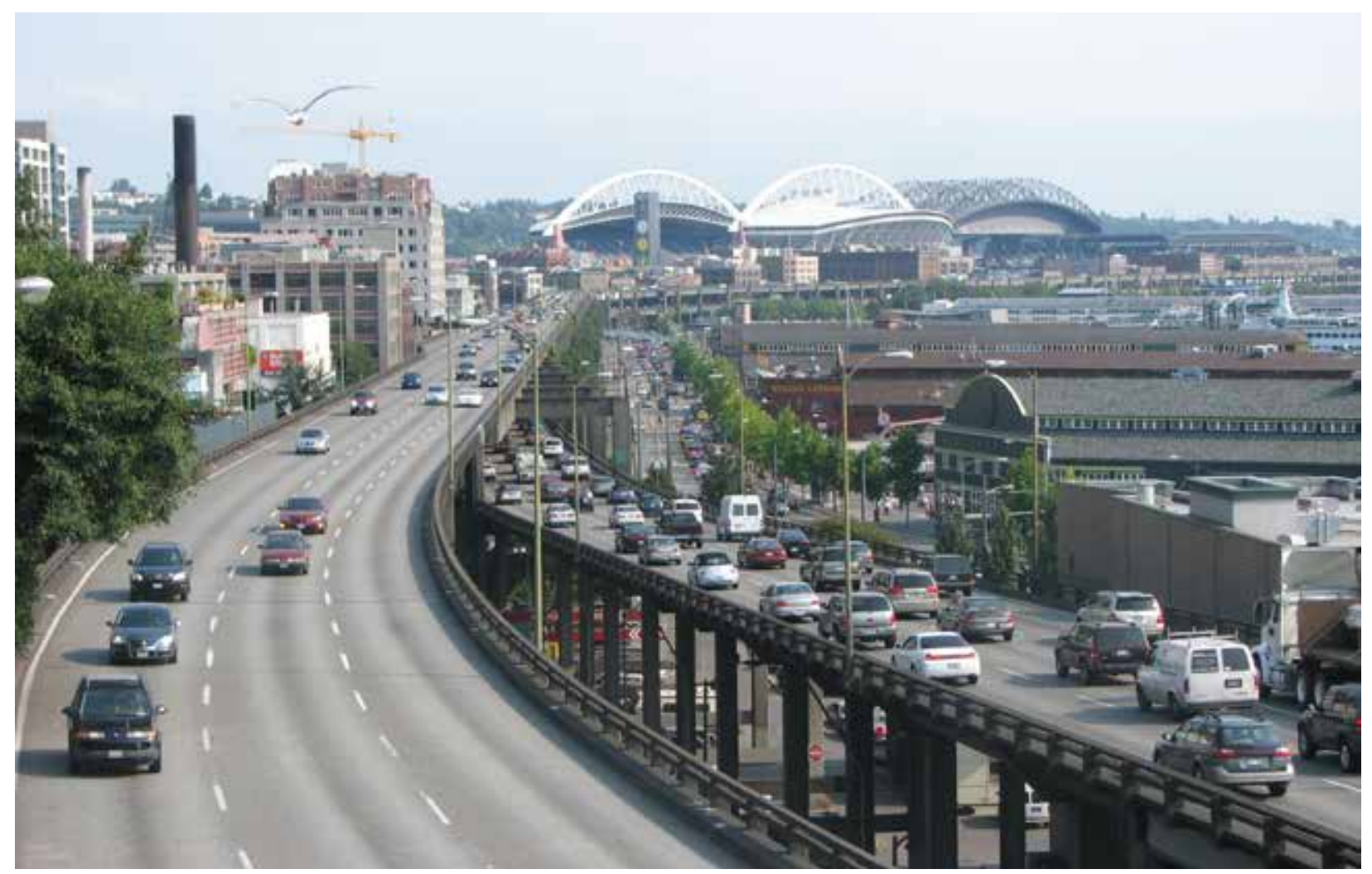

Figure 12 Seattle Alaskan Way Diaduct (Wikipedia, 2008)

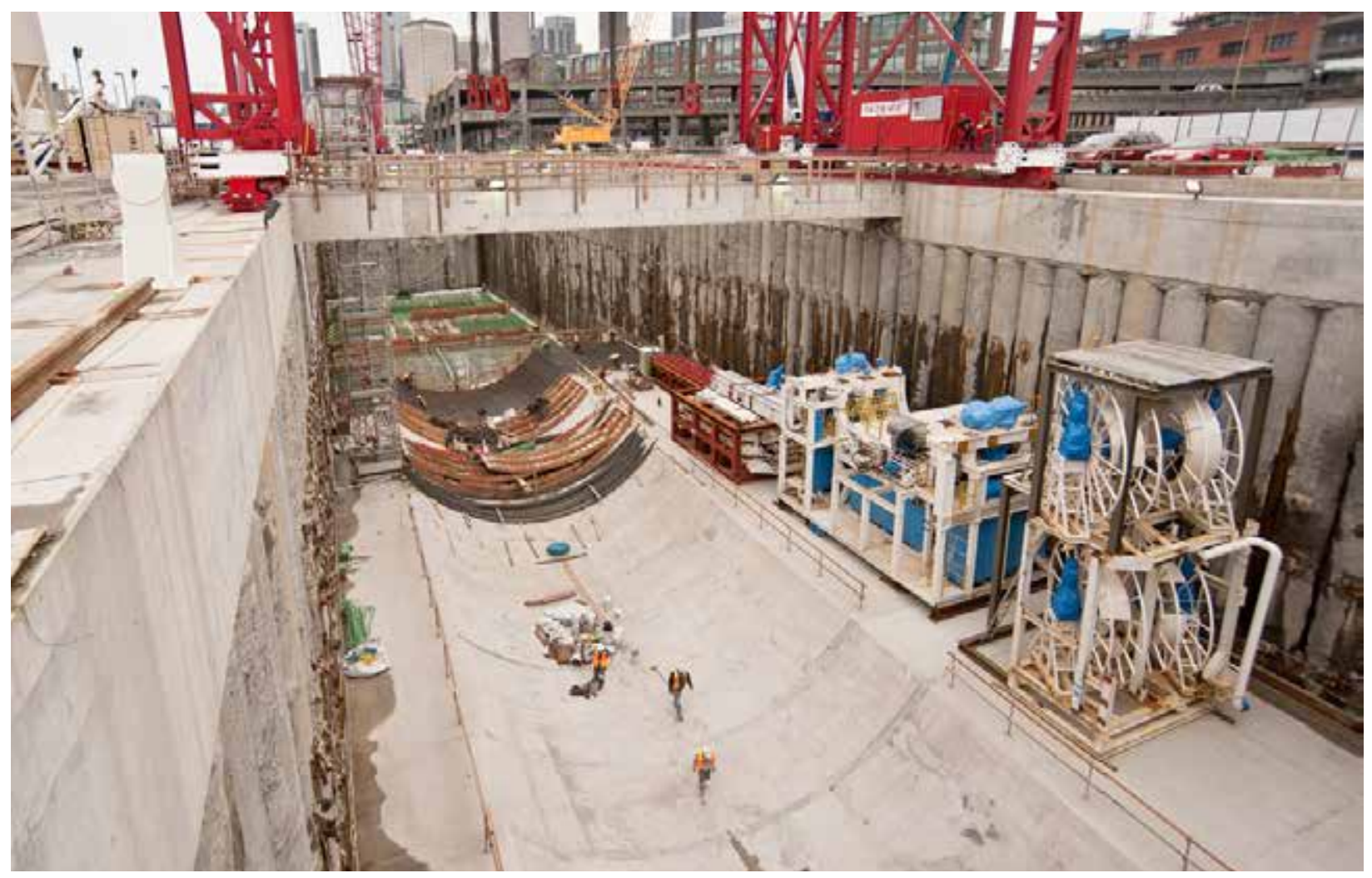

Figure 13 Tunneling project to replace the Viaduct below grade (WDOT, 2014) 
infrastructure funds were designated for a particular option - in this case, a tunnel.

\section{An Analysis of Infrastructure and Urban Forms}

The expressway as built in 1951 can best be described to function as both a path and an edge, depending on the perspective of the user. From a pedestrian perspective, it serves to limit access to the waterfront area, due to its low permeability. Pedestrians are only able to move beneath the structure at designated crossings, while the imposing nature of the structure means that the expressway works to psychologically cut off the waterfront from the downtown core of Seattle.

The expressway can also be viewed as a path for drivers, who use the expressway to move through the downtown. The elevated nature of the expressway means that there are few opportunities for entry and exit, which limit the mobility of the driver. The waterfront area can also be seen as encompassing several different districts, or neighborhoods. The southernmost district affected by the Viaduct was SoDo (South of Downtown), which is comprised of the port industrial area, as well as two sport stadiums. The functioning of the Viaduct as an edge is least problematic in this district, due to the ongoing industrial functions of the port and the lack of access needed or desired in this area. The next district to the north is the historic Pioneer Square neighbourhood, which is the original area of settlement in Seattle. In this district, the function of the expressway as an edge means that access to the waterfront from this district by pedestrian would be restricted. This restricted access is continued into the next waterfront districts to the north, West Edge and Bell Town. Once the expressway 


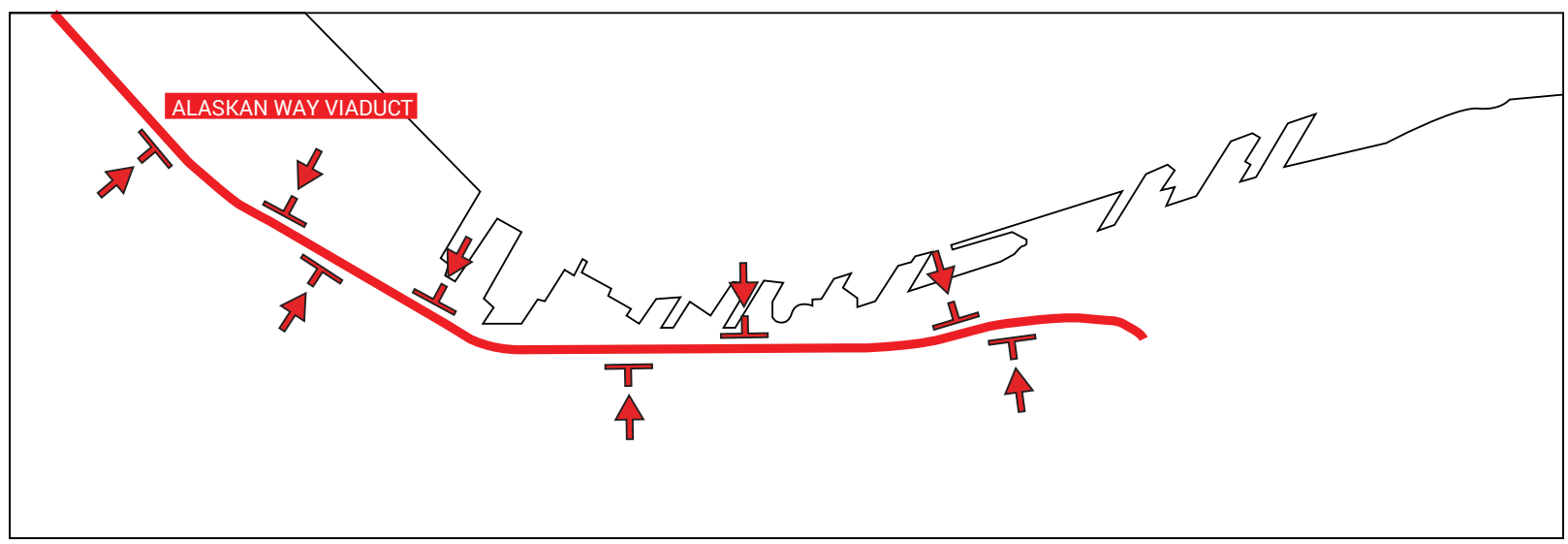

Figure 14 Barriers created by Alaskan Way Viaduct (Base map: Google, 2014)

ends in Bell Town, the waterfront is once again openly accessible.

The replacement of the expressway with a tunnel improves the accessibility of the waterfront by burying the path underground. Although the entirety of the expressway is not being relocated underground, it still means that a large portion of the waterfront is opened up in a number of neighbourhoods. The impact on the ground means that these districts (SoDo, Pioneer Square, West Edge and Bell Town) are able to orient themselves towards the waterfront. It could also have the effect of turning the waterfront into a landmark destination for urban inhabitants, as it becomes a more recognizable and accessible part of the city.

While the question of accessibility was not the primary consideration when the city of Seattle was debating the future of the Viaduct, it was nonetheless part of the discourse that surrounded the debate. An aspect of the debate was the consideration of a "waterfront for all", which was advanced by a group of residents that was advocating for the removal of the expressway, with no replacement. In its place would be an 


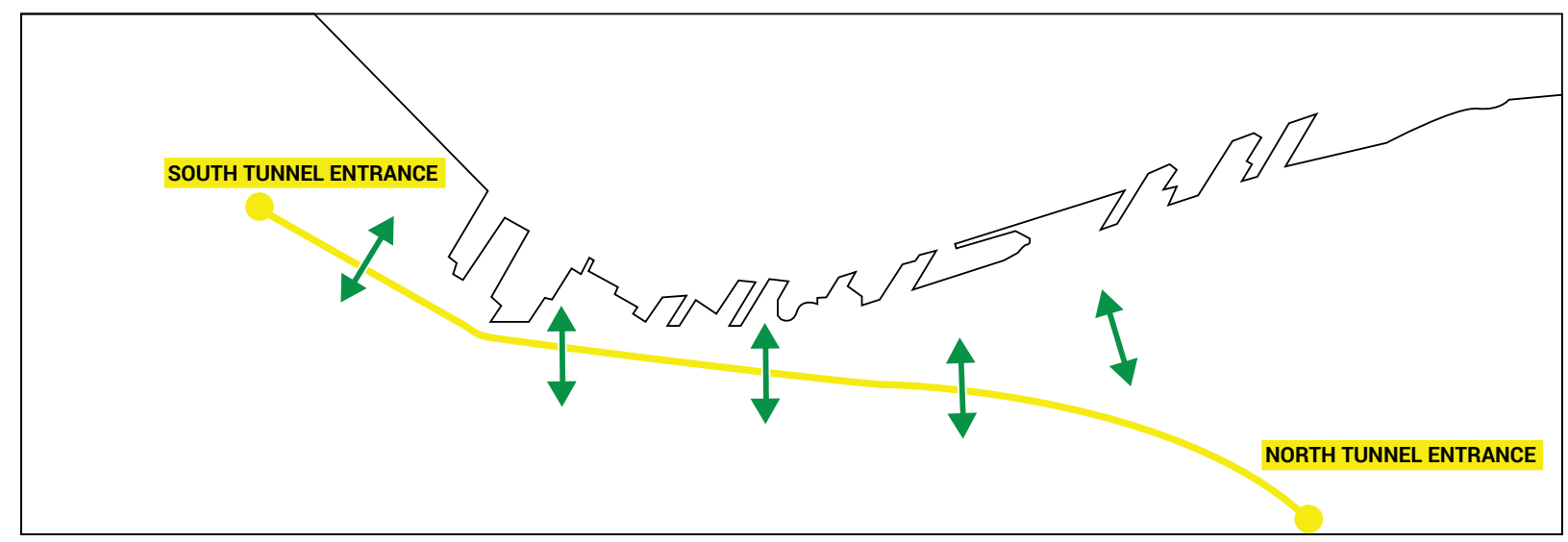

Figure 15 Removal of barriers after demolition of Alaskan Way Viaduct (Base Map: Google, 2014)

expansion of the transit capacity along the waterfront and an expansion of the open space along the waterfront as well. This was described as an "activist" option, and would share a common urban philosophy with the anti-expressway activists of the 1960's, led by Jane Jacobs (Ramsey, 2011).

\section{The Politics of Mobility}

The replacement of the Alaskan Way Viaduct provided a focal point for a debate that is happening in many urban areas regarding the 'politics of mobility'. As discussed earlier, the expressway is a product of the Modernist-planning era, built to support Modernist-planning ideals, such as suburban housing. The expressway continues to function to support this type of land use by allowing (theoretically) ease of access for commuters from the suburbs into and through downtown. However, as suburbs have grown, there 
has not always been a corresponding growth in road capacity to accommodate the influx of commuters, and has resulted in considerable congestion on expressways. The question then becomes, who is served by what expressway replacement options? Commuters would most benefit from a rebuilt expressway (either above or below ground), whereas downtown dwellers would benefit more from an expansion of the public realm and an increase in transit. The debate pits urban dwellers against suburban dwellers, groups that often do not see eye-to-eye on these issues. The open space provided by the removal would mean that all residents would have greater access to the waterfront. However, it was argued that downtown residents would benefit the most from the no replacement option, as they live in the closest proximity to the waterfront and would allow for the greatest access (Ramsey, 2011). The replacement of the Alaskan Way Viaduct with a tunnel was deemed the option best able to satisfy both the downtown and suburban groups, as it maintains road capacity through the downtown, yet still opens up access to the waterfront.

Case Precedent: Boston

\section{Background}

Boston is the capital of, and largest city in, the State of Massachusetts. The Port of Boston dates back nearly four hundred years, and remains one of the major ports on the eastern seaboard of the Unites States with access to the North Atlantic Ocean. However, it is not considered one of the major US ports, with New York and Savannah handling more port traffic. Initial settlement saw much of the port function occur in 
close proximity to what is now the historic downtown area. Much of this port function has migrated to the southeast to South Boston and the Conley Container Terminal (see figure 6). One of the oldest and most historically significant cities in the United States, Boston has developed as a city with a number of distinct districts or neighbourhoods.

\section{Waterfront Infrastructure}

The Boston Central Artery, officially known as the John F. Fitzgerald freeway, is a 2.6-kilometer portion of freeway that runs through downtown Boston, from Andrew Square in South Boston to US Route 1 in Charleston. Constructed in 1959 as a partially elevated and partially buried freeway, it was the focus of the largest infrastructure project in US history - the "Big Dig", which buried the entire section of the freeway that passed through downtown Boston (See Figure 7). The planning for the Big Dig began in 1982, and work was officially concluded in 2007 at a cost of $\$ 15$ billion US, the largest infrastructure project of its kind in the US to date (Hume, 2013). The impetus for replacement came from the massive congestion that often clogged the expressway. Nearly twice the intended capacity of 75,000 cars per day travelled along the freeway by the time that the tunnels opened in 2003 (Fein, 2012). The conceptualization of the project began in the 1970s, partially as a reaction against the freeway revolts against precisely the type of expressway that had been built in Boston. 


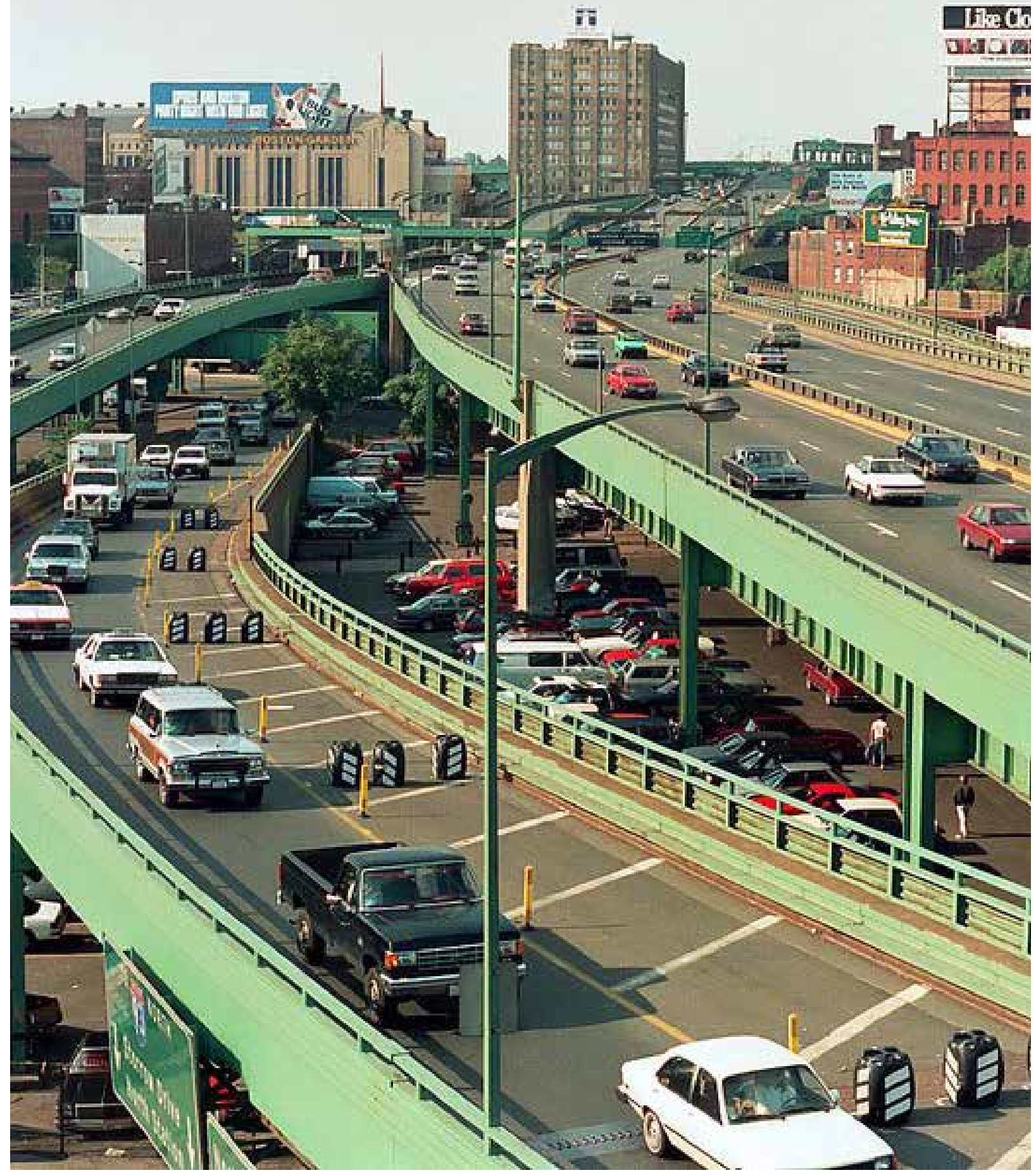

Figure 16 Condition of the Central Artery before the Big Dig (Flickr, 2009) 


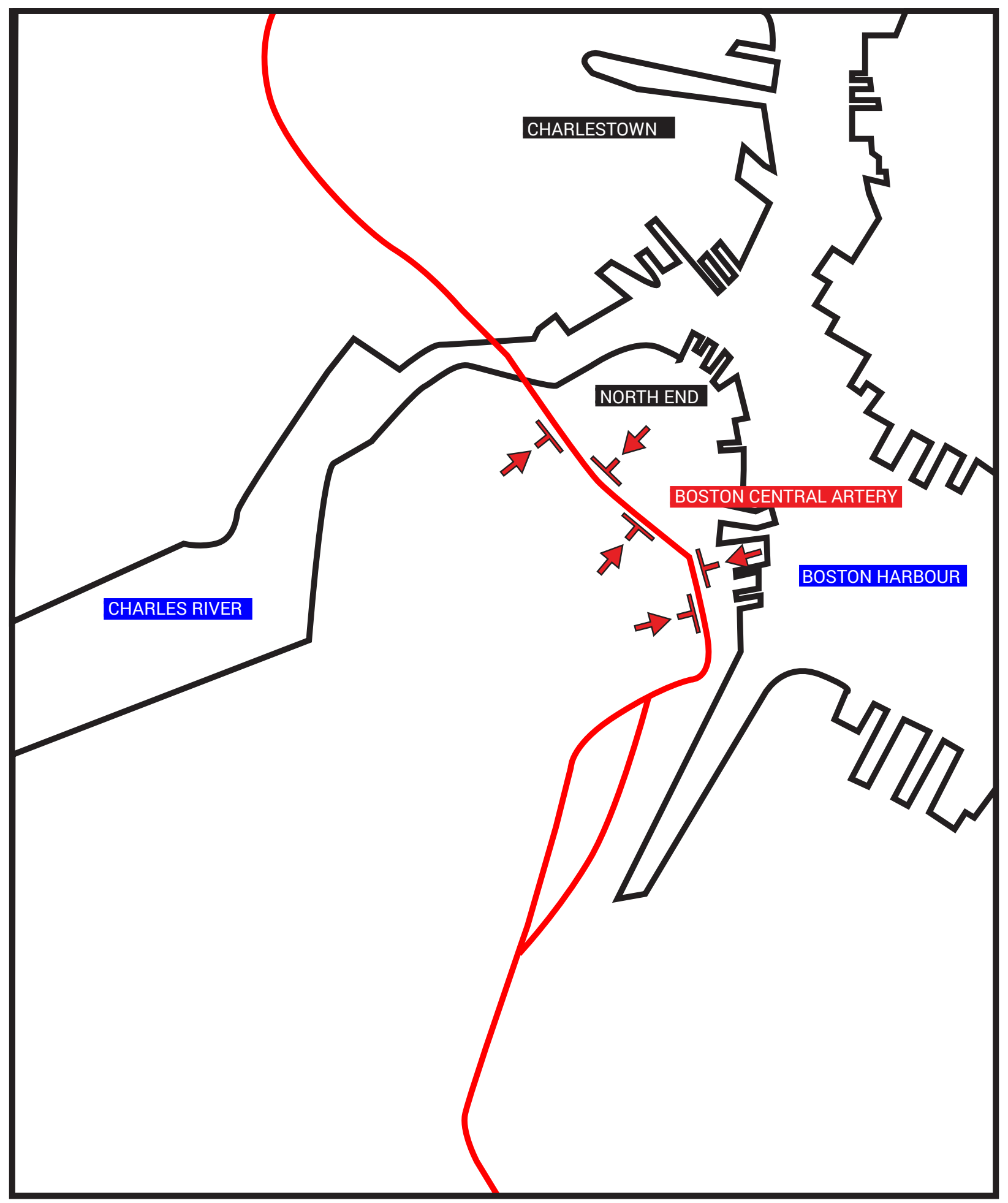

Figure 17 Location of Boston Central Artery pre-Big Dig (Base Map: Google, 2014) 


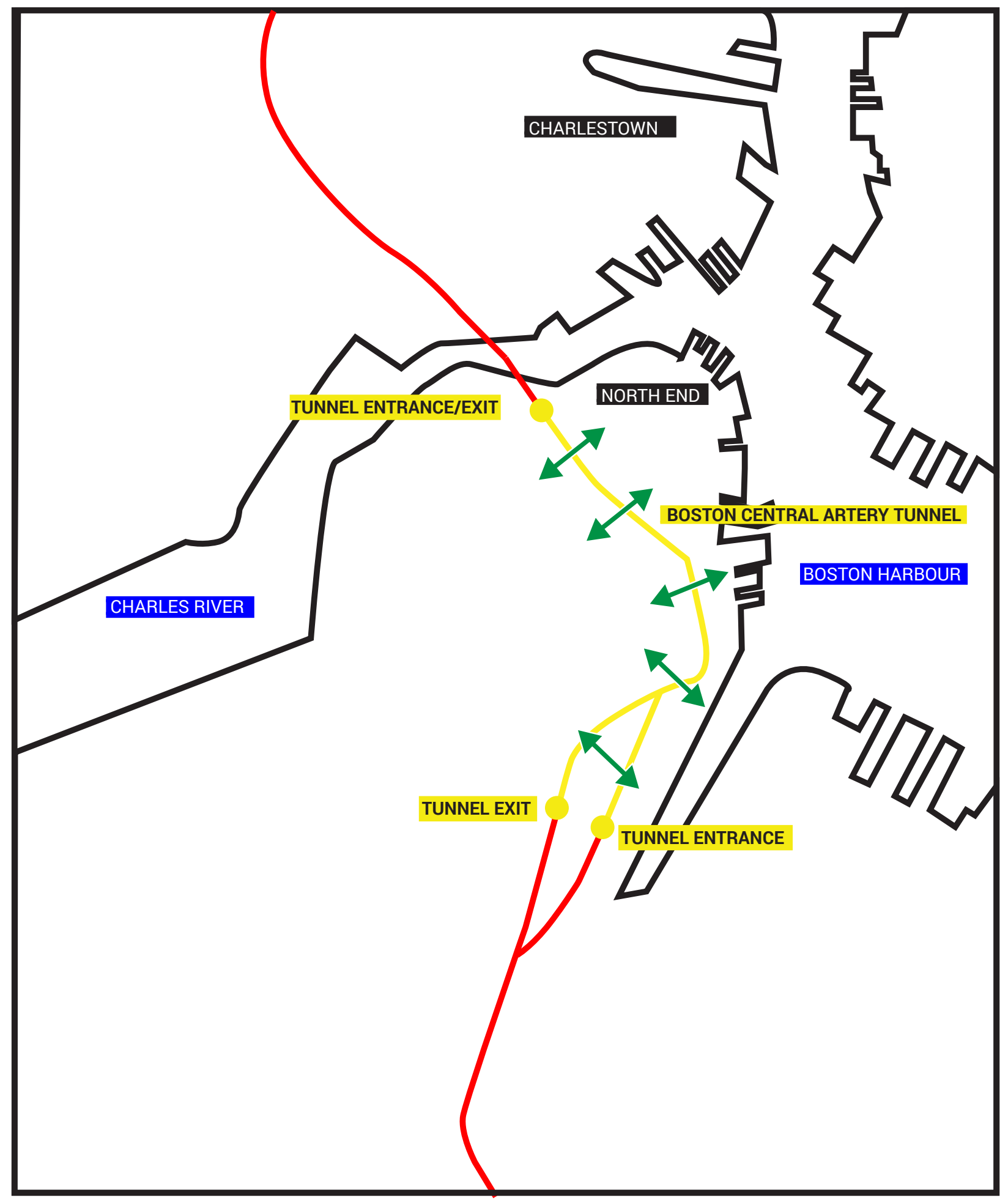

Figure 18 Location of Boston Central Artery Tunnel (Base Map: Google, 2014) 


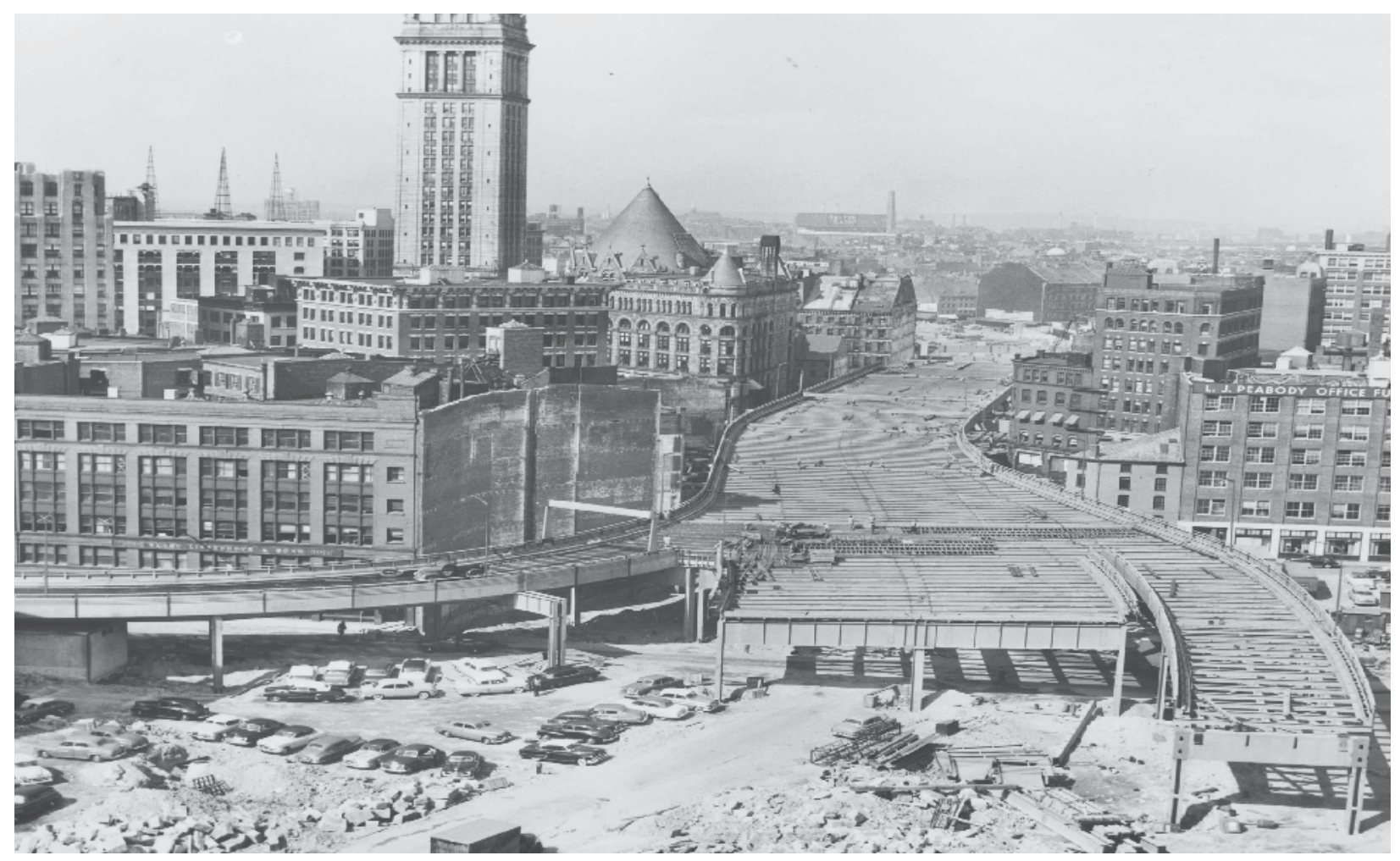

Figure 19 Construction of Boston Central Artery circa 1956 (Brown, Morris and Taylor, 2009)
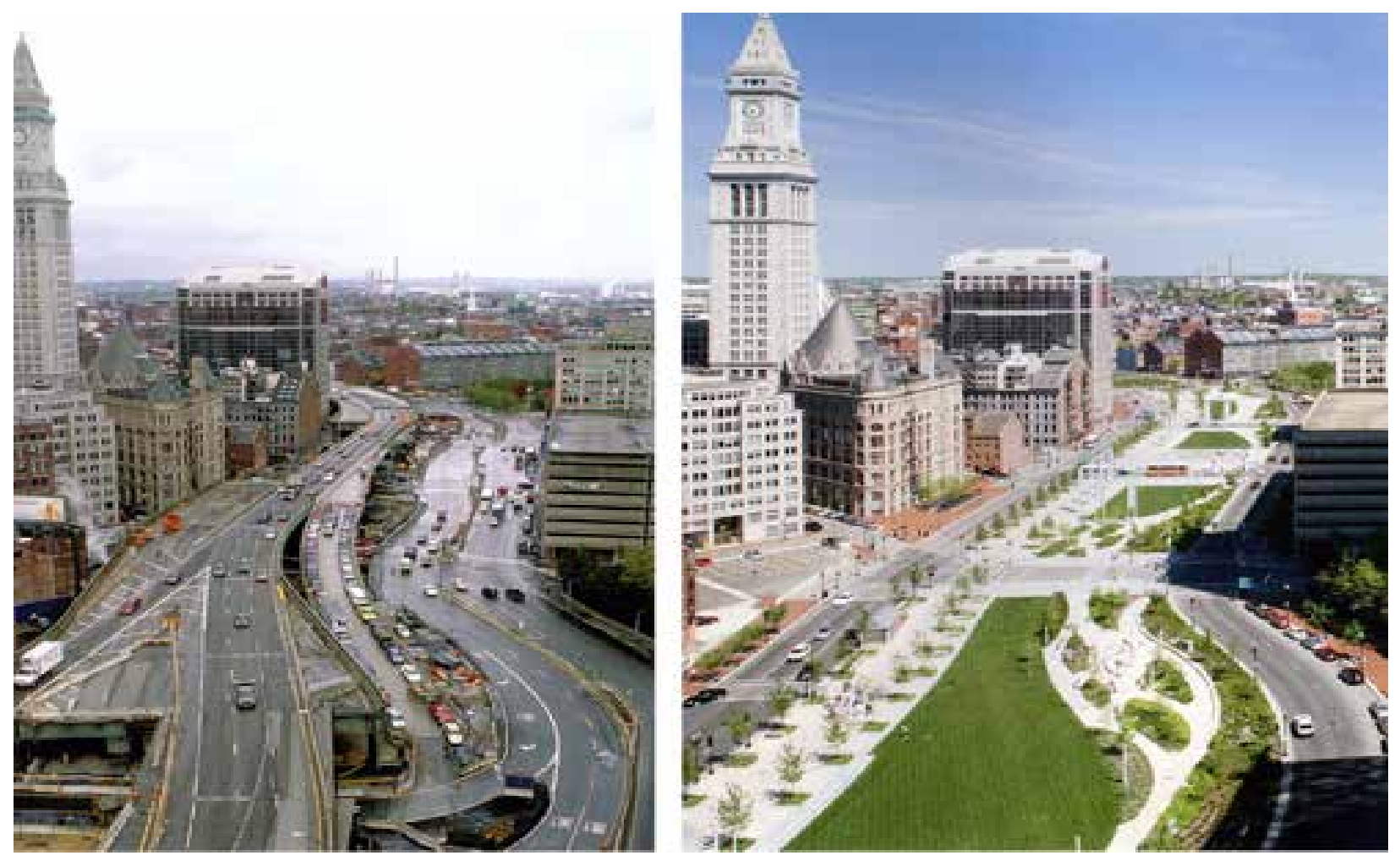

Figure 20 The Big Dig before and after (Turenscape, 2007) 


\section{An Analysis of Infrastructure and Urban Forms}

The Central Artery in its initial form as an elevated freeway is most easily identified as an edge for pedestrians that are attempting to move from virtually any of the districts through to the waterfront area. The construction of the Central Artery divided neighbourhoods and created a barrier, often in close proximity to the downtown fabric, and displaced 20,000 residents (see Figure 19). The Central Artery functions as a path for drivers (although perhaps not in its initial form, given its nicknames "The Distressway" and "The World's Largest Parking Lot").

The burying of the Central Artery, while extremely costly and time-consuming, allowed the Central Artery to no longer function as an edge to pedestrians. The area that was once occupied by the freeway has become a greenway, with bike paths and a system of open parks (Figure 20).

\section{Lynch: Then and Now}

Boston is a unique case study among those presented here, as it is one of the original cities that Lynch used in developing his work related to urban form (the other two being Los Angeles, California and Jersey City, New Jersey). It is therefore possible to compare Lynch's analysis of Boston at the time of his writing The Image of the City (1960) with the analysis of the urban form of Boston that has been conducted here, through the lens of his work. Lynch notes that Boston is a city of many distinct and vibrant districts, and that people are often able to orient themselves based on the 
character of the surrounding area (Lynch, 1960, p. 22). However, despite the legibility of the district, Lynch also notes that the path system that has been established in Boston is not always equally legible, which is likely partially due to the radial-style road network of the initial settlement pattern. This is in contrast to the more typical grid-style street pattern common to most North American settlements.

Perhaps most notable from Lynch's work is the impact of the Central Artery, which was studied based on its form before it was buried during the Big Dig. Lynch compares the Central Artery to another downtown highway, Storrow Drive which is closely related to the Charles River: "The Central Artery on the other hand, winds inexplicably through the center, and breaks the orientation link with the North End by blocking Hanover Street” (Lynch, 1960, p. 23).

This analysis is useful in assessing both the impact that the Central Artery had on downtown, and how much the character of the central downtown area has been changed by it being relocated underground. The dividing nature of the elevated Central Artery is well established in Lynch's analysis.

\section{Case Precedent: San Francisco}

\section{Background}

San Francisco is located in Northern California, on the San Francisco Peninsula, which separates the Pacific Ocean from the San Francisco Bay. With a population of approximately 825,000 it is the fourteenth largest city in the United States, as measured by population (US Census Bureau , 2014). The Port of San Francisco was never a major port on the west coast of the United States, given the proximity to the ports of 
Los Angeles, Long Beach, and Oakland, the latter of which is located directly across San Francisco Bay and is the fifth busiest port in the United States. Geographic constraints and environmental opposition prevented San Francisco from expanding its port facilities and therefore the port plays a minor role in the industrial port functions on the west coast of the United States.

Much of the focus of the San Francisco waterfront has been devoted to attractions that bring people to the waterfront, such as Fisherman's Wharf, Pier 39, and AT\&T Park.

\section{Waterfront Infrastructure}

While San Francisco has less of an industrial port legacy than the other cities presented here, it followed a similar route in constructing an expressway through sections of the downtown. The Embarcadero Freeway was intended to be a 2-kilometer elevated freeway that would connect the Golden Gate Bridge to the Bay Bridge through the northern section of downtown along the waterfront area (see figure 12). The Embarcadero Freeway was never fully completed, in part due to funding issues, and partially due to freeway protests. Debate began in the late 1980s about removing the freeway, although voters rejected this option by a nearly 2-to-1 margin in a 1988 referendum on the issue. However, an earthquake in 1989 forced the issue of what to do with the freeway, much in the same way that Seattle was forced to address the future of the Alaskan Way Viaduct after seismic activity compromised the structure. It was decided that the freeway should come down, and was replaced with an at-grade 
promenade, which is still referred to as the Embarcadero (see Figure 24). The atgrade roadway was chosen over the option of creating a tunnel, as was the case in Boston and Seattle. Although the construction of a depressed freeway was an early replacement option, the at-grade promenade was deemed to be the best option from an economic standpoint (Cevero, Kang, \& Shively, 2009). The promenade has become an important part of San Francisco's identity, as it has opened up large sections of the waterfront to residents and tourists.

\section{An Analysis of Infrastructure and Urban Forms}

The Embarcadero Freeway, even in its partially built form, served to divorce much of the city from the waterfront of the southern San Francisco Bay. Similarly to the other urban expressways presented here, the Embarcadero Freeway functioned as an edge for pedestrians attempting to access the waterfront. The freeway functioned as a path for drivers that were attempting to move through the downtown. Due to the incomplete nature of the expressway, it was an incomplete path by virtue of the fact that drivers had to enter and exit the freeway at multiple nodes in order to navigate the pathway.

Unlike the other expressways presented and discussed here, the Embarcadero was not replaced by tunneling the expressway underground. Rather, the expressway was replaced with an at-grade, six-lane promenade, now known simply as the Embarcadero. While the Embarcadero right-of-way is still substantial, the character of area means that the impact of the roadway as an edge is significantly lessened. It has 


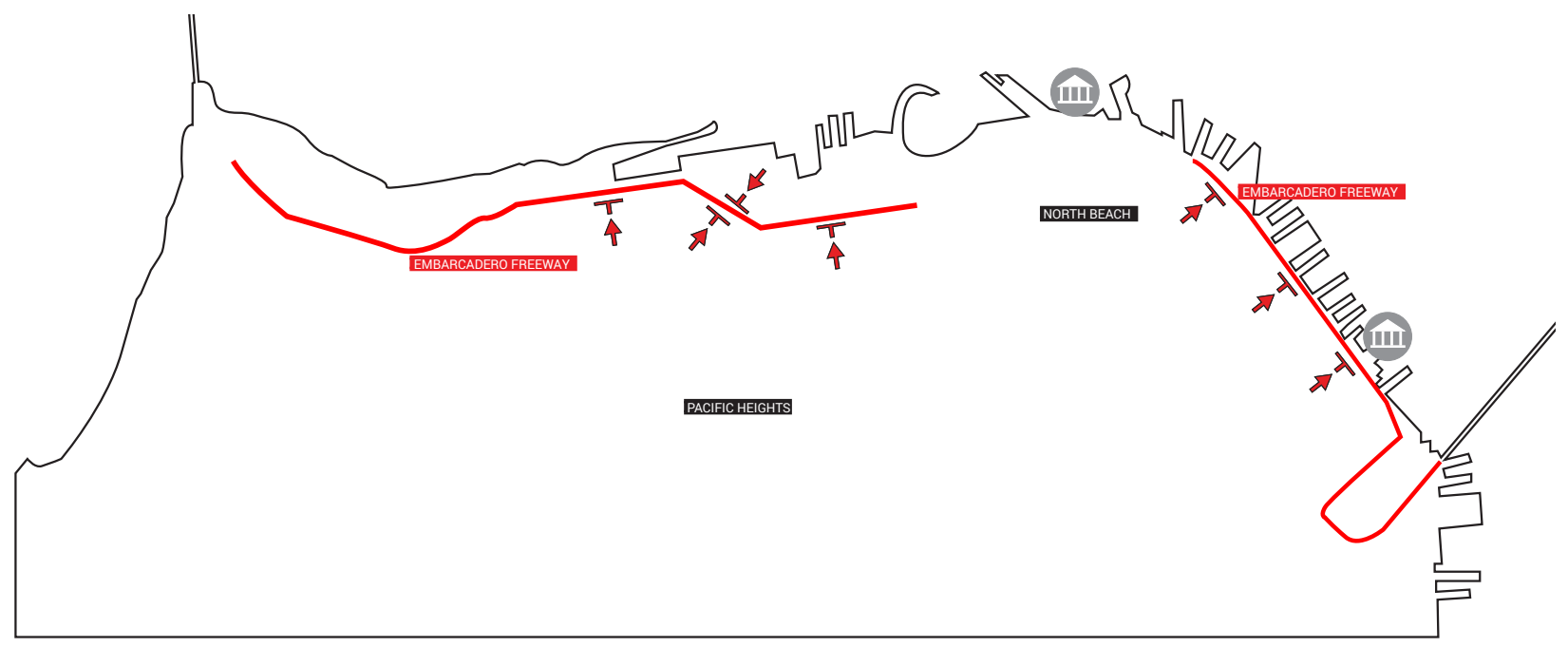

Figure 21 Location of the Embarcadero Freeway and surrounding districts (Base map: Google, 2014).

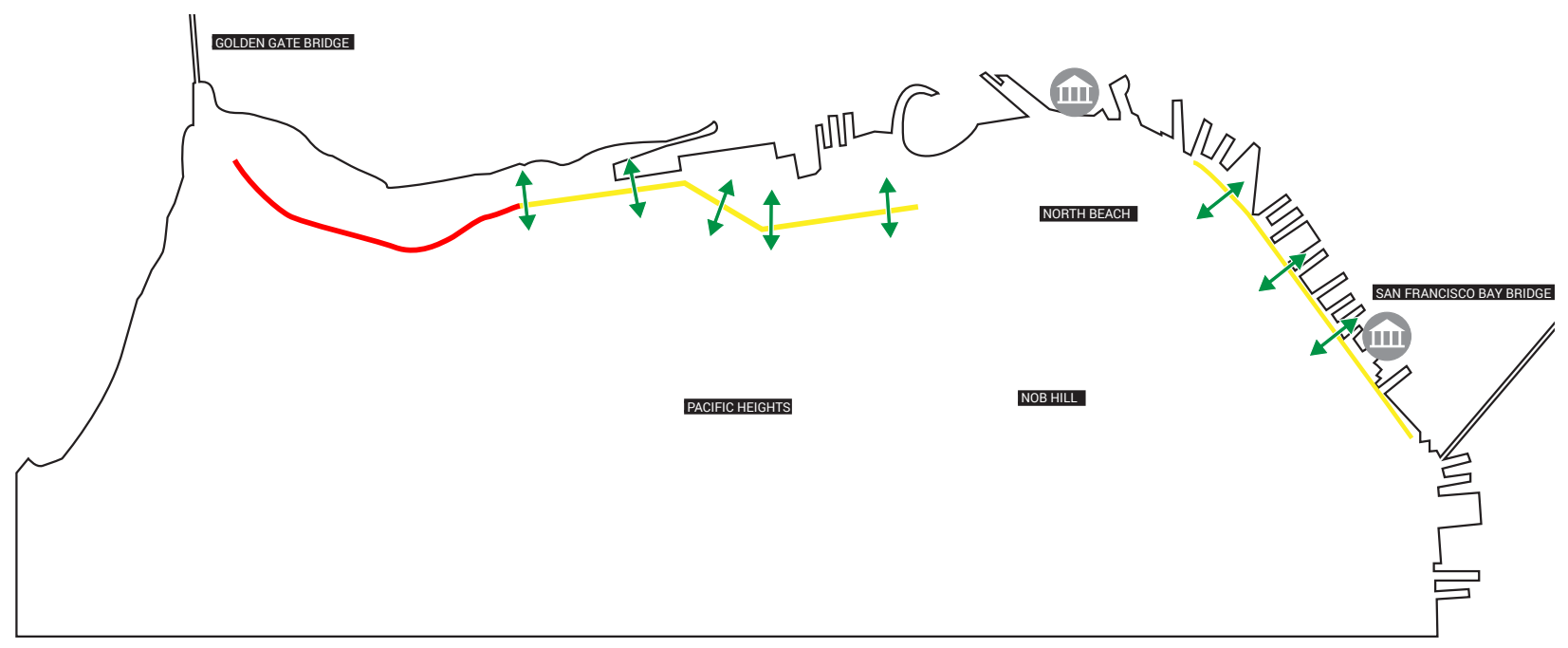

Figure 22 San Francisco waterfront after the removal of the Embarcadero Freeway (Base Map: Google, 2014) 


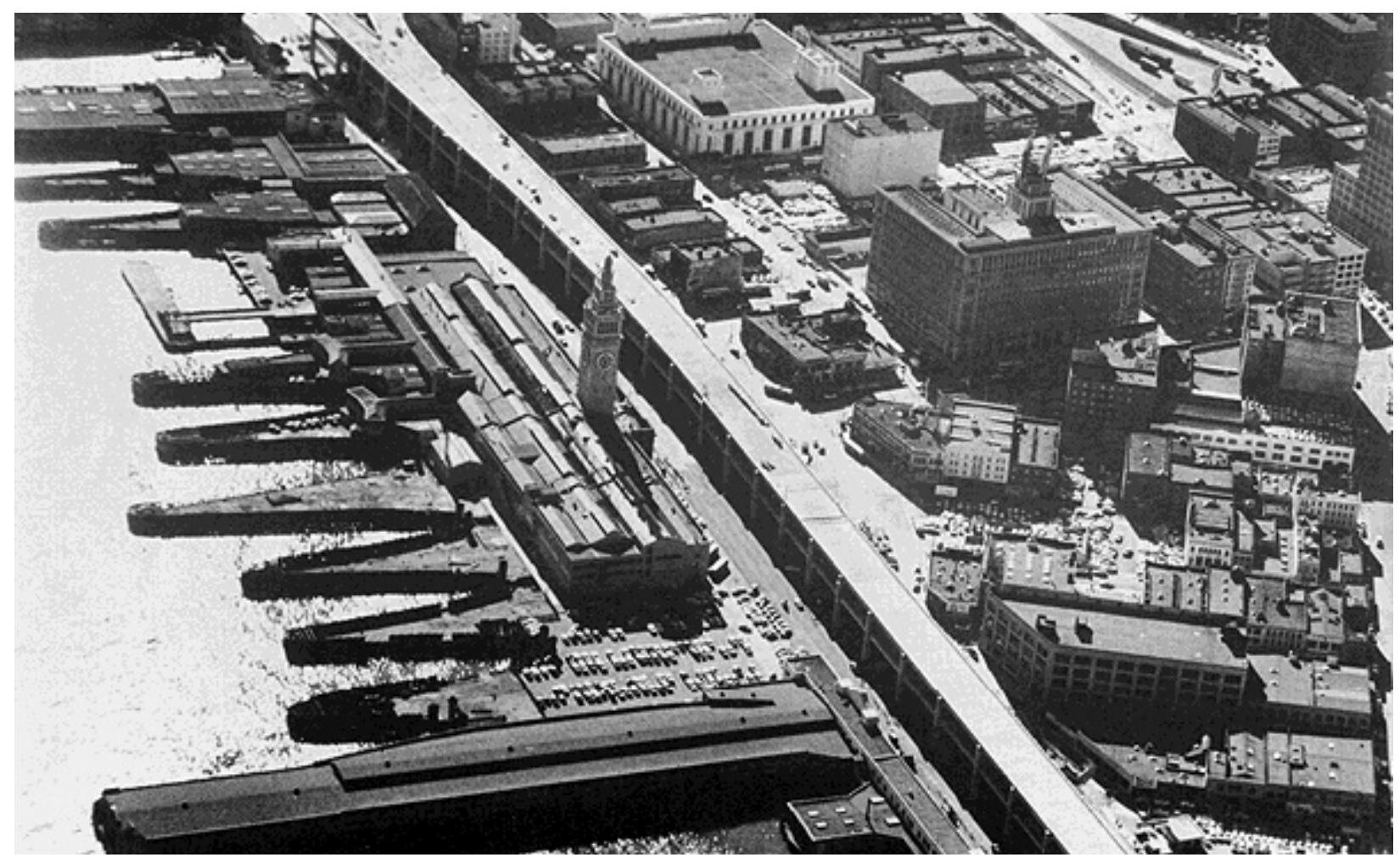

Figure 23 Embarcadero Freeway and Ferry Building (Found San Francisco, 2014)

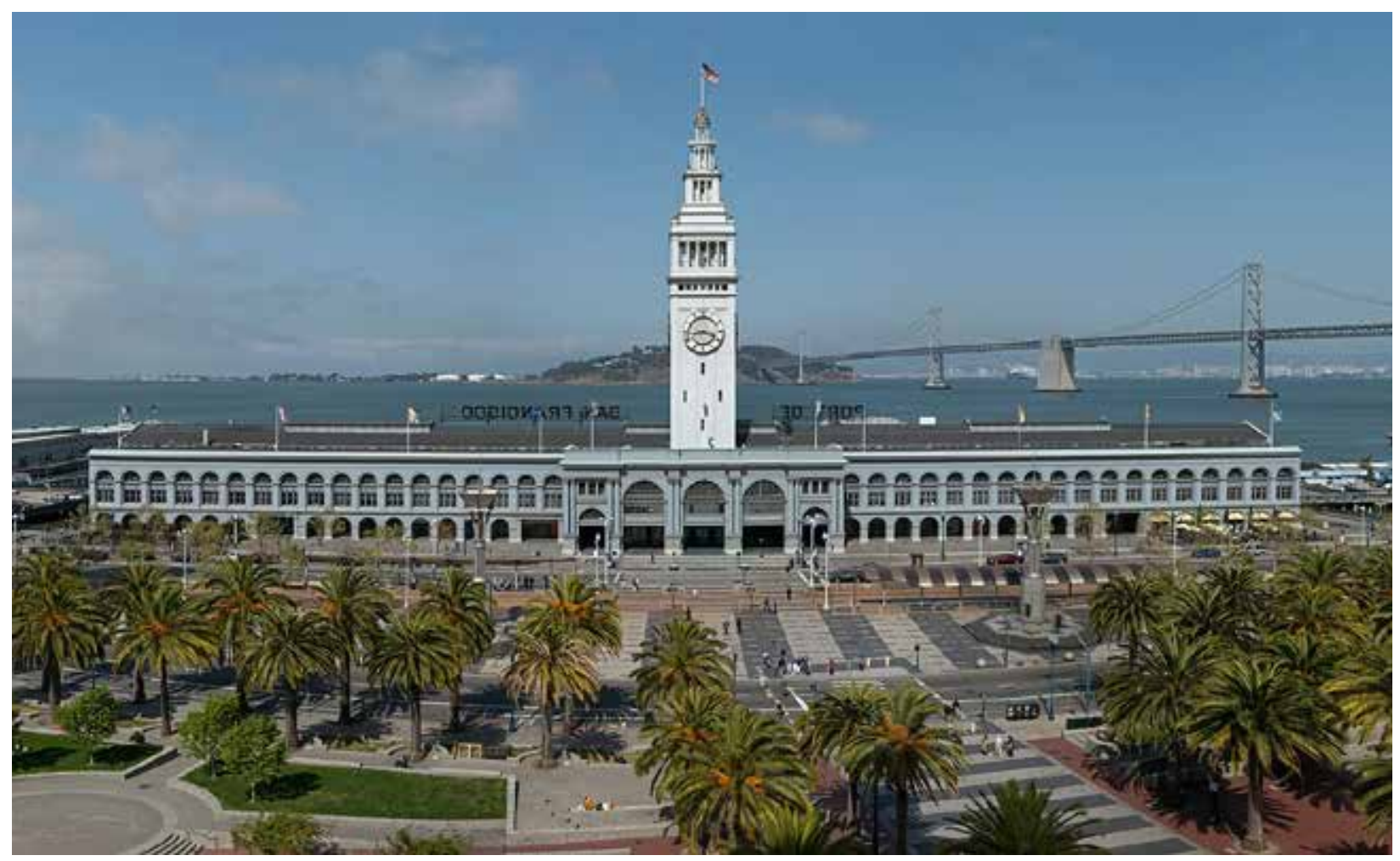

Figure 24 Current state of the Ferry Building after removal of the Embarcadero Freeway (Wikipedia, 2008) 
allowed for the reintegration of historic areas, such as the Central Embarcadero Piers Historic District, with the rest of the city fabric.

\section{The Impact of Neoliberalism on the Waterfront}

The redevelopment of the San Francisco waterfront provides an interesting opportunity to examine the economic and political forces behind waterfront development, such as the impact of neoliberalism on planning. Neoliberalism has had a profound effect on U.S. cities, where it has had an impact on governance and has resulted in the creation of "rules, regulations, programs, and policies to resuscitate cities as sites for capital accumulation" (Wilson, 2004). The impact of neoliberalism on the waterfront has often resulted in a focus on attracting new capital to the waterfront, in order to produce a new built environment, such as hotels, condominiums, and office space (Rubin, 2011). There is often a tension between this type of waterfront development and the uses that would put a greater emphasis on open space and access to the waterfront. The latter outcome would require a different planning approach, one that has been pursued in San Francisco and allows for a greater social benefit (Wilson, 2004).

San Francisco has a long history of dealing with the question of waterfront redevelopment, due to the primacy of the Port of Oakland having been established in the late 1960's, and the lack of necessity for industrial land uses along much of the San Francisco waterfront. Since that time, San Francisco has wrestled with trying to establish "public and civic space instead of accumulation and spectacle" (Rubin, 2011, 
p. 143). This has involved the rejection of a number of redevelopment proposals that would have seen the creation of a significant amount of non-marine related uses, such as office and hotel space.

Jurisdictional struggles dominated attempts at planning the San Francisco waterfront throughout much of the 1970's and 1980's, which culminated in the development of the Waterfront Land Use Plan (WLUP) in 1997, which envisioned "A network of parks, plazas, walkways, open space and integrated transportation improvements should improve access to, and enhance the enjoyment and appreciation of, the Bay environment" (Port of San Francisco , 2004).

San Francisco was able to implement a waterfront vision that emphasized open and civic space by not developing its waterfront in a way that is consistent with a neoliberal approach to urban planning. While the impacts of neoliberalism can be seen elsewhere in the city, they stop at the waterfront. San Francisco has nevertheless been able to create waterfront spaces that are important landmark destinations for residents as well as visitors, such as Fishermans Wharf, AT\&T Park, and the Ferry Building 
Case Study: Toronto

\section{Background}

Toronto is the capital city of Ontario, the most populated city in Canada, and the fourth largest city by population in North America with a population of 2.7 million in 2013. It was originally established as Fort York in 1793 on the northeastern shore of Lake Ontario. Since its initial founding, Toronto has grown into one of the most important cities in Canada both financially and culturally. The settlement area of Toronto was chosen primarily for it's protected harbour, as well as the location between two rivers -

the Humber to the west and the Don to the east (Desfor \& Laidley, 2011). The waterfront grew rapidly after initial settlement, and Toronto became an important port for trade along the Great Lakes and St. Lawrence River. There was initial a strong connection between the inhabitants and the waterfront, but this ended with the construction of a railway to serve the growing industrial corridor along the waterfront (Greenberg, 1996). The waterfront continued to grow as industrial and maritime activities grew throughout the first half of the twentieth century. As port functions peaked in 1969, and industrial uses began to migrate away the waterfront began to transition into a 'terrain of availability' for post-industrial development (Greenberg, 1996).

\section{Toronto Waterfront Redevelopment History}

The Toronto waterfront has been the subject of redevelopment debate for several decades, from the time that the first areas of land became available for redevelopment. 


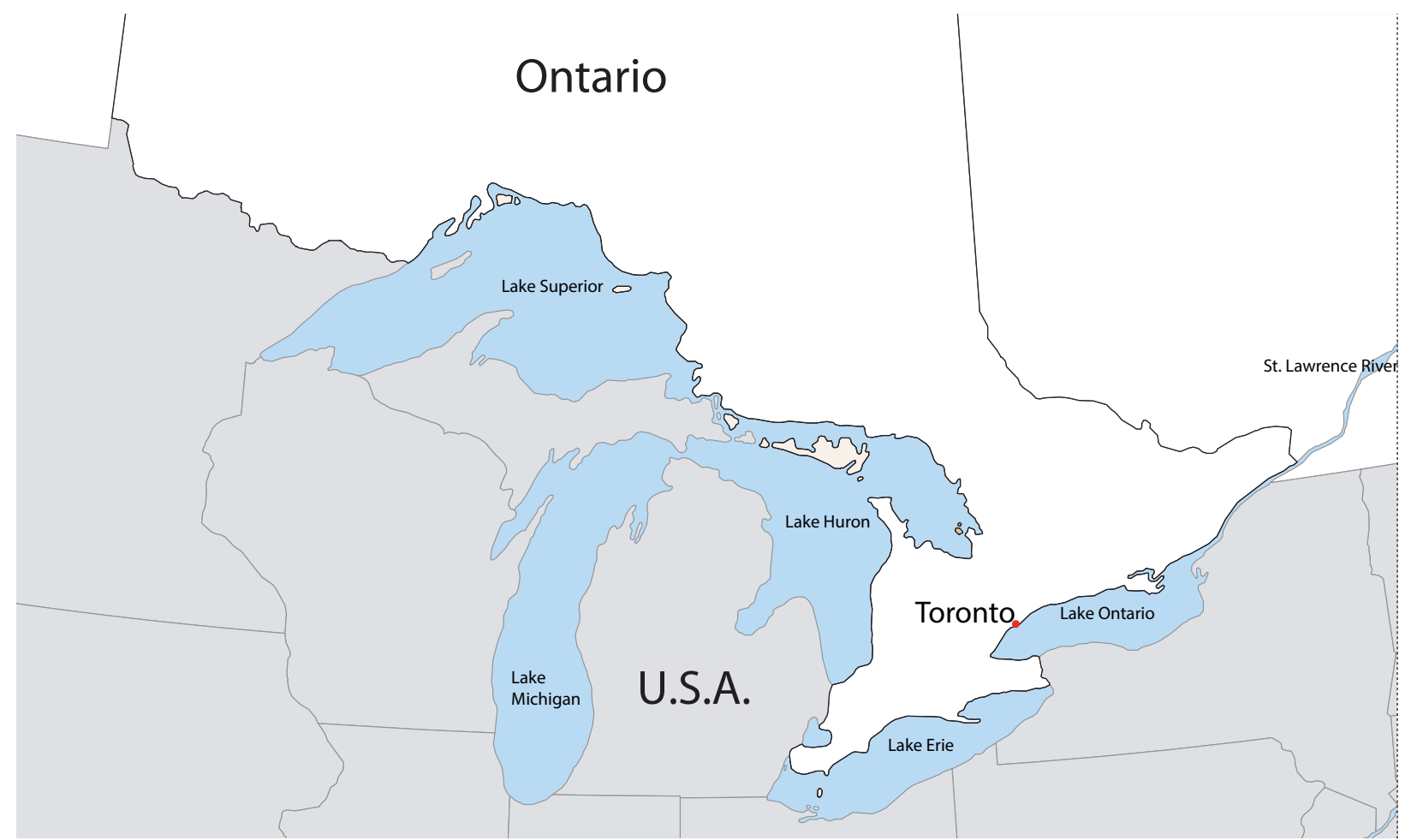

Figure 25 Regional context of Toronto and relation to the St Lawrence River and Great Lakes (Ontario Ministry of Infrastructure, 2006).

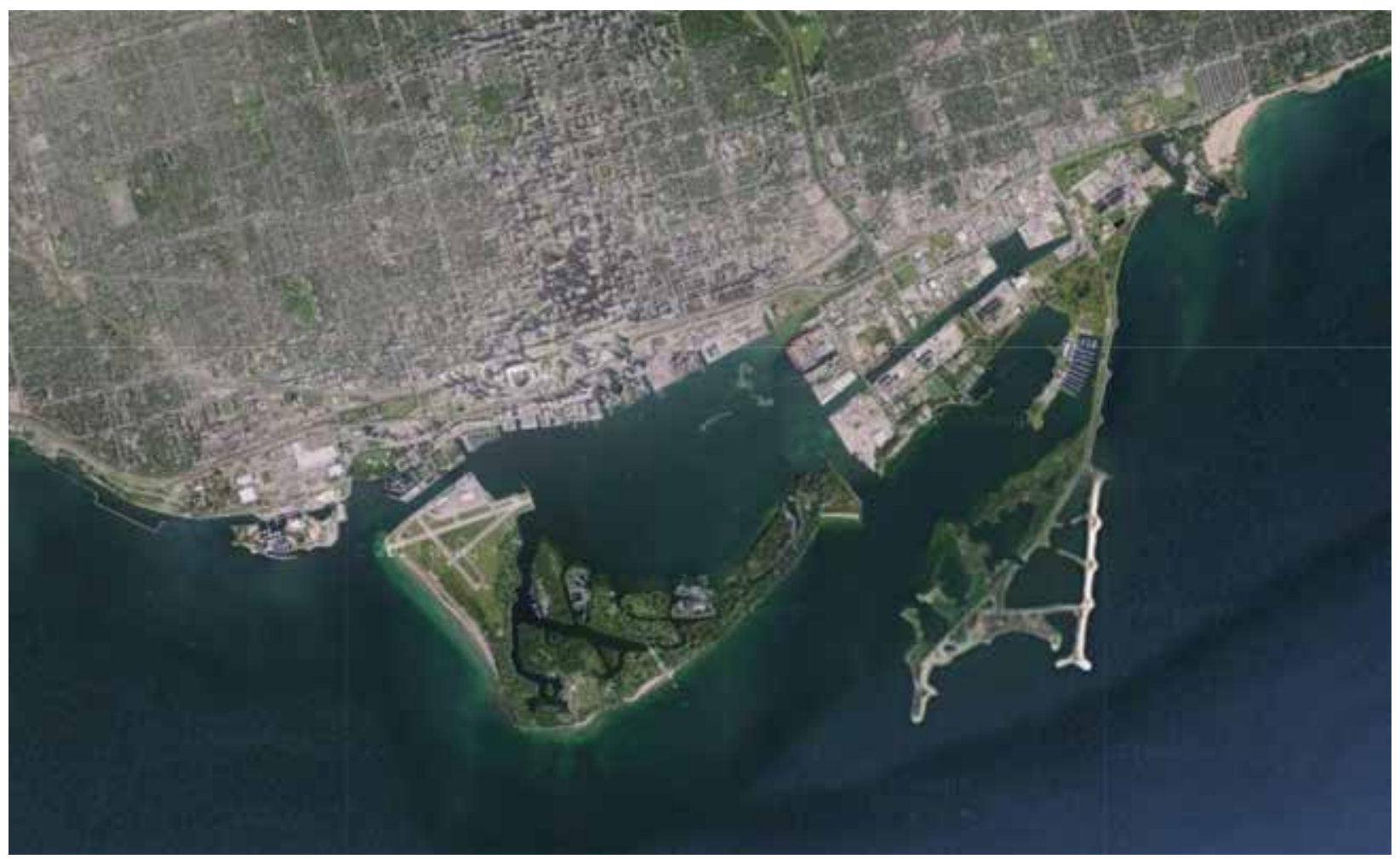

Figure 26 Image of the Toronto Waterfront (Google Maps, 2014). 
Redevelopment initially proceeded in a piecemeal fashion, partially due to the jurisdictional, and partially due to the fact that waterfront redevelopments often have start up times of five to ten years (Gordon, 1997). The startup time involves developing a plan, securing the political approval and site control that is necessary for a project to proceed, as well as resolving the fundamental debates about what the future use of a site is going to be.

The earliest examples of Toronto waterfront redevelopment began to be developed in the early 1960's with a plan for Harbour Square that was adopted in 1969. The plan was strongly supported by the Toronto Harbour Commission, which was the vendor of the land, and saw the development as a way to raise revenue in the face of declining port activity (Greenberg, 1996). The development did little to stimulate public life along the waterfront.

Subsequent projects throughouth the 1970's and 1980's that sought to redevelop the industrial area followed a similar approach as Harbour Square, although the scales of the projects differed. The proposed Metro Centre plan (1968-1974) would have been the largest redevelopment scheme in North America at the time. Financial infeasibility of the project meant that the only aspect of the plan constructed was the CN Tower (Greenberg, 1996).

A development that ultimately had a significant impact on the way that future development was undertaken was the Harbourfront project that envisioned a mixed use development on thirty-five hectares of waterfront land. The time line of the redevelopment was quite long, with ten years elapsing between when it was announcedby the federal governement in 1972 and the approval of planning and zoning 
in 1982. The redevelopment was overseen by the Harbourfront Corportation, which was established as a federal Crown Corporation in 1972 . Problems with the Corportion's mission, especially the requirement that it be economically self-sufficient, meant that it prioritized development would pay for itself, as opposed to development that was popular with the public (Greenberg, 1996).

An economic downturn in the 1980's proved to be the undoing of the Harbourfront Corporation, as it highlighted the Corporation's emphasis on the economics of redevelopment above all else. Public confidence in the ability of the Crown Corporation to undertake redevelopment that had civic value evaporated. As a result of widespread displeasure at the direction of waterfront redevelopment, in 1988 the federal government esablished the Royal Comission on the Future of the Toronto Waterfront to

inquire into and make recommendations regarding the future of the Toronto waterfront and to seek the concurrence of affected authorities in such recommendations, in order to ensure that, in the public interest, federal lands and jurisdiction serve to enhance the physical, environmental, legislative and administrative context governing the use, enjoyment and development of the Toronto waterfront and related lands. (Crombie, 1992, p. 1)

The Harbourfront Corporation was ultimately dissolved in 1990 after completing half of the intended project. Waterfront redevelopment in Toronto was then somewhat stalled for nearly a decade, as jurisdictional relationships and a framework for undertaking site remediation were sorted out. As described earlier, a task force to study the revitalization potential of the waterfront ahead of Toronto's bid for the 2008 summer 
Olympics was established in 1999. Despite the Olympic bid being unsuccessful, revitalization plans for the waterfront based on the approach outlined by the task force proceeded.

Waterfront Toronto (initially named Toronto Waterfront Redevelopment Corporation) was established in 2001 as a tri-partite agreement between the federal, provincial and municipal governments to oversee the planning and development of Toronto's Waterfront. Importantly, Waterfront Toronto is not a Crown Corporation; there is equal representation from all three levels of government. Each level of government has contributed $\$ 500$ million in order to fund the initial costs and start revitalization, and initiate a cycle of private investment in the waterfront. The scope of the waterfront redevelopment being managed by Waterfront Toronto is 800 hectares, making it the largest urban redevelopment presently underway in North America, and one of the largest waterfront redevelopments in the world (Waterfront Toronto, 2014).

\section{Waterfront Infrastructure}

Toronto has accumulated much transportation infrastructure near its waterfront, due primarily to the fact that the port of Toronto long served industrial functions, and public or pedestrian access to the waterfront was not a primary concern during this time. As a result, the infrastructure that was built, such as railway corridors and the Gardiner Expressway, functioned to facilitate the movement of goods and support industrial functions. Figure 14 shows the early accumulation of railway infrastructure along Toronto's waterfront as a result of the establishment of port facilities. The regional 
commuter transportation network, operated by GO Transit, now utilizes these rail lines that were initially built to support industrial functions.

Toronto also followed in the path of many other North American cities and constructed an expressway through its downtown area. The Gardiner expressway was built between 1956 and 1966 to move traffic into and through the downtown from the surrounding suburban areas. The rationale for constructing the expressway was predicated upon a growing population, and the resulting increase in car ownership. The location of the Gardiner Expressway along the waterfront was considered at the time as the best option, due to the lack of waterfront access either required or desired on the part of the public. The placement of the Gardiner was also intended to facilitate the movement of goods, as on-road trucking became a dominant method of transporting goods, as opposed to railways.

The construction of the Gardiner had a significant impact on the urban landscape. It severed the connection of the Parkdale neighbourhood from the waterfront, and required the removal of a number of pedestrian access points to the waterfront. It also required the reconfiguration of Lakeshore Boulevard from tree-lined avenue to a collector route (Dillon Consulting et al., 2009).

While initially built to help alleviate traffic congestion that had begun to occur as a result of increasing car ownership, the Gardiner Expressway was soon dealing with substantial traffic volume well above its intended capacity - with 200,000 cars traveling on it each day when it was intended to accommodate only 70,000 (Get Toronto Moving, 2014). The Gardiner has undergone some change since construction: as part of the downloading of services from the provincial to municipal level of government in the 


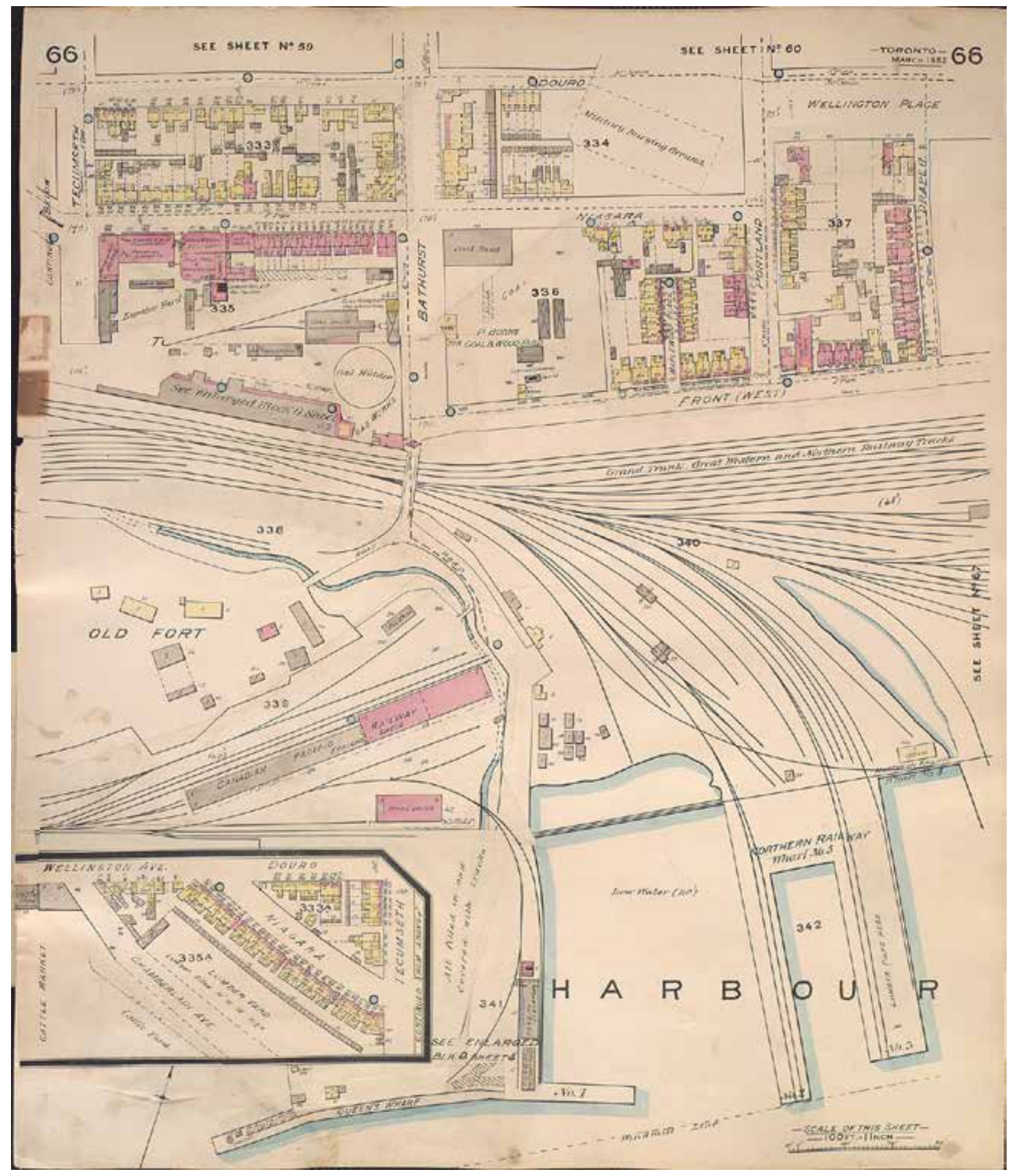

Figure 27 Accumulation of waterfront infrastructure in Toronto circa 1892 (City of Toronto, 2013). 
1990s, a section of what had previously part of the provincial 400-series highway was designated part of the Gardiner Expressway. In 2001, the elevated portion of the Gardiner east of the Don Valley Parkway (DVP) was demolished and integrated with Lakeshore Boulevard.

Figure 16 Accumulation of waterfront infrastructure in Toronto circa 1892 (City of Toronto, 2013).

\section{An Analysis of Infrastructure and Urban Forms}

The Gardiner Expressway functions as an edge to pedestrians attempting to access the central Toronto waterfront from numerous points throughout the downtown area. True to its primary function to serve vehicle traffic, there is little accommodation for pedestrians to move beneath the elevated structure. The extent of the Gardiner Expressway means that it has the effect of cutting off nearly the entire waterfront from the rest of the city. At 18 kilometers, the Gardiner is the longest of the urban expressways presented in the case study (the section shown in figures 28 and 29 is approximately 8.5 kilometers). The position of the expressway means that pedestrians are often inconvenienced in trying to get from the downtown to the waterfront prominent downtown streets. Figures 31 and 32 illustrate the type of edge that pedestrian confront when attempting to access the waterfront from one of Toronto's main downtown avenues, Spadina. The fact that pedestrian crossings are not prioritized means that pedestrians attempting to cross underneath the expressway have to fend for themselves, and engage in crossing behaviour that is unsafe. While it is 


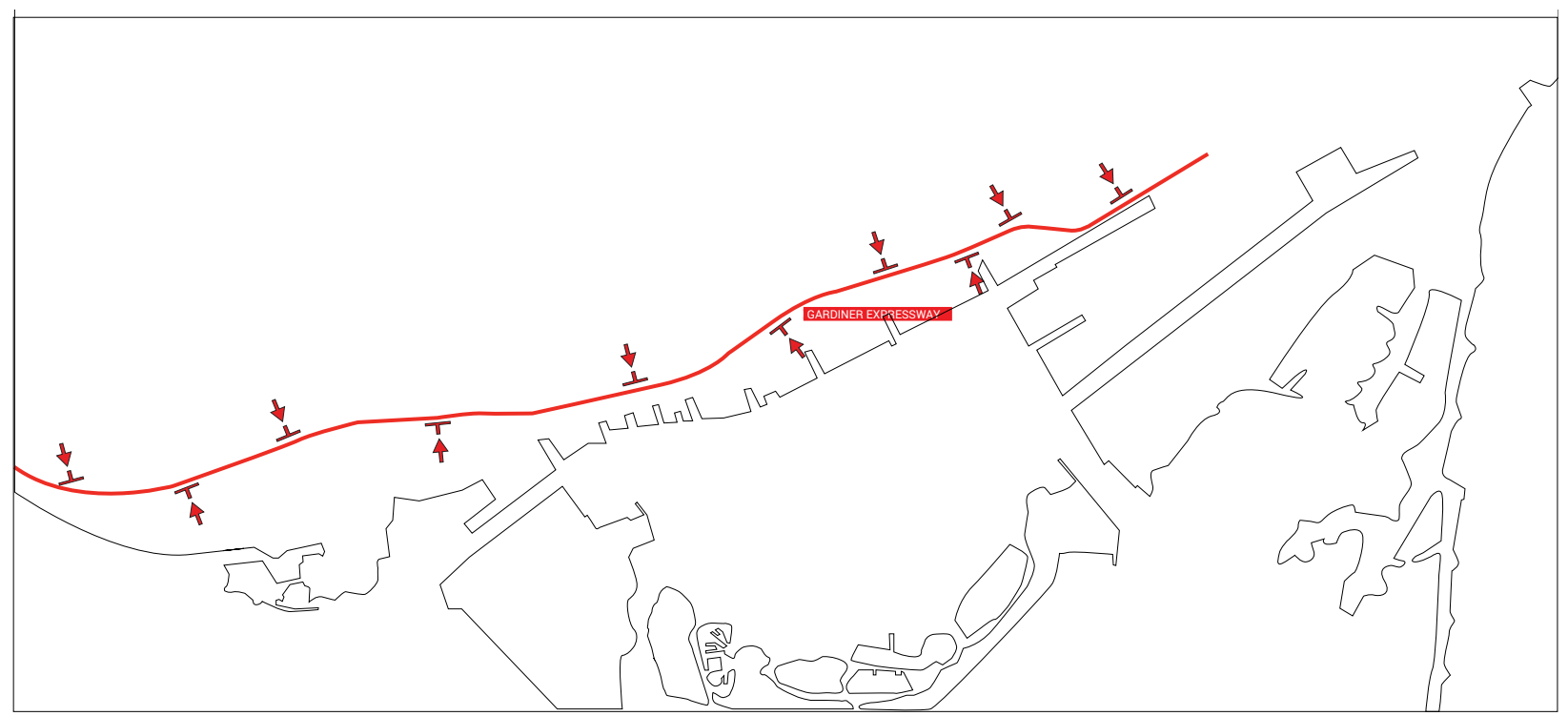

Figure 28 Location of Gardiner Expressway (Base Map: Google, 2014)

possible to cross underneath the expressway at controlled crossings, the Gardiner creates an environment that does not invite pedestrians to move across it. The scale of the Gardiner adds to the inhospitable environment for pedestrians to pass under it, as shown in Figure 23.

The function of the Gardiner Expressway as an edge that isolates the waterfront from the rest of the city has been well established. The Royal Commission on the Future of the Toronto Waterfront highlighted this function, as did the final report from the Waterfront Revitalization Task Force, published in 2000. With the function of the Gardiner as an edge well established, it is possible to examine what this has meant in the context of an evolving debate about the future of the Gardiner Expressway. 


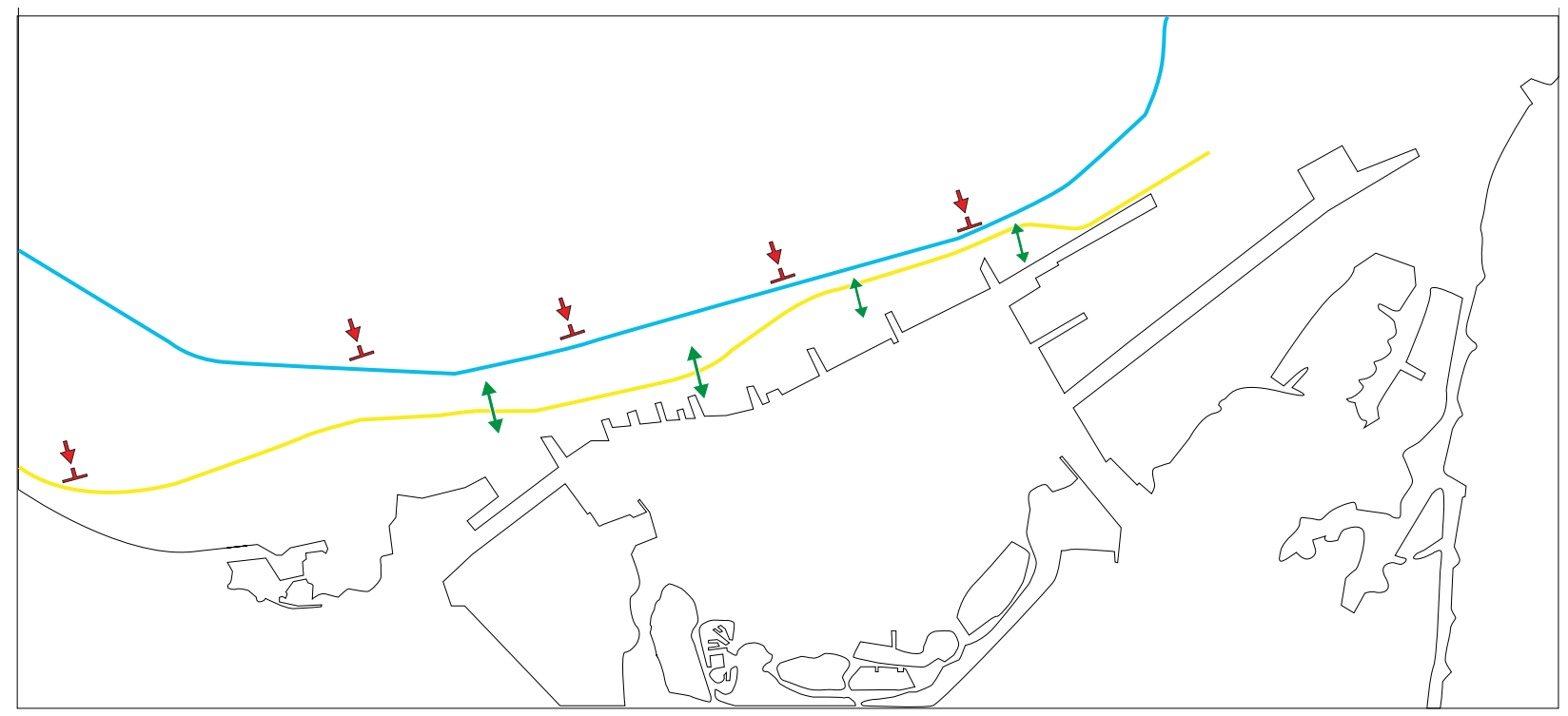

Figure 29 Potential city-waterfront connection with removal of the Gardiner Expressway (Base Map: Google, 2014)

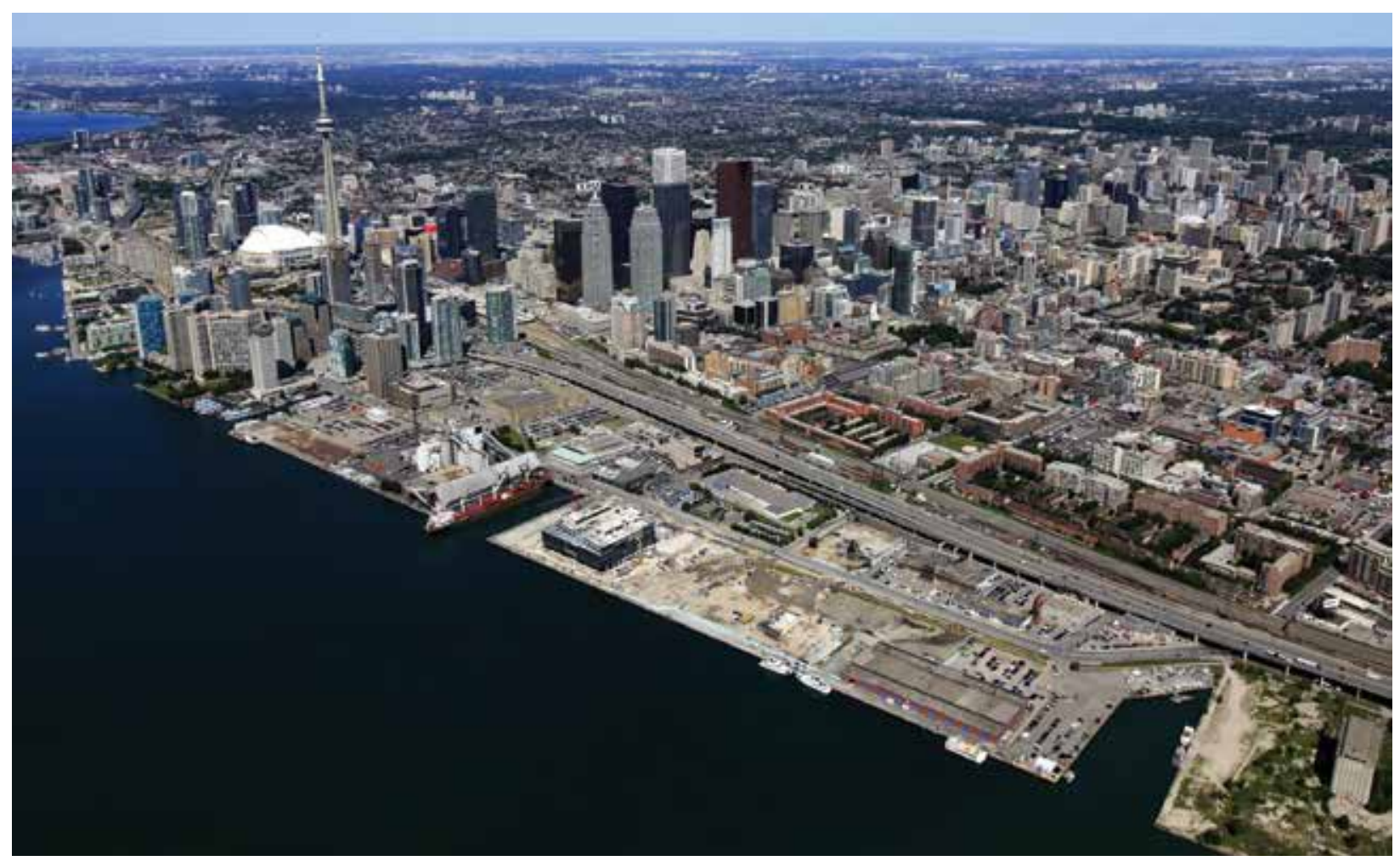

Figure 30 Eastern Section of the Gardiner Expressway (James Corner Field Operations, et al. , n.d.) 


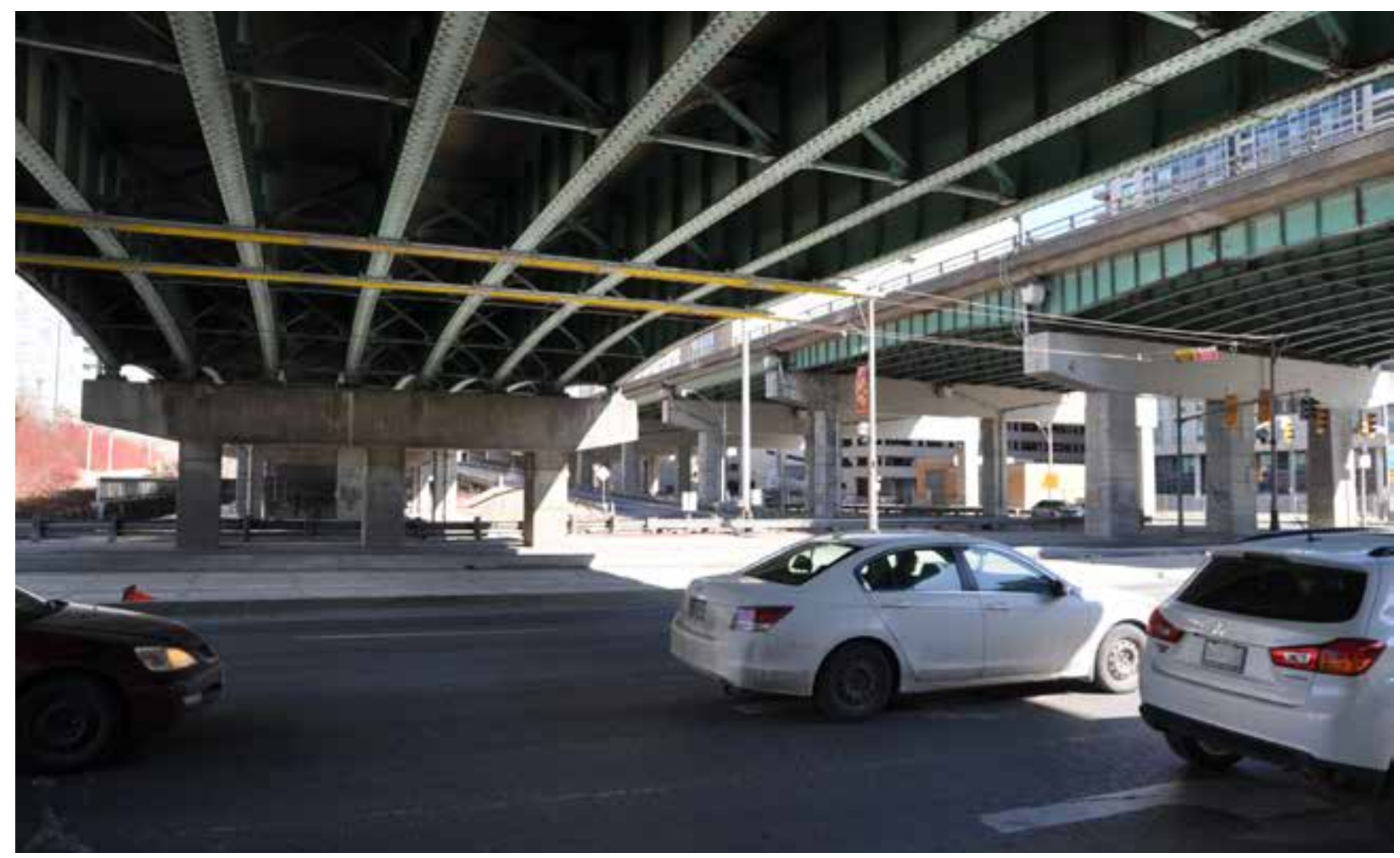

Figure 31 Condition for pedestrians underneath the Gardiner Expressway (Gordon, 2014)

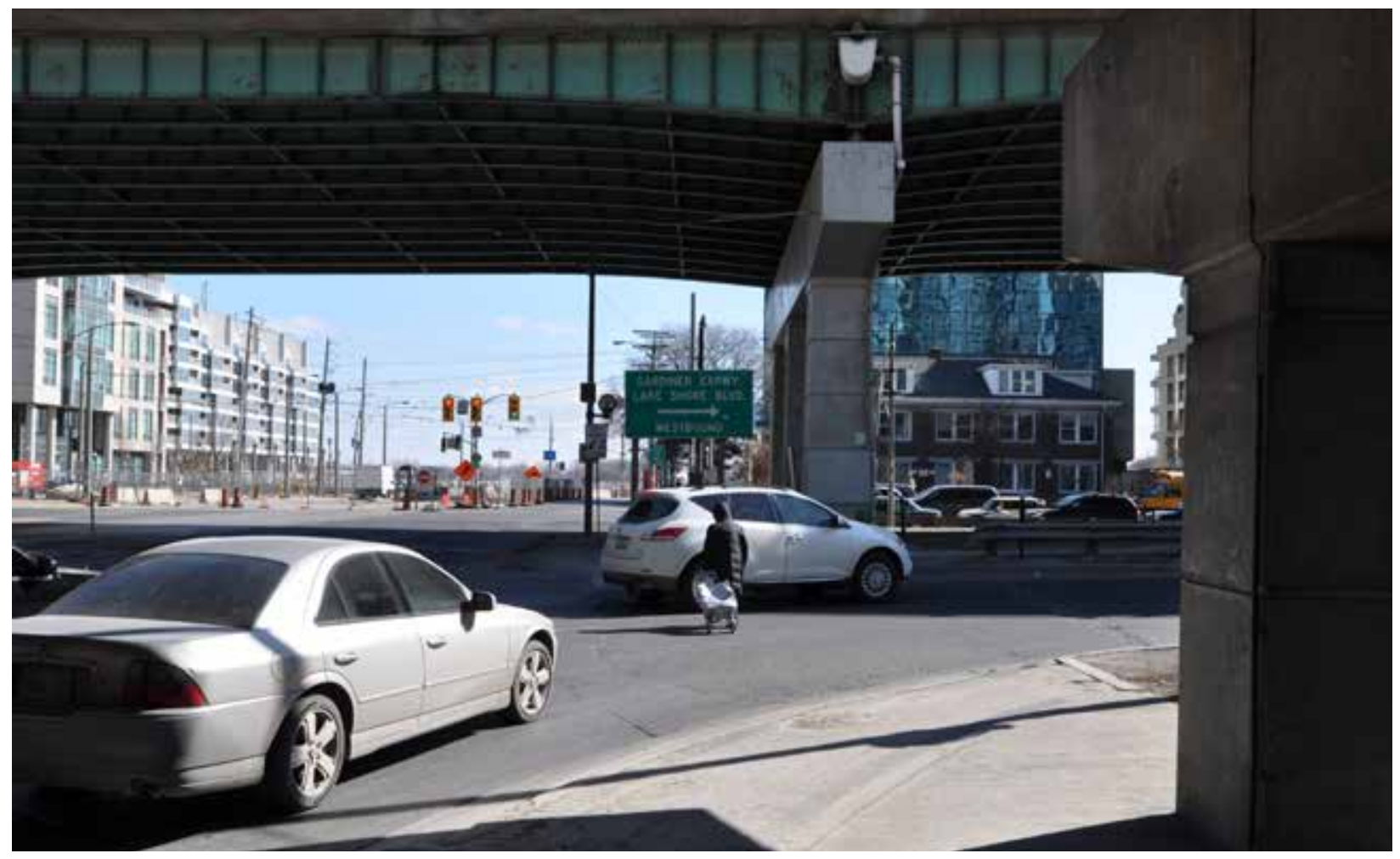

Figure 32 Lack of accomodation for pedestrians resuts in unsafe crossing. (Gordon, 2014) 
Anatomy of a debate

\section{Aging Infrastructure}

The age of the Gardiner Expressway has forced Toronto to enter into a conversation regarding its future. As a piece of aging infrastructure, it requires ongoing repair work to maintain the safety of the roadway. The Gardiner was not designed to withstand the heavy use of road salt in the winter. The use of salt results in corrosion underlying structure, which in turn has resulted in a number of incidents where small sections of concrete have fallen from the Gardiner. These incidents have resulted in Toronto City Council passing a $\$ 505$ million, 10 -year rehabilitation for the Gardiner (Livey, 2013). Given the state of the Gardiner, and the need for significant investment, there currently exists an opportunity to explore future options for some of the elevated sections. To this end, the City of Toronto and Waterfront Toronto have initiated an Environmental Assessment regarding the future of the section east of Jarvis Street (See

Figure 33). This assessment is part of a larger debate about the future of the Gardiner that has been going on for the last two decades.

The issue of what to do with the Gardiner was raised by David Crombie in the

Royal Commission on the Future of Toronto's Waterfront report, in which it was stated,

Transportation corridors parallel to the shore, such as the railways and expressways, provide barriers to recreational access. A lakeshore that is hidden behind a wall of industrial, public or private fences provides few public benefits.

(Crombie, 1992, p. 165) 
The Royal Commission found that the structure of the Gardiner was problematic in the context of waterfront renewal, because it would impede the sort of redevelopment envisioned for the waterfront. The recommendations contained in the final report from the Commission did not necessarily involve complete removal, but envisioned treating a redesigned Gardiner differently at different points - some sections could remain elevated, while others should be reduced to at-grade roadways, and in some instances, buried (Crombie, 1992). The rationale for this redesign was based not only on the need to reestablish a waterfront connection, but also justified based on the declining importance of the Gardiner as a means of getting commuters into the downtown as transit options were expanded (Waterfront Toronto, 2008).

The Waterfront Revitalization Task Force again highlighted the need to address the Gardiner Expressway in order for the type of waterfront redevelopment that was envisioned to occur. In their 2000 report, Our Toronto Waterfront, the authors highlighted the function of the Gardiner as a barrier to the revitalization due to the imposing nature of the structure (Waterfront Revitalization Task Force, 2000)

The options presented for the future of the eastern section of the Gardiner Expressway include: maintain, improve, replace, and remove. The option of burying portions of the Expressway, as was done in Boston and Seattle, has not been include in the current debate. While the debate continues, Waterfront Toronto has deemed the remove option to be the preferred option, based on a number of different criteria including economics, environment, urban design, and transportation and infrastructure (see Appendix A for a complete matrix of criteria). 
A scan of the public media sources highlights the contentious nature of the current debate. Arguments by some city councilors and the mayor against removal are predicated on the need to keep the Gardiner as is, because removal would result in increased commuting times (Winsa \& Mendelson, 2014). Other members of the city staff, which notably include senior executive staff, have stated that the eastern section of the Gardiner needs to come down (Lorinc, 2014). The deputy mayor has stated that removing the expressway without careful consideration of what would replace it is problematic. Transportation infrastructure that would alleviate road congestion, such as a downtown relief subway line, has yet to be built (Kuitenbrouwer \& Alcob, 2014). Public opinion is also divided, and appears to cleave along geographic lines: those that live outside of the downtown and rely on the Gardiner to drive in are in favour of options that keep an elevated structure, while those that have little use for it favour removal.

\section{Public Consultation}

The options currently under discussion have been the subject three rounds of public forums conducted to determine the status of public opinion on the future of the Gardiner. The results of the consultation show that there is support (based on the input of those that showed up to the consultation) for the need to balance modes of transportation, enhance waterfront connectivity, enhance the public realm, and incorporate alternative modes of transportation (Lura Consulting , 2013a). Arguments against removing the expressway presented during the consultations were based on the increased congestion and commuting times that would result. On the other hand, 
there were concerns expressed that if the Gardiner continued to exist in any form, it would represent a missed opportunity to open up the waterfront to revitalization (Lura Consulting , 2013b). Ultimately, the outcome of the consultations were for Waterfront Toronto to recommend the removal of the eleveated section east of Jarvis Street.

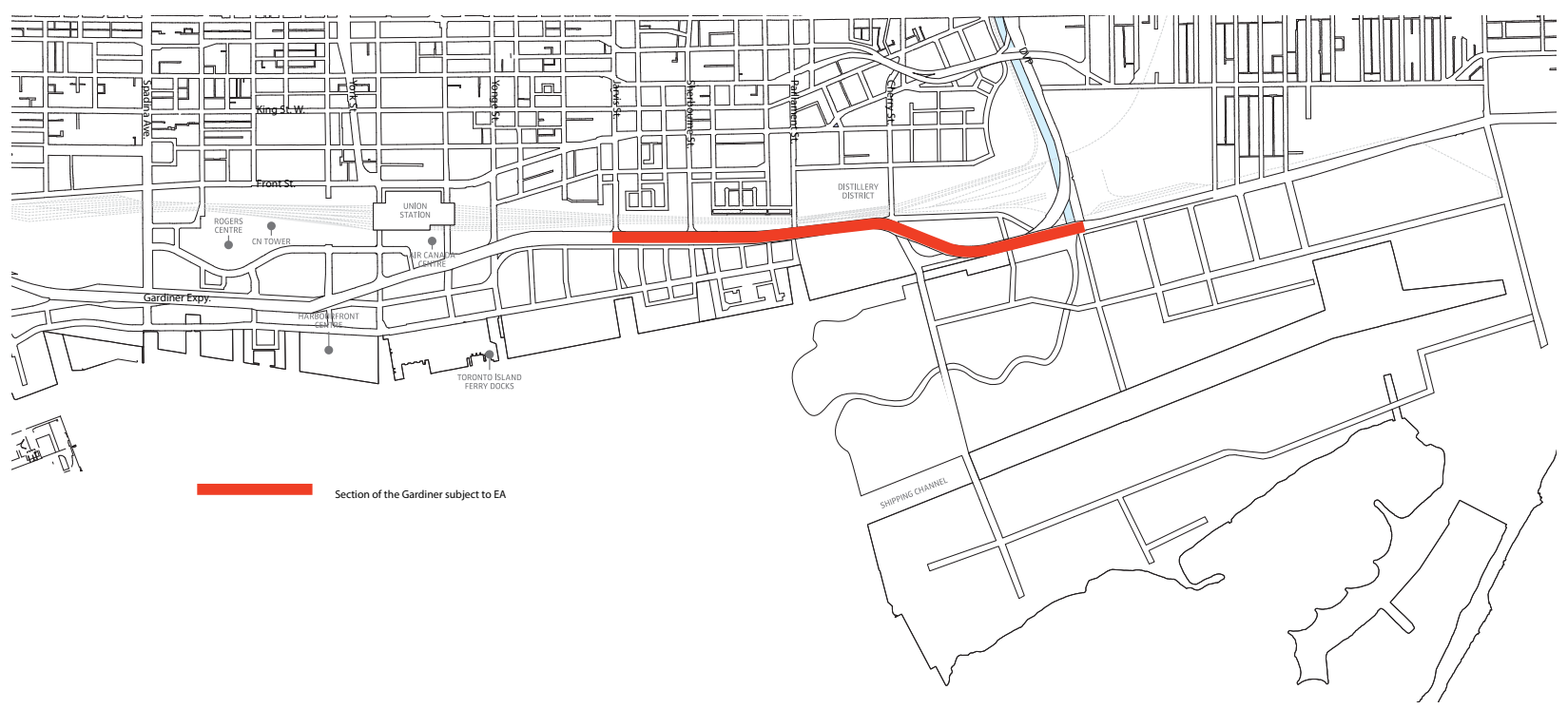

Figure 33 Section of the Gardiner Expressway subject to Environmental Assessment (Waterfront Toronto , 2012) 


\section{Evaluation of Options}

Three of the options presented - maintain, improve, and replace all serve the same function when evaluated through a Lynchian lens, as an edge. However, the replacement option would lessen the expressway's impact as an edge because advances in construction technology means that the footprint and structure of the expressway would be reduced. While the overhead structure would remain, the renderings presented as part of the public consultation show a less imposing structure. This would potentially allow for better access to the waterfront.

The removal option would certainly create the most desirable environment for pedestrian access to the waterfront. From the perspective of Lynch's framework, there is no doubt that the removal option is best not only for eliminating an edge, but also allowing for the creation of more distinct districts as the waterfront is redeveloped. As currently configured, and in the case of any option that involves keeping the Gardiner, the development plans that are indented for the central waterfront will always be segregated from the rest of the city. If the Gardiner were to be removed, the development of future districts and landmarks would be far more likely to become integrated into the image of the city. 


\section{Section 4}

\section{Conclusions and Recommendations}

Waterfronts are truly dynamic places, as they have served successive military, transportation, economic, and industrial functions throughout the evolution of urban areas. Their forms were shaped by these functions, through the creation of water infrastructure, such as piers and wharfs, an inland infrastructure such as railways, roads, warehouses, and industrial buildings. Their shorelines were changed through the infilling of harbours and controlling the pattern of sediment deposition, as well as the construction of dock walls and the channelization of rivers. These modifications were implemented to serve the functional purpose of waterfronts - which through much of the 19th and 20th centuries were primarily industrial. The 21 st century has witnessed the dawn of a new period in the evolution of waterfronts. Many waterfronts are no longer suited to the industrial functions that helped givee rise to the urban fabric that surrounds them. There are a number of forces that are working to redevelop postindustrial waterfronts, globalization being chief among them. In the drive to remain globally competitive, may post-industrial waterfronts are being redeveloped to capitalize on investment to spur growth and create jobs. Progressive redevelopment proposals also seek to re-establish a greater connection with natural processes that have been suppressed.

One of the barriers that post-industrial waterfront redevelopment has needed to overcome is the infrastructure legacy that has been left as a result of previous development. In many cases, this infrastructure is the result of planning rationales that 
have left waterfronts disconnected from the rest of the city. This infrastructure functions as an as an edge, using the terminology from Kevin Lynch. However, many cities Seattle, Boston, and San Francisco among them - have been able to ameliorate the negative impacts of the infrastructure that has bisected urban areas.

In debating the future of the Gardiner Expressway, Toronto is currently grappling a similar situation that the cities presented in this paper have already dealt with. Part of the inertia in Toronto has been as a result of jurisdictional gridlock over what level of government is responsible for what, and - perhaps more importantly - who is going to pay for what. These issues have largely been resolved through the establishment of a tri-partite corporation, Waterfront Toronto.

The time has come for Toronto to act. There have been calls to action before - with the Royal Commission and the Waterfront task force advocating removing the Gardiner, and action has not been taken. The decision over the future of the eastern section of the Gardiner is clear - it should be removed. The changing nature of the waterfront necessitates this removal. If the Gardiner were to remain in any form, it would serve as an edge to separate the waterfront from the city, and seriously undermine the extensive redevelopment currently underway on the central waterfront. The creation of a globally significant waterfront would remain hidden behind infrastructure that is the product of a bygone era of urban planning.

Urban planning in Toronto is at a critical juncture. It is perhaps too simplistic to look at the removal of the Gardiner without looking at the larger context of issues that are confronting the region - which are outside the scope of this paper to examine in detail. Nevertheless, it is important to note that the removal of the Gardiner is related to 
larger transit issues that need to be dealt with. Removal of the Gardiner will create longer travel times - something that is unpalatable to many. In order to mitigate this issue, there needs to be a greater investment in transit - another issue with significant political inertia. This inactivity should not be used as justification to keep the Gardiner a decision that would prevent the waterfront from achieving its true potential as a source of civic pride.

This debate over the future of the Gardiner does not require a decision that Toronto needs to pioneer. There are numerous examples, a few of which have been presented here, of cities removing elevated expressways with very successful results. Toronto need only look to these examples to understand the benefits of removing a significant edge in its urban core.

Waterfronts are unique areas in many cities, because of their post-industrial nature. Few other sites would generate the same level of debate regarding their redevelopment. As the functions of waterfronts change over time, so too does the planning and design of the areas surrounding the waterfronts. Contemporary waterfront redevelopment seeks a greater integration between waterfronts and urban areas. The renewal of natural processes that had long been subverted is once again having an impact on the shape of natural waterfront areas. Innovative redevelopments are reimagining waterfronts as places of living, working, and playing. The succession of waterfront redevelopment approaches has meant that waterfronts around the world are becoming desirable places that contribute to the attraction of global investment. As these changes occur, it is only logical that the urban forms related to the waterfront change to serve these new purposes, and not those purposes that they served when 
the waterfront was still a primarily industrial area. The (re)emergence of the waterfront as a part of the urban area depends on a reimagining of the infrastructure that surrounds it. 


\section{Appendix A}

\section{Preliminary Evaluation Results Matrix}

Gardiner Expressway East / Lake Shore Boulevard Reconfiguration Environmental Assessment And Integrated Urban Design Study

The Preliminary Evaluation Results Matrix is an excerpt representing key findings from the larger comparative evaluation of the four options for the future of the Gardiner Expressway East. It is based on extensive analysis conducted by the project team through the four evaluation lenses: Urban Design, Transportation \& Infrastructure, Environment, and Economics. For the evaluation, the project team took into account the nature of the four alternatives and the study area characteristics. The Study Lenses, Criteria and measures are all considered of equal importance, meaning they were not weighted.

\begin{tabular}{|c|c|c|c|c|c|}
\hline & Study Lens/ Criteria Group Summary & MAINTAIN & IMPROVE & REPLACE & REMOVE \\
\hline \multirow{7}{*}{ 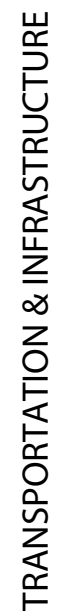 } & Automobiles & & & & \\
\hline & Transit & & & & \\
\hline & Pedestrians & & & & \\
\hline & Cycling & & & & \\
\hline & Movement of Goods & & & & \\
\hline & Safety & & & & \\
\hline & Constructability & & & & \\
\hline \multirow{3}{*}{ 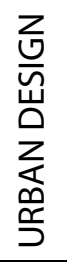 } & Planning & & & & \\
\hline & Public Realm & & & & \\
\hline & Built Form & & & & \\
\hline \multirow{3}{*}{ 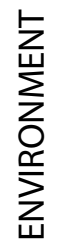 } & Social \& Health & & & & \\
\hline & Natural Environment & & & & \\
\hline & Cultural Resources & & & & \\
\hline \multirow{3}{*}{ 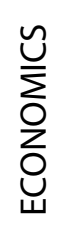 } & Regional Economics & & & & \\
\hline & Local Economics & & & & \\
\hline & Direct Cost and Benefit & & & & \\
\hline
\end{tabular}

\begin{tabular}{|l|l|l|}
\hline Preferred & Moderately Preferred & Least Preferred \\
\hline
\end{tabular}

(February 5, 2014) 


\section{Bibliography}

Bassett, K., Griffiths , R., \& Smith, I. (2002). Testing governance: Partenerships, planning and conflict in waterfront regeneration. Urban Studies , 39 (10), 17571775.

Brown, J. R., Morris, E. A., \& Taylor, B. D. (2009). Planning for cars in cities: Planners, engineers, and freeways in the 20th century. Journal of the American Planning Association , 75 (2), 161-177.

Cevero, R., Kang, J., \& Shively, K. (2009). From elevated freeways to surface boulevards:neighborhood and housing price impacts in San Francisco. Journal of Urbanism , 31 (50), 31-50.

City of Toronto. (2013). Insurance plan of the city of Toronto. Retrieved from City of Toronto Library: http://www.torontopubliclibrary.ca/detail.jsp?Entt=RDMDC-A TLAS-R-286\&R=DC-ATLAS-R-286

Crombie, D. (1992). Regeneration: Toronto's waterfront and the sustainable city: final report. Toronto: Queen's Printer of Ontario .

Eidelman, G. (2011). Jurisdictional gridlock and the genesis of waterfront toronto. In G. Desfor, J. Laidley, \& (Eds.), Reshaping Toronto's Waterfront (pp. 263-286). Toronto: University of Toronto Press.

Daamen, T. A., \& Vries, I. (2013). Governing the European port-city interface: Institutional impacts on spatial projects between city and port. Journal of Transport Geography , 27, 4-13.

Desfor, G., \& Jorgensen, J. (2004). Flexible urban governance: The case of Copenhagen's recent waterfront development. European Planning Studies , 12 (4), 479-496.

Desfor, G., \& Laidley, J. (2011). Introduction. In G. Desfor, J. Laidley, \& [Eds], Reshaping Toronto's Waterfront (pp. 2-19). Toronto : University of Toronto Press.

Dillon Consulting et al. (2009). Gardiner Expressway and Lake Shore Boulevard Reconfiguration EA Terms of Reference. Toronto: Waterfront Toronto.

Fein, M. R. (2012). Tunnel vision" "Invisible" highways and Boston's "big dig" in the age of privatization. Journal of Planning History , 11 (1), 47-69.

Ferrari, M. S., \& Fraser, D. (2012). Design strategies for urban waterfronts. In H. Smith, \& M. S. Ferrari, Waterfront Regeneration: Experiences in City-building. New York: Routledge. 
Filion, P. (1999). Rupture or continuity? Modern and postmodern planning in Toronto. International Journal of Urban and Regional Planning , 23 (3), 421-444.

Fisher, B. (2004). Waterfront Design . In Remaking the urban waterfront. Washnigton, D.C.: Urban Land Institue .

Found SF. (2014). Aerial of Ferry building 1958. Retrieved April 3, 2014, from Found SF: http://foundsf.org/index.php?title=Aerial_of_Ferry_building_1958

Gutfreund, O. D. (2007). Rebuilding New York in the auto age: Robert Moses and his highways. In H. Ballon, K. T. Jackson, \& (Eds.), Robert Moses and the Modern City: The Transformation of New York (pp. 86-93). New York: W. W. Norton and Company.

Galland, D., \& Hansen, C. J. (2012). The roles of planning in waterfront redevelopment: From plan-led and market-driven styles to hybrid planning? Planning Practice and Research , 27 (2), 203-225.

Get Toronto Moving. (2014). Waterfront. Retrieved April 2, 2014, from Get Toronto Moving: http://www.gettorontomoving.ca/Waterfront.php

Google. (2014). Boston. Retrieved from Google Maps: https://maps.google.ca/

Google. (2014). San Francisco. Retrieved from Google Maps: https://maps.google.ca/

Google. (2014). Seattle. Retrieved from Google Maps: https://maps.google.ca/

Google. (2014). Toronto. Retrieved March 13, 2014, from Google Maps: https://maps. google.ca/

Gordon, D. L. (1997). Managing the changing political environment in urban waterfront redevelopment. Urban Studies , 34 (1), 61-83.

Gordon, D. L. (1996). Planning, design and managing change in urban waterfront redevelopment. Town Planning Review , 67 (3), 261-290.

Gordon, G. (2014, March 25). Gardiner Expressway Photos. Toronto, Canada.

Greenberg, K. (1996). Toronto: the urban waterfront as a terrain of availability. In P. Malone, City, Capital and Water (pp. 195-218). New York, NY: Routledge.

Hume, C. (2013, November 22). Toronto could learn from Boston's Big Dig. Retrieved March 9, 2014, from The Toronto Star: http://www.thestar.com/news/ gta/2013/11/22/toronto_could_learn_from_bostons_big_dig_hume.html 
Hayuth, Y. (1982). The port-urban interface: An area in transition. Area , 14 (3), 219-224.

HafenCity Hamburg. (2014). Management . Retrieved March 8, 2014, from HafenCity Hamburg: http://www.hafencity.com/en/management/development-managementand-hafencity-hamburg-gmbh.html

Hoyle, B. (2000). Global and local change on th eport-city waterfront. Geographical Review , 90 (3), 395-417.

Hoyle, B. S. (1989). The port-city interface: Trends, problems and examples. Geoforum , 20 (4), 429-435.

Hopper, T. (2011, September 20). Councillors sink Fords' Port Lands plan. Retrieved March 27, 2014, from National Post: http://news.nationalpost.com/2011/09/20/ councillors-sink-fords-port-lands-plan/

Javanrouh, S. Harbourfront Toronto . http://wvs.topleftpixel.com/08/01/30/. Toronto.

Jacobs, J. (1993). The Death and Life of Great American Cities. New York: The Modern Library (Original Work Published 1961).

James Corner Field Operations, et al. . (n.d.). Toronto's great street the lakeshore boulevard corridor. Retrieved March 14, 2014, from Gardiner East: http:// gardinereast.ca/sites/default/files//designideas/Remove_JCFO_Booklet.pdf

Kuitenbrouwer , P., \& Alcob, N. (2014, February 26). Forces for and against tearing down Gardiner Expressway set to clash at city hall on Friday. Retrieved April 1, 2014, from National Post: http://news. nationalpost.com/2014/02/26/forces-forand-against-tearing-down-gardiner-expressway-set-to-clash-at-city-hall-on-friday/

KCAP. (2014). HafenCity. Retrieved April 2014, from KCAP: http://www.kcap.eu/en/ projects/v/hafencity/

Kremer, W. (2013, 04 13). How much bigger can container ships get? Retrieved 024 , 2014, from BBC: http://www.bbc.co.uk/news/magazine-21432226

Lura Consulting . (2013b, November). Gardiner Expressway/Lake Shore Boulevard East Reconfiguration Environmental Assessment (EA) and Integrated Urban Design Study. Retrieved April 1, 2014, from Gardiner East: http://www. gardinereast.ca/sites/default/files//documents/Future\%20of\%20the \%20 Gardiner\%20East\%20Consultation\%20Report_Round\%20Two\%20 \%28Draft\%29.pdf 
Lura Consulting. (2013a, July). Gardiner Expressway/Lake Shore Boulevard East Reconfiguration Environmental Assessment (EA) and Integrated Urban Design Study. Retrieved April 1, 2014, from Gardiner East: http://www. gardinereast.ca/sites/default/files//documents/Future\%20of\%20the\%20 Gardiner\%20East\%20Consultation\%20Report_Round\%200ne\%20 \%28Draft\%29.pdf

Lynch, K. (1960). The Image of the City. Cambridge, Mass: The MIT Press.

Laidley, J. (2011). The 'ecosystem approach' and the olympics on Toronto's watertfront. In G. Desfor, J. Laidley, \& (Eds.), Reshaping Toronto's Waterfront (pp. 203-223). Toronto: University of Toronto Press.

Livey, J. (2013). Revisions to the F.G. Gardiner Expressway Rehabilitation Project . Retrieved April 1, 2014, from City of Toronto : http://www.toronto.ca/legdocs/ $\mathrm{mmis} / 2013 / \mathrm{pw} / \mathrm{bgrd} / \mathrm{backgroundfile-57200.pdf}$

Libarary and Archives Canada. (2014). Sketch of the ground in advance of and including York, Upper Canada. by Geo. Williams, R.M.S.D. Nov. 7, 1813. [cartographic material]. . Retrieved April 10, 2014, from Library and Archives Canada: http://collectionscanada.gc.ca/pam_archives/index.php?fuseaction=genitem. displayltem\&lang=eng\&rec_nbr=4139378

Lister, N.-M. (2009, 05 08). Water/Front. Retrieved 03 21, 2014, from Places: http:// places.designobserver.com/feature/water-front/10227/

Lorinc, J. (2014, March 14). Tear down the Gardiner East? This city official won't mince words. Retrieved April 1, 2014, from The Globe and Mail: http://www. theglobeandmail.com/news/toronto/tear-down-the-gardiner-east-this-city-officialwont-mince-words/article17502722/

Moir, M. (2011). Planning for change: Harbour comissions, civil engineers, and large scale manipulation of nature. In G. Desfor, \& J. Laidley (Eds.), Reshaping Toronto's Waterfront (pp. 23-48). Toronto: University of Toronto Press.

Mohl, R. A. (2004). Stop the road freeway revolts in Amercican cities. Jounal of Urban History , 30 (5), 674-706.

Mohl, R. A. (2012). The expressway teardown movement in american cities: Rethinking postwar highway policy in the post-interstate era. Journal of Planning History , 11 (1), 89-103.

Mohl, R. A. (2012). The expressway teardown movement in American cities: Rethinking postwar highway policy in the post-interstate era. Journal of Planning History , 11 (1), 89-103. 
Ontario Bureau of Mines. (1913). Map of Toronto and Vicinity . Toronto.

Ontrario Ministry of Infrastructure. (2006). Growth Plan for the Greater Golden Horseshoe. Retrieved April 11, 2012, from Ontrario Ministry of Infrastructure: https://www.placestogrow.ca/index.php?option=com_ content\&task=view\&id=9\&ltemid $=14$

Port of San Francisco . (2004). Chapter 2: Goals of the Waterfront Land Use Plan. Retrieved March 13, 2014, from Port of San Francisco: http://www.sf-port.org/ index.aspx?page $=294$

Port of Seattle . (2014). About the Port. Retrieved March 1, 2014, from Seaport Statistics: http://www.portseattle.org/About/Publications/Statistics/Seaport/Pages/ default.aspx

Sanderson, C., \& Fillion, P. (2011). From harbour commission to port authority: Instiutionalizing the federal government's role in waterfront development. In G.

Desfor, \& J. Laidley, Reshaping Toronto's Waterfront (pp. 224-244). Toronto: University of Torono Press.

Schubert, D. (2011). Waterfront revitalizations: From a local to a regional perspective in London, Barcelona. Rotterdam, and Hamburg. In G. Desfor, J. Laidley, Q. Stevens, D. Schubert, \& [Eds.], Transforming Urban Watefronts: Fixity and Flow (pp. 74-97). New York: Routledge.

Shaw, B. (2001). History at the water's edge. In R. Marshall (Ed.), Waterfronts in PostIndustrial Cities. London: Spon Press.

Skelley, J. (2011, April 20). Tear down that freeway! Retrieved Janurary 11, 2014, from http://urbanland.uli.org/sustainability/tear-down-that-freeway/

Smith, H., \& Ferrari , M. S. (2012). Sustainable waterfront regeneration around the north sea in a global context. In S. Harry, \& M. S. Ferrari (Eds.), Waterfront Regeneration: Experiences in City-building. New York, NY: Routledge.

Smith, H., \& Ferrari, M. S. (2012). Exprerinces in participation in the port city of Hamburg. In H. Smith, \& M. S. Ferrari, Watefront Regeneration: Experineces in City Building (pp. 95-113). New York: Routledge.

Stanislawski, D. (1946). The origin and spread of the grid-pattern town. Geographical Review , 36 (1), 105-120. 
Rubin, J. (2011). San francisco's waterfront in the age of noliberal urbanism. In G. Desfor, J. Laidley, Q. Stevens, \& D. Schubert (Eds.), Transforming Urban Waterfronts. New York: Routledge.

Raynsford, A. (2011). Civic art in an age of cultural relativisim: The aesthetic origins of Kevin Lynch's Image of the City . Journal of Urban Design , 16 (1), 43-65.

Rafferty, L., \& Holst, L. (2004). An intriduction to urban waterfront redevelopment . In U. -T. Institute, Remaking the Urban Waterfront (pp. 2-18). Washington, D.C.: ULI-the Urban Land Institute.

Ramsey, K. (2011). Urban waterfront transformations as a politics of mobility: Lessons from Seattle's Alaskan Way Viaduct debate. In G. Desfor, J. Laidley, Q. Stevens, \& D. Schubert (Eds.), Transforming Urban Waterfronts: Fixity and Flow (pp. 101120). New York: Routledge.

Robinson, D. (2011). Modernism at a crossraod: The spadina expressway controversy in toronto, ontario ca. 1960-1971. The Canadian Historical Review , 92 (2), 295322.

Turenscape . (2007). Boston's Big Dig. Retrieved March 11, 2014, from Turenscape: http://www.turenscape.com/english/news/view.php?id=240

Taylor, N. (2009). Legibility and aesthetics in urban design. Journal of Urban Design , 14 (2), 189-202.

US Census Bureau . (2014, January 6). San Francisco County, California. Retrieved March 2014, 2014, from U.S. Census Bureau: State and County QuickFacts: http://quickfacts.census.gov/qfd/states/06/06075.html

US Census Bureau. (2014, January 07). Seattle, Washington. Retrieved March 1, 2014, from U.S. Census Bureau: State and County QuickFacts. : http://quickfacts. census.gov/qfd/states/53/5363000.html

Washington Department of Transportation. (2014). Alaskan Way Viaduct Demolition. Retrieved April 1, 2014, from WDOT: https://www.flickr.com/ search/?w=7821771@N05\&q=alaskan\%20way

Waterfont Toronto. (2014). Design review panel. Retrieved March 29, 2014, from Waterfront Toronto: http://www.waterfrontoronto.ca/our_waterfront_vision/design_ excellence/design_review_panel 
Waterfront Revitalization Task Force. (2000). Toronto Waterfront Revitalization Task Force Report (Fung Report). Retrieved April 1, 2014, from City of Toronto: http:// www1.toronto.ca/city_of_toronto/waterfront_secretariat/files/pdf/torontow.pdf

Waterfront Toronto . (2012). Explore out new blue edge. Retrieved March 14, 2014, from Waterfront Tornto : http://www.waterfrontoronto.ca/

Waterfront Toronto . (2014, February 5). Preliminary Evaluation Results Matrix. Retrieved March 14, 2014, from Gardiner East: http://www.gardinereast.ca/sites/ default/files//media/Preliminary\%20Evaluation\%20Results\%20Matrix_0.pdf

Waterfront Toronto. (2013). waterfront revitalization projects around the world. Retrieved January 23, 2013, from Waterfront Toronto : http://www.waterfrontoronto.ca/ about_us/scope_and_scale

Waterfront Toronto. (2014). Fort York Barracks, 1804. Retrieved April 10, 2014, from Waterfront Toronto : http://www.waterfrontoronto.ca/about_us/history_and_ heritage

Waterfront Toronto. (2014). History and Heritage. Retrieved April 1, 2014, from Waterfront Toronto: http://www.waterfrontoronto.ca/image_galleries/history_and_ heritage/?8112\#8119

Waterfront Toronto. (2014). Scope and Scale. Retrieved March 11, 2014, from Waterfront Toronto : http://www.waterfrontoronto.ca/about_us/scope_and_scale

Waterfront Toronto. (2008, June). Transforming the Gardiner/Lake Shore Corridor. Retrieved April 1, 2014, from Waterfront Toronto : http://www.waterfrontoronto.ca/ dbdocs//48517e6c69030.pdf

West, N. (1989). Urban-waterfont developments: A geographic problem in search of a model. Geoforum , 20 (4), 459-468.

Wikipedia. (2008). Alaskan Way Viaduct. Retrieved April 11, 2014, from Wikipedia: http://en.wikipedia.org/wiki/Alaskan_Way_Viaduct

Wikipedia. (2008). San Francisco Ferry Building. Retrieved March 13, 2014, from Wikipedia: http://en.wikipedia.org/wiki/San_Francisco_Ferry_Building

Wilson, D. (2004). Toward a contingent urban neoliberalism. Urban Geography , 25 (8), 771-783.

Winsa, P., \& Mendelson , R. (2014, February 6). Report favours tearing down Gardiner east of Jarvis St. Retrieved April 1, 2014, from Toronto Star: http://www.thestar. com/news/gta/2014/02/06/gardiner_expressway_live_blog.html 